\title{
MATRIX (Multiconfiguration Aerosol TRacker of mIXing state): an aerosol microphysical module for global atmospheric models
}

\author{
S. E. Bauer ${ }^{1}$, D. L. Wright ${ }^{2,}{ }^{*}$, D. Koch ${ }^{1}$, E. R. Lewis ${ }^{2}$, R. McGraw ${ }^{2}$, L.-S. Chang ${ }^{2, * *}$, S. E. Schwartz ${ }^{2}$, and R. Ruedy ${ }^{3}$ \\ ${ }^{1}$ The Earth Institute at Columbia University and NASA Goddard Institute for Space Studies, New York, USA \\ ${ }^{2}$ Brookhaven National Laboratory, Upton, New York, USA \\ ${ }^{3}$ Sigma Space Partners (SSP) and NASA Goddard Institute for Space Studies, New York, USA \\ * present address: School of Arts and Sciences, Rutgers University, New Brunswick, NJ 08901, USA \\ *** present address: Global Res. Center, National Institute of Environmental Res., Kyungseo-dong Seo-gu, Incheon, Korea
}

Received: 26 March 2008 - Published in Atmos. Chem. Phys. Discuss.: 29 May 2008

Revised: 28 August 2008 - Accepted: 4 September 2008 - Published: 21 October 2008

\begin{abstract}
A new aerosol microphysical module MATRIX, the Multiconfiguration Aerosol TRacker of mIXing state, and its application in the Goddard Institute for Space Studies (GISS) climate model (ModelE) are described. This module, which is based on the quadrature method of moments (QMOM), represents nucleation, condensation, coagulation, internal and external mixing, and cloud-drop activation and provides aerosol particle mass and number concentration and particle size information for up to 16 mixed-mode aerosol populations. Internal and external mixing among aerosol components sulfate, nitrate, ammonium, carbonaceous aerosols, dust and sea-salt particles are represented. The solubility of each aerosol population, which is explicitly calculated based on its soluble and insoluble components, enables calculation of the dependence of cloud drop activation on the microphysical characterization of multiple soluble aerosol populations.
\end{abstract}

A detailed model description and results of box-model simulations of various aerosol population configurations are presented. The box model experiments demonstrate the dependence of cloud activating aerosol number concentration on the aerosol population configuration; comparisons to sectional models are quite favorable. MATRIX is incorporated into the GISS climate model and simulations are carried out primarily to assess its performance/efficiency for global-scale atmospheric model application. Simulation results were compared with aircraft and station measurements of aerosol mass and number concentration and particle size to assess the ability of the new method to yield data suitable for such comparison. The model accurately captures the observed size distributions in the Aitken and accumulation

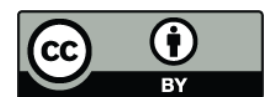

Correspondence to: S. E. Bauer (sbauer@giss.nasa.gov) modes up to particle diameter $1 \mu \mathrm{m}$, in which sulfate, nitrate, black and organic carbon are predominantly located; however the model underestimates coarse-mode number concentration and size, especially in the marine environment. This is more likely due to oversimplifications of the representation of sea salt emissions - sea salt emissions are only calculated for two size classes - than to inherent limitations of MATRIX.

\section{Introduction}

The impact of natural and anthropogenic aerosols on the climate system is the subject of numerous laboratory, experimental, and theoretical studies (Ghan and Schwartz, 2007). The spatial and temporal scales of these studies span several orders of magnitude. Global climate models, at the upper end of those time scales, are the ultimate integrative tool to estimate the impacts of aerosols on climate and their role in climate change. The treatment of aerosol properties and processes in regional and global models is becoming increasingly complex (Ackermann et al., 1998; Adams and Seinfeld, 2002; Binkowski and Shankar, 1995; Binkowski and Roselle, 2003; Easter et al., 2004; Gong et al., 2003; Herzog et al., 2004; Jacobson, 2001; Lauer et al., 2005; Riemer et al., 2003; Stier et al., 2005; Wilson et al., 2001; Wright et al., 2000, 2001; Yu et al., 2003), taking into account detailed microphysical and chemical interactions that underlie the formation of aerosol particles which then impact the climate system. Increasingly detailed representations of key aerosol properties such as size distributions, chemical composition (e.g., internal vs. external mixtures), hygroscopicity, optical properties, and cloud activation are also being incorporated into global climate models. One challenge is to determine

Published by Copernicus Publications on behalf of the European Geosciences Union. 
the most appropriate method of implementing this increased detail.

The most common methods of including aerosol size distributions and aerosol mixing information into models are the sectional-, modal-, and moment-based schemes. Sectional models (Adams and Seinfeld, 2002; Gong et al., 2003; Jacobson, 2001) divide the size domain into intervals, or bins, and calculate the evolution of the number concentrations in each size bin. This method is very accurate when a large number of size bins is used to track detailed information about mixing state and size distribution, but has the disadvantage of being computationally expensive because of the large number of bins required to accurately represent size and chemical mixing information. The modal method (Wilson et al., 2001; Iversen, 2002; Stier et al., 2005) approximates the size distribution by an assumed statistical function, most commonly multiple lognormal functions. This approach can be very flexible and computationally fast, but accuracy is dependent on the suitability of the aerosol size distribution. The quadrature method of moments (QMOM) (McGraw, 1997) provides a computationally efficient statistically-based alternative to modal and sectional methods for aerosol simulation that does not make a priori assumptions about the shape of the size distribution. Numerous modules based on the flexible and efficient moments method, tracking 26 moments, have been implemented into three-dimensional transport models (Ackermann et al., 1998; Binkowski and Shankar, 1995; Binkowski and Roselle, 2003; Easter et al., 2004; Herzog et al., 2004; Riemer et al., 2003; Wright et al., 2000, 2001; Yu et al., 2003). According to the theoretical framework, key moments of the aerosol population (such as number and mass) that enter the covariance matrix of a principal component analysis are tracked instead of the distribution itself. The approach is flexible and highly efficient, yet can provide comprehensive representation of natural and anthropogenic aerosols and their mixing states.

The representation of advanced chemistry and thermodynamics in climate models has evolved considerably, with a focus on the chemical composition. In contrast, aerosol microphysical models have developed with a focus on the prediction of the size distribution and with less detail of the aerosol composition. Yet the aerosol mixing state in turn affects the microphysical, chemical, and radiative properties of aerosols. The computational burden of multicomponent aerosol models with size-resolved description of the mixing state is too demanding for long-term transient climate simulations of the global aerosol system with current computational resources. Up to now, only a few global aerosol models suitable for long-term integrations simulate the size distribution and mixing state of interacting multicomponent aerosols (Ghan et al., 2001a,b; Stier et al., 2005).

In this paper we introduce MATRIX, a microphysical scheme that can simulate very detailed aerosol mixing state information but is also computationally very efficient. Until recently, the GISS climate model (Schmidt et al., 2006) aerosols were treated in a mass-based scheme, in which the life cycles of sulfate, nitrate, black and organic carbon, sea salt, and dust were relatively independent of each other, except for surface reactions on mineral dust (Bauer and Koch, 2005; Bauer et al., 2007; Koch et al., 2006; Miller et al., 2006). Size information was included only for dust and sea salt (using a bin scheme). For other species, size distributions were specified, number concentrations were not calculated, and water uptake effects were parameterized to depend upon relative humidity in the radiation and gravitational settling schemes. The implementation of MATRIX into the GISS climate model provides detailed aerosol characterization calculations of formation, removal, and climate interactions. In the current module each of several aerosol populations is treated by a two-moment method, in which a set of mass and number concentrations evolves. Efficient solvers based on analytic solutions to the moment equations are available (Binkowski and Roselle, 2003). This two-moment method is free of the concerns with moment consistency associated with larger moment sets, as number and mass concentrations are mathematically independent (unlike sets of three or more moments per mode), and solver errors cannot generate inconsistent moment sets (Wright, 2007).

The goal of this paper is to give a complete model description of the microphysical model MATRIX (Sect. 2), present applications of MATRIX as a box model (Sect. 3), and as part of the GISS global climate model (Sect. 4). The MATRIX model provides a large set of possible model configurations of aerosol population formulations and microphysical parameterizations. The full range of population formulations is discussed and tested with the box model in Sect. 3; however, we evaluate the model against field and station observations (Sect. 5) observations using only a single set of microphysical parameterizations. In a subsequent publication we will test the sensitivity of the global model performance for several new particle formation schemes, thermodynamical modules, coagulation settings, and aerosol population formulations. Summary and conclusions are given in Sect. 6.

\section{The microphysical model MATRIX}

MATRIX aims at an intermediate degree of detail, completeness, and computational burden, greater than that typical of models with a small number of two-moment modes, but less than that of a sectional representation of multiple aerosol populations. The module represents new particle formation, particle emissions, gas-particle mass transfer, incorporation of sulfate from cloud-phase chemistry into the various modes, condensational growth, and coagulation within and between aerosol populations.

One goal of the model is to provide the number concentration and particle size information characterizing soluble particles for the treatment of cloud drop activation. This requires a representation of internal and external aerosol 
Table 1a. Populations, constituents, and transported variables for aerosol configuration 1. $D_{g, E}$, are the geometric mean diameter values used for primary emissions, and $\sigma_{g, E}$ are the geometric standard deviations.

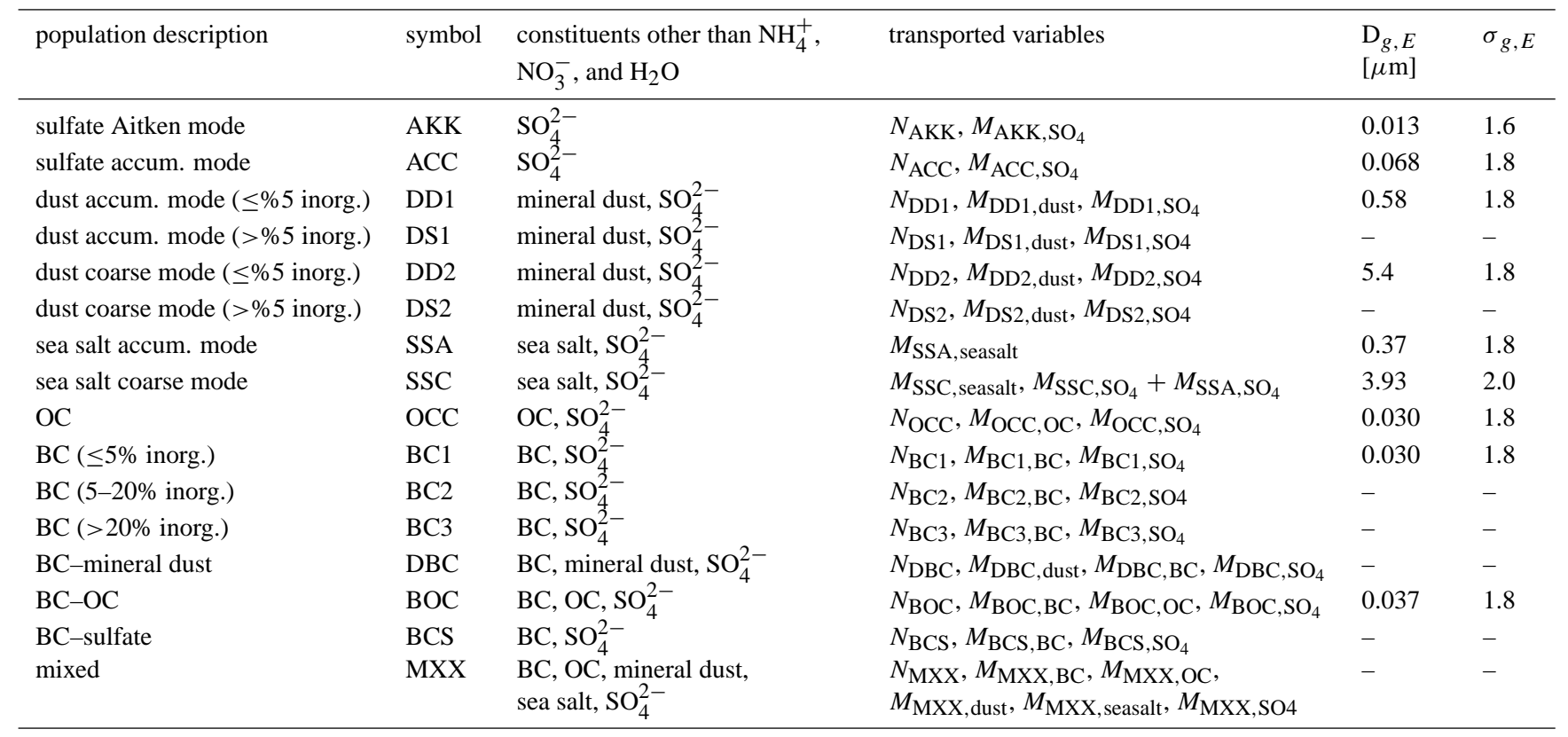

Table 1b. Coagulation interactions for aerosol configuration 1. Donor populations are in bold font, receptor populations in normal font.

\begin{tabular}{|c|c|c|c|c|c|c|c|c|c|c|c|c|c|c|c|c|}
\hline \multirow{2}{*}{ donor population } & \multicolumn{16}{|c|}{ donor population } \\
\hline & AKK & ACC & DD1 & DS1 & DD2 & DS2 & SSA & SSC & OCC & BC1 & BC2 & BC3 & DBC & BOC & BCS & MXX \\
\hline AKK & AKK & ACC & DD1 & DS1 & DD2 & DS2 & SSA & SSC & OCC & BCS & BCS & BCS & DBC & $\mathrm{BOC}$ & BCS & MXX \\
\hline ACC & $\mathrm{ACC}$ & $\mathrm{ACC}$ & DD1 & DS1 & DD2 & DS2 & SSA & $\mathrm{SSC}$ & $\mathrm{OCC}$ & BCS & BCS & $\mathrm{BCS}$ & DBC & BOC & $\mathrm{BCS}$ & MXX \\
\hline DD1 & DD1 & DD1 & DD1 & DD1 & DD2 & DD2 & MXX & MXX & MXX & DBC & DBC & DBC & DBC & MXX & DBC & MXX \\
\hline DS1 & DS1 & DS1 & DD1 & DS1 & DD2 & DS2 & MXX & MXX & MXX & DBC & DBC & DBC & $\mathrm{DBC}$ & MXX & $\mathrm{DBC}$ & MXX \\
\hline DD2 & DD2 & DD2 & DD2 & DD2 & DD2 & DD2 & MXX & MXX & MXX & DBC & DBC & DBC & DBC & MXX & DBC & MXX \\
\hline DS2 & DS2 & DS2 & DD2 & DS2 & DD2 & DS2 & MXX & MXX & MXX & DBC & DBC & DBC & DBC & MXX & DBC & MXX \\
\hline SSA & SSA & SSA & MXX & MXX & MXX & MXX & SSA & $\mathrm{SSC}$ & MXX & MXX & MXX & MXX & MXX & MXX & MXX & MXX \\
\hline SSC & $\mathrm{SSC}$ & $\mathrm{SSC}$ & MXX & MXX & MXX & MXX & $\mathrm{SSC}$ & $\mathrm{SSC}$ & MXX & MXX & MXX & MXX & MXX & MXX & MXX & MXX \\
\hline OCC & $\mathrm{OCC}$ & $\mathrm{OCC}$ & MXX & MXX & MXX & MXX & MXX & MXX & $\mathrm{OCC}$ & $\mathrm{BOC}$ & $\mathrm{BOC}$ & $\mathrm{BOC}$ & MXX & $\mathrm{BOC}$ & $\mathrm{BOC}$ & MXX \\
\hline BC1 & BCS & BCS & DBC & DBC & DBC & DBC & MXX & MXX & $\mathrm{BOC}$ & $\mathrm{BC} 1$ & $\mathrm{BC} 1$ & $\mathrm{BC} 1$ & DBC & BOC & BCS & MXX \\
\hline BC2 & BCS & BCS & DBC & DBC & DBC & DBC & MXX & MXX & $\mathrm{BOC}$ & $\mathrm{BC} 1$ & BC2 & BC2 & DBC & BOC & BCS & MXX \\
\hline BC3 & BCS & BCS & DBC & DBC & DBC & DBC & MXX & MXX & BOC & $\mathrm{BC} 1$ & BC2 & $\mathrm{BC} 3$ & DBC & BOC & BCS & MXX \\
\hline DBC & DBC & DBC & DBC & DBC & DBC & DBC & MXX & MXX & MXX & DBC & DBC & DBC & DBC & MXX & DBC & MXX \\
\hline BOC & $\mathrm{BOC}$ & BOC & MXX & MXX & MXX & MXX & MXX & MXX & $\mathrm{BOC}$ & BOC & $\mathrm{BOC}$ & $\mathrm{BOC}$ & MXX & $\mathrm{BOC}$ & $\mathrm{BOC}$ & MXX \\
\hline BCS & BCS & BCS & DBC & DBC & DBC & DBC & MXX & MXX & BOC & BCS & BCS & BCS & DBC & BOC & BCS & MXX \\
\hline MXX & MXX & MXX & MXX & MXX & MXX & MXX & MXX & MXX & MXX & MXX & MXX & MXX & MXX & MXX & MXX & MXX \\
\hline
\end{tabular}

mixing processes. For example, insoluble particles can become soluble by acquiring soluble inorganic coatings as a result of either condensation of soluble species or coagulation with particles containing soluble materials.

The total aerosol is represented by a user-selected set of distinct populations, along with a specification of the coagulation interaction between the aerosol populations, that we refer to as an "aerosol module configuration". Each population has a distinct composition or set of chemical components, which is treated as being independent of size. Aerosol populations may be primary (those that receive particle emissions), secondary (those formed by coagulation among primary aerosol populations or condensation of gaseous components onto primary particles); or a mixed population, which includes all aerosol constituents. When particles from two populations coagulate such that the resulting particle cannot be accommodated in one of the defined populations, the particle is placed into the mixed population.

The aerosol species treated in the present study are sulfate, nitrate, ammonium, water, black carbon (BC), organic 
Table 2. Table of aerosol configurations.

\begin{tabular}{|c|c|c|c|}
\hline $\begin{array}{l}\text { configuration } \\
\text { number }\end{array}$ & $\begin{array}{l}\text { number of } \\
\text { populations }\end{array}$ & $\begin{array}{c}\text { number of } \\
\text { transported species }\end{array}$ & populations represented \\
\hline 1 & 16 & 51 & $\begin{array}{l}\text { AKK, ACC, DD1, DS1, DD2, DS2, SSA, SSC, OCC, } \\
\text { BC1, BC2, BC3, BCS, DBC, BOC, MXX }\end{array}$ \\
\hline 2 & 16 & 51 & $\begin{array}{l}\text { AKK, ACC, DD1, DS1, DD2, DS2, SSA, SSC, OCC, } \\
\text { BC1, BC2, OCS, BCS, DBC, BOC, MXX }\end{array}$ \\
\hline 3 & 13 & 41 & $\begin{array}{l}\text { AKK, ACC, DD1, DS1, DD2, DS2, SSA, SSC, OCC, } \\
\text { BC1, BC2, BOC, MXX }\end{array}$ \\
\hline 4 & 10 & 34 & $\begin{array}{l}\text { ACC, DD1, DS1, DD2, DS2, SSS, OCC, } \\
\text { BC1, BC2, MXX }\end{array}$ \\
\hline 5 & 14 & 45 & $\begin{array}{l}\mathrm{AKK}, \mathrm{ACC}, \mathrm{DD} 1, \mathrm{DS} 1, \mathrm{SSA}, \mathrm{SSC}, \mathrm{OCC} \\
\mathrm{BC} 1, \mathrm{BC} 2, \mathrm{BC} 3, \mathrm{BCS}, \mathrm{DBC}, \mathrm{BOC}, \mathrm{MXX}\end{array}$ \\
\hline 6 & 14 & 45 & $\begin{array}{l}\text { AKK, ACC, DD1, DS1, SSA, SSC, OCC, } \\
\text { BC1, BC2, OCS, BCS, DBC, BOC, MXX }\end{array}$ \\
\hline 7 & 11 & 35 & $\begin{array}{l}\text { AKK, ACC, DD1, DS1, SSA, SSC, OCC, } \\
\text { BC1, BC2, BOC, MXX }\end{array}$ \\
\hline 8 & 8 & 28 & $\begin{array}{l}\mathrm{ACC}, \mathrm{DD} 1, \mathrm{DS} 1, \mathrm{SSS}, \mathrm{OCC}, \\
\mathrm{BC} 1, \mathrm{BC} 2, \mathrm{MXX}\end{array}$ \\
\hline
\end{tabular}

carbon (OC), mineral dust, and sea salt. Not all species are defined for each population, but the inorganic species $\mathrm{NO}_{3}^{-}$, $\mathrm{NH}_{4}^{+}$, and $\mathrm{H}_{2} \mathrm{O}$ are defined for all populations containing $\mathrm{SO}_{4}^{2-}$. Although the aerosol consists of particles with differing composition and arbitrary size, the particles are assumed to be internally mixed with respect to the ammonium/sulfate, nitrate/sulfate and water/sulfate such that ratios of the amounts of these substances are the same for all $\mathrm{SO}_{4}^{2-}$ containing populations and all particle sizes (except for the additional water uptake by sea salt due to $\mathrm{NaCl}$ ). This approach greatly reduces the required number of transported variables. Sulfate is transported for each $\mathrm{SO}_{4}^{2-}$ containing population; however for ammonium, nitrate, and aerosol water, only the total concentrations summed over all populations needs to be transported. The ammonium, nitrate, and water concentrations are directly proportional with sulfate and hence the distribution of these species among the populations is derived from the sulfate distribution. An aerosol equilibrium module is used for gas-particle partitioning of inorganic species $\left(\mathrm{SO}_{4}^{2-}, \mathrm{NO}_{3}^{-}, \mathrm{NH}_{4}^{+}, \mathrm{Na}^{+}, \mathrm{Cl}^{-}\right.$, $\mathrm{H}_{2} \mathrm{O}$ ). Aerosol liquid water is a transported variable so that deliquescence-crystallization hysteresis can be represented.

MATRIX can be compiled in a variety of alternative "configurations", each defined with a different set of aerosol populations. The module also includes multiple alterna- tive parameterizations for processes with important uncertainties, especially new particle formation. There are also multiple options for calculation of coagulation coefficients, intermodal transfer between the Aitken and accumulation modes, and inorganic aerosol equilibrium models. This paper presents a version of the module in which population $i$ of aerosol species $q$ is transported as a set of mass concentrations $\left(M_{i}, q\right)$ and a number concentration $\left(N_{i}\right)$, which provides the total mass and number in a population and yields a 2-moment-per-population representation.

\subsection{Aerosol population configurations}

MATRIX allows different choices in defining an aerosol population, called an aerosol population configuration. The configurations presented here vary in the number, composition, and the interaction among the populations defined. Eight configurations are currently set up as summarized in Tables 1 and 2. The design of these configurations follows in large part the sectional model of Jacobson (2002) (J02 hereinafter). All configurations track the total aerosol ammonium, total aerosol nitrate, and total aerosol water, in addition to the species defined for individual populations.

Configuration 1, the most complex mechanism, consists of 16 populations and requires 51 transported species. Table $1 \mathrm{a}$ and $\mathrm{b}$ presents the populations, species, lognormal 
parameters, and coagulation interactions for configuration 1. Configuration 1 has 9 primary populations that receive particles through particle emissions: Aitken mode sulfate particles (AKK; ambient diameter less than $0.1 \mu \mathrm{m}$ ), accumulation mode sulfate (ACC; ambient diameter greater than $0.1 \mu \mathrm{m}$ ), insoluble fine mineral dust (DD1) and coarse mineral dust (DD2), fine sea salt (SSA), coarse sea salt (SSC), organic carbon (OCC), insoluble black carbon $(\mathrm{BC} 1)$ and mixed BC-OC (BOC). The transfer between Aitken (AKK) and accumulation (ACC) mode is described in Sect. 2.8.

Among these populations, AKK also receives particles from new particle formation, population $\mathrm{BOC}$ also receives particles through $\mathrm{BC}-\mathrm{OC}$ coagulation, and $\mathrm{ACC}$ also receives particles through growth of particles in population AKK. All other populations acquire particles only as receptor population for particles formed through coagulation of other (donor) populations, or reclassification of particles from other populations as they become soluble through acquisition of inorganic coatings. All populations undergo condensational growth and self-coagulation, and all but the mixed population (MXX) undergo loss due to hetero-coagulation with other populations. Population $\mathrm{BC} 1, \mathrm{BC} 2$, and $\mathrm{BC} 3$ contain black carbon with different volume fractions of inorganic coating (set to $0-5 \%, 5-20 \%$, and $>20 \%$, respectively). All (nonbiomass burning) black carbon is emitted into the insoluble primary population $\mathrm{BC} 1$. Biomass burning emissions are assumed to go into the BOC population. Condensation of inorganics on $\mathrm{BC} 1, \mathrm{BC} 2$, and $\mathrm{BC} 3$, and coagulation among these three populations may increase the volume fraction of inorganics in these populations. When $\mathrm{BC} 1$ (BC2) coagulates with $\mathrm{BC} 2(\mathrm{BC} 3)$, the resulting particles initially go into $\mathrm{BC} 1$ (BC2) since they may have insufficient coating for classification as $\mathrm{BC} 2$ (BC3). At the end of each time step, if the volume fraction of inorganics in $\mathrm{BC} 1$ (BC2) rises above $5 \%$ (20\%), all BC1 (BC2) particles are moved to population $\mathrm{BC} 2$ (BC3). Particles in population BCS (BC-sulfate) are formed solely through coagulation of AKK or ACC with $\mathrm{BC} 1, \mathrm{BC} 2$, or BC3. The secondary populations DS1 (soluble dust accumulation mode) and DS2 (soluble dust coarse mode) represent soluble particles produced by condensation of inorganics onto DD1 (insoluble dust accumulation mode) and DD2 (insoluble dust coarse mode), respectively. Population DD1 and DD2 can also acquire inorganics through coagulation with population AKK or ACC. Particles are transferred from DD1 to DS1 or DD2 to DS2 when the volume fraction of inorganics in DD1 or DD2 exceeds a threshold (set to 5\%). The secondary population DBC (dust-BC) receives particles solely through coagulation of any of the populations DD1, $\mathrm{DD} 2$, DS1, DS2 with any of the populations $\mathrm{BC} 1, \mathrm{BC} 2$, $\mathrm{BC} 3, \mathrm{BCS}$. The mixed population MXX receives the more complex aerosol mixtures and grows as the total aerosol approaches an internally mixed state. The transported species for the sea salt populations are the mass concentrations of dry sea salt (treated as $\mathrm{NaCl}$ ) and the total non-sea salt sulfate summed over both populations. The non-sea salt sulfate is apportioned between the SSA and SSC populations in proportion to the sea salt $(\mathrm{NaCl})$ in each population. Number concentrations are derived from mass concentrations using assumed lognormal distributions $\left(\sigma_{g, N}\right)$ given in Table 1a.

Configuration 2, which also consists of 16 populations and 51 transported species, differs from configuration 1 only in omission of population $\mathrm{BC} 3$ and inclusion of population OCS (OC-sulfate) resulting from coagulation of population OCC with population AKK or ACC, analogous to population BCS. Configuration 3 consists of 13 populations and requires 41 transported species. It differs from configuration 1 in that (1) populations BC3 and BCS are omitted and black carbon aerosols are represented only by populations $\mathrm{BC} 1$ (insoluble) and $\mathrm{BC} 2$ (soluble), and (2) population DBC (mineral dust-BC) is omitted and these particles are now placed in the mixed population MXX.

Configuration 4 consists of 10 populations and requires 34 transported species, described in Table 2. It differs from configuration 1 in the omissions of populations $\mathrm{AKK}, \mathrm{BC} 3$, $\mathrm{BCS}, \mathrm{DBC}$, and BOC, and the use of a single population for sea salt (SSS). Configuration 5-8 differ from configuration 1-4 only in the representation of mineral dust by one insoluble and one soluble population only. The numbers of populations are $14,14,11$, and 8 , and the number of transported species are $45,45,35$, and 28 , respectively.

\subsection{Equations for evolution of number and mass concentra- tions}

Equations for number and mass concentrations for each population must be solved. These equations are similar to those solved by the Community Multiscale Air Quality (CMAQ) chemical transport model as described in Binkowski and Roselle (2003). Secondary particle formation from gaseous precursors, condensational growth, all coagulation processes, and addition of sulfate formed by in-cloud oxidation are treated as a group without operator splitting. The partitioning of semi-volatiles between the gas- and particlephases is done just prior to, and again subsequent to, the calculation of the primary dynamical processes just cited. Any reclassification of particles from one population to another is done at the end of the time step.

For the number concentration $N_{i}$ of population $i$

$$
\begin{aligned}
& \frac{d N_{i}}{d t}=P_{i}-L_{i} \\
& P_{i}=J_{i}+E_{i}^{\mathrm{num}}+R_{i}=J_{i}+E_{i}^{\mathrm{num}}+\sum_{k \neq 1}^{n} \sum_{l>k, l \neq i}^{n} d_{i k l} K_{k l}^{(0)} N_{k} N_{l} \equiv c_{i} \\
& L_{i}=\frac{1}{2} K_{i i}^{(0)} N_{i}^{2}+\left(\sum_{j \neq i}^{n} d_{i j} K_{i j}^{(0)} N_{j}\right) N_{i} \equiv a_{i} N_{i}^{2}+b_{i} N_{i}
\end{aligned}
$$

where $P_{i}$ and $L_{i}$ are the production and loss rates of number concentrations, $J_{i}$ the secondary particle formation rate (to 
be distinguished from the nucleation rate below), $E_{i}^{\text {num }}$ the number concentration emission rate, $R_{i}$ the rate at which particles enter population $i$ due to coagulation among all other populations. $K_{k l}^{(0)}$ is the population-average coagulation coefficient (defined in Sect. 2.7 and Appendix B) for population $i$ and $j ; n$ is the number of populations, $d_{i k l}$ is unity if coagulation of population $k$ with $l$ produces particles in population $i$ and zero otherwise; $d_{i j}$ is unity if coagulation of population $j$ with $i$ results in the removal of particles from population $i$ and zero otherwise. The coefficients $a_{i}, b_{i}$, and $c_{i}$ are defined for convenience and all subscripts are dropped in considering solutions to the resulting equation, which is solved for each population.

$$
\frac{d N}{d t}=c-a N^{2}-b N
$$

Analytic solutions are obtained by holding the coefficients constant over a time step $\Delta t=t-t_{0}$ and are expressed using the quantities

$\delta=\left(b^{2}+4 a c\right)^{1 / 2}, r_{1}=\frac{2 a c}{b+\delta}, r_{2}=-\frac{b+\delta}{2}, \gamma=-\left(\frac{r_{1}-a N\left(t_{0}\right)}{r_{2}-a N\left(t_{0}\right)}\right)$

For $c \neq 0$ the solution to Eq. (4) is

$N(t)=\frac{r_{1}+r_{2} \gamma \exp (-\delta t)}{a[1+\gamma \exp (-\delta t)]}$

For $c=0$ and $b \neq 0$ the solution is

$N(t)=\frac{b N\left(t_{0}\right) \exp (-b t)}{b+a N\left(t_{0}\right)[1-\exp (-b t)]}$

and for $c=0$ and $b=0$ the solution is

$N(t)=\frac{N\left(t_{0}\right)}{1+a N\left(t_{0}\right) t}$

where sign errors in Eqs. (7) and (8) have been corrected from Binkowski and Roselle (2003).

For the mass concentration $Q_{i, q}$ of species $q$ in population $i$

$\frac{d Q_{i, q}}{d t}=P_{i, q}-L_{i, q}=P_{i, q}-f_{i}^{(3)} Q_{i, q}$

where $P_{i, q}$ and $L_{i, q}$ are the production and loss rates of mass concentration and $f_{i}^{(3)}$ is defined through the second equality. Analytic solutions are again obtained by holding the coefficient constant over the time step. For $f_{i}^{(3)} \neq 0$ the solution is

$Q_{i, q}(t)=\frac{P_{i, q}}{f_{i}^{(3)}}+\left[Q_{i, q}\left(t_{0}\right)-\frac{P_{i, q}}{f_{i}^{(3)}}\right] \exp \left(-f_{i}^{(3)} t\right)$

and for $f_{i}^{(3)}=0$ the solution by an Euler forward step is

$Q_{i, q}(t)=Q_{i, q}\left(t_{0}\right)+P_{i, q} \Delta t$

The mass concentration production and loss terms treated in the aerosol module are

$P_{i, q}=P_{i, q}^{\mathrm{emis}}+P_{i, q}^{\mathrm{npf}}+P_{i, q}^{\mathrm{coag}}+P_{i, q}^{\mathrm{growth}}+P_{i, q}^{\text {cloud }}$
$L_{i, q}=L_{i, q}^{\text {coag }}+L_{i, q}^{\text {gas-particle }}$

where terms are included for particle emissions, new particle formation, coagulation, growth due to condensation and other gas-particle mass transfer, and incorporation of sulfate produced by in-cloud oxidation. Each of these terms and those for number concentrations in Eqs. (2) and (3) are discussed in a following section.

\subsection{New particle formation}

This section describes the formation of new particles through nucleation. The nucleation rate is the rate at which criticalsized clusters of $\sim 1 \mathrm{~nm}$ diameter are formed. The NPF rate $J_{\mathrm{p}}$ is usually defined as the rate at which particles at the minimum detectable size are formed and is thus a function of measurement techniques, but in the present context $J_{\mathrm{p}}$ is the rate at which particles of a user-selected small ambient diameter $D_{\text {npf }}(3-20 \mathrm{~nm})$ enter the Aitken mode. Explicit representation of particle dynamics at sizes less than $D_{\text {npf }}$ is avoided through parameterizations that convert the nucleation rate $J$ to the NPF rate at size $D_{\text {npf }}$, or directly give a NPF rate derived from field observations without reference to a nucleation rate.

The new particle formation production term is

$P_{i, q}^{\mathrm{npf}}=J_{\mathrm{p}, i} m_{i, q}^{\mathrm{npf}}$

where $m_{i, q}^{\text {npf }}$ is the mass of species $q$ in a newly formed particle added to population $i$, and $J_{\mathrm{p}, i}$ is the new particle formation (NPF) rate, determined from and less than the nucleation rate $J$. Only population AKK receives nucleated particles, and only sulfate is directly acquired by population AKK; water and ammonium uptake are determined by subsequent equilibrium calculations. $J_{\mathrm{p}, i}$ is zero for all other populations.

This section describes the MATRIX NPF model, which contains several nucleation parameterizations. The following submodules of the NPF model are described in Appendix A: (A1) parameterizations to convert $J$ to $J_{\mathrm{p}, i}$ by implicitly treating the particle dynamics at sizes less than $D_{\text {npf }}$, (A2) calculation of the mass of sulfate in a newly formed particle, and (A3) calculation of the steady-state concentration $\left[\mathrm{H}_{2} \mathrm{SO}_{4}\right]_{\mathrm{SS}}$ used in the nucleation and NPF parameterizations.

Five nucleation or direct NPF parameterizations can be chosen in MATRIX, two for binary homogeneous nucleation of $\mathrm{H}_{2} \mathrm{SO}_{4}-\mathrm{H}_{2} \mathrm{O}$ (Jaecker-Voirol and Mirabel, 1989; Vehkamäki et al., 2002), one for ternary homogeneous nucleation of $\mathrm{H}_{2} \mathrm{SO}_{4}-\mathrm{NH}_{3}-\mathrm{H}_{2} \mathrm{O}$ (Napari et al., 2002), one for nucleation by ion-ion recombination (Turco et al., 1998), and one for formation of particles of 3-nm diameter derived from field observations (Eisele and McMurry, 1997). The ionion recombination mechanism is taken as independent of the homogeneous mechanisms, and the ion-ion recombination 
contribution to the total nucleation rate is optionally included or set equal to zero.

- The Jaecker-Voirol and Mirabel (1989) parameterization, is based on classical binary nucleation theory with hydrates, presented graphically and designed for simple interpolation in $T$ and RH. Each plot of $\log J$ vs. $\log \left[\mathrm{H}_{2} \mathrm{SO}_{4}\right]$ for $T=[223,248,273,298,323] \mathrm{K}$ and $\mathrm{RH}=[20,40,60,80,100] \%$ was scanned, digitized, and fit to low-order polynomials. The range of $J$ covered by these fits is $10^{-3}-10^{5} \mathrm{~cm}^{-3} \mathrm{~s}^{-1}$.

- The Vehkamäki et al. (2002) parameterization, also based on classical binary nucleation theory with hydrates, is valid for $T=230.15-305.15 \mathrm{~K}$ and extrapolation to $190 \mathrm{~K}, \mathrm{RH}=0.01-100 \%$ and $\left[\mathrm{H}_{2} \mathrm{SO}_{4}\right]=10^{4}$ $10^{11}$ molecules $/ \mathrm{cm}^{3}$. The parameterization is limited to conditions for which $10^{-7}<\mathrm{J}<10^{10} \mathrm{~cm}^{-3} \mathrm{~s}^{-1}$ and the critical nucleus contains at least 4 molecules.

- The Napari et al. (2002) parameterization, based on classical ternary nucleation theory involving $\mathrm{H}_{2} \mathrm{SO}_{4}$, $\mathrm{NH}_{3}$ and $\mathrm{H}_{2} \mathrm{O}$ is valid for $T=240-300 \mathrm{~K}, \mathrm{RH}=5-95 \%$, $\left[\mathrm{H}_{2} \mathrm{SO}_{4}\right]=10^{4}-10^{9}$ molecules $/ \mathrm{cm}^{3}$, and $\left[\mathrm{NH}_{3}\right]=0.1-100$ ppt (parts per trillion). The parameterization is limited to conditions for which $10^{-5}<\mathrm{J}<10^{6} \mathrm{~cm}^{-3} \mathrm{~s}^{-1}$. For $\left[\mathrm{NH}_{3}\right]>100 \mathrm{ppt}, J$ is calculated using $\left[\mathrm{NH}_{3}\right]=100 \mathrm{ppt}$.

- The Turco et al. (1998) parameterization for ion induced nucleation is

$J=Q_{i} f_{i 0}\left(\frac{\left[\mathrm{H}_{2} \mathrm{SO}_{4}\right]}{\left[\mathrm{H}_{2} \mathrm{SO}_{4}\right]_{0}}\right)^{n^{*}}$

where $Q_{i}$ is the local ionization (and recombination) rate, and $f_{i 0}$ is the fraction of stabilizing recombination events at a reference vapor concentration of $\left[\mathrm{H}_{2} \mathrm{SO}_{4}\right]_{0}$. Following Turco et al. (1998), we set $\left[\mathrm{H}_{2} \mathrm{SO}_{4}\right]_{0}$ to $5 \times 10^{6} \mathrm{~cm}^{-3}, n^{*}$ to 3 , and $f_{i 0}$ to $1 \times 10^{-3}$. The ionization rate $Q_{i}$ increases linearly and varies with altitude from $2 \mathrm{~cm}^{-3} \mathrm{~s}^{-1}$ near the surface to $\sim 30 \mathrm{~cm}^{-3} \mathrm{~s}^{-1}$ at $\sim 12 \mathrm{~km}$. Latitudinal variations of cosmic rays (Usoskin and Kovaltsov, 2006) are not considered in the current model. The ionization rate is an upper limit on the nucleation rate. No lower limit is placed on this rate.

- The observations of Eisele and McMurry (1997) for the flux of particles through the size 3-4 nm diameter were fit to the form $J=K\left[\mathrm{H}_{2} \mathrm{SO}_{4}\right]^{n}$ with $(n, K)$ given by (1, $5.8 \times 10^{-13}$ ) for the lower curve of Fig. 7 in Eisele and McMurry (1997), $\left(2,3.5 \times 10^{-15}\right)$ for the upper curve, and $\left(1.5,3.7 \times 10^{-14}\right)$ for a curve drawn intermediate between the two. There are no bounding limits on input concentrations or new particle formation rates.

The conversion of the nucleation rate into a NPF and the calculation of the sulfate mass in a newly formed particle are presented in Appendix A and further discussion can be found in Chang et al. (2008).
2.4 Condensational growth and gas-particle mass transfer

The total production rate (averaged over the time step) of species $q$ in population $i$ due to condensation of nonvolatile species and subsequent gas-particle mass transfer due to equilibration of other species is given by

$P_{i, q}^{\text {growth }}=P_{i, q}^{\text {kinetic }}+P_{i, q}^{\text {equil }}=h_{i} P_{q}^{\text {kinetic }}+P_{i, q}^{\text {equil }}$

where $P_{i, q}^{\text {growth }}$ is the total production rate of species $q$ in population $i$ averaged over the time step, $P_{q}^{\text {kinetic }}$ represents species treated kinetically $\left(\mathrm{H}_{2} \mathrm{SO}_{4}\right), P_{i, q}^{\text {equil }}$ represents species for which equilibrium is assumed $\left(\mathrm{H}_{2} \mathrm{O}, \mathrm{NH}_{3}, \mathrm{HNO}_{3}\right), h_{i}$ is the fraction of the total $\mathrm{H}_{2} \mathrm{SO}_{4}$ condensation rate due to particles in population $i$, and $P_{i, q}^{\text {kinetic }}$ is the total condensation rate of $\mathrm{H}_{2} \mathrm{SO}_{4}$ summed over all populations, calculated as

$P_{q}^{\text {kinetic }}=\frac{\left|\Delta\left[\mathrm{H}_{2} \mathrm{SO}_{4}\right]_{\text {cond }}\right|}{\Delta t}=\frac{\left[\mathrm{H}_{2} \mathrm{SO}_{4}\right]\left[1-\exp \left(-k_{c} \Delta t\right)\right]}{\Delta t}$,

where $k_{c}$ is the total condensation sink. The condensation sink is the first-order rate constant for loss of $\left[\mathrm{H}_{2} \mathrm{SO}_{4}\right]$ onto particle surfaces (Kulmala et al., 2001) and is obtained as $k_{c}=\sum_{i=1}^{n} k_{c, i}$ with $k_{c, i}$ the contribution of population $i$. For each population the calculation of $k_{c, i}$ is based upon a single particle size, the diameter of average mass $\bar{D}_{\mathrm{p}, i}$, and an adjustment factor $\theta_{i}=\exp \left[-\left(\ln \sigma_{g, i}\right)^{2}\right]$ to prevent excessive condensation due to the use of a monodisperse distribution of diameter $\bar{D}_{\mathrm{p}, i}$ (Okuyama et al., 1988). For population $i$

$k_{c, i}=2 \pi D_{\text {diff }} \int D_{\mathrm{p}} \beta\left(K n_{i}, \alpha\right) n_{i}\left(D_{\mathrm{p}}\right) d D_{\mathrm{p}}$

calculates as

$k_{c, i}=2 \pi \theta_{i} D_{\text {diff }} \bar{D}_{\mathrm{p}, i} \beta\left(K n_{i}, \alpha\right) N_{i}$

where $D_{\text {diff }}$ is the binary diffusion coefficient of $\mathrm{H}_{2} \mathrm{SO}_{4}$ in air, $D_{\mathrm{p}}$ is the particle diameter, $K n_{i}=2 \lambda / D_{\mathrm{p}, i}$ is the Knudsen number with $\lambda$ the vapor $\left(\mathrm{H}_{2} \mathrm{SO}_{4}\right)$ mean free path in air, $\alpha$ the mass accommodation coefficient of $\mathrm{H}_{2} \mathrm{SO}_{4}, n_{i}$ the number size distribution of population $i, N_{i}$ the particle number concentration in population $i$, and $\beta$ the transition regime correction to the condensational mass flux (Seinfeld and Pandis, 1998), given by

$\beta\left(K n_{i}, \alpha\right)=\frac{1+K n_{i}}{1+0.377 K n_{i}+1.33 K n_{i}\left(1+K n_{i}\right) / \alpha}$

A particle density is needed for each population to obtain the diameter of average mass; this is calculated as $\rho=m / V$, where the volume concentration $V$ is calculated as a sum of contributions for each chemical component based on the current populations composition. The condensation sink is implemented through lookup tables for $k_{c, i} / N_{i}$ as a function of particle diameter calculated at representative heights for each vertical level of the host model using the standard atmosphere to obtain an appropriate characteristic temperature 
and pressure to calculate $D_{\text {diff }}$ and $\lambda$. The condensation sink was calculated with the mass accommodation coefficient $\alpha$ for $\mathrm{H}_{2} \mathrm{SO}_{4}$ set to 0.86 (Hanson, 2005), $\alpha=1$ and $\lambda=\lambda_{\text {air }}$, at the ambient temperature and pressure.

\subsection{Partitioning $\left(P_{i, q}^{\text {equil }}\right)$ of semi-volatile species}

Two different thermodynamic modules are included in MATRIX. The highly computational efficient EQSAM (Metzger et al., 2002b,a, 2006) which is built upon a simplified non-iterative expression for the activity coefficients, and ISORROPIA (Nenes et al., 1998) a model that calculates the composition and phase state of an ammonia-sulfate-nitratechloride-sodium-water inorganic aerosol in thermodynamic equilibrium, which is more accurate than EQSAM but has a much greater computational burden.

At each time step, the number concentrations and mass concentrations of sulfate, $\mathrm{BC}, \mathrm{OC}$, mineral dust, sea salt are passed for each population, and also the total aerosol nitrate, ammonium, liquid water, $\mathrm{NH}_{3}(\mathrm{~g})$ and $\mathrm{HNO}_{3}$ (g) to MATRIX. The chosen aerosol thermodynamic model is used to partition the total $\left[\mathrm{NH}_{3}\right]+\left[\mathrm{NH}_{4}^{+}\right]$and total $\left[\mathrm{HNO}_{3}\right]+\left[\mathrm{NO}_{3}^{-}\right]$between the gas and condensed phase, and to obtain the liquid aerosol water concentration.

Aerosol phase water concentrations are calculated in two parts: (1) the water associated with all aerosol phase sulfate, nitrate, ammonium, and mineral dust concentrations summed over all populations, omitting sea salt (treated as $\mathrm{NaCl}$ ) concentrations, using either EQSAM or ISORROPIA, and (2) the water associated with sea salt. The water from step 1 is distributed over populations in proportion to its sulfate concentration, whereas the water from step 2 is distributed over populations in proportion to their sea salt concentrations. Note, we neglect the impact of organic carbon in this parameterization, as this parameterization is not included in the current version of the thermodynamical models we apply.

Water uptake by sea salt aerosol and its dependence on $\mathrm{RH}$ (parameterized by fraction $h \equiv \mathrm{RH}(100 \%)$ ) is calculated after Lewis (2006) as follows. The assumption is made that the volume concentration of water (volume $\mathrm{H}_{2} \mathrm{O}(l)$ per unit volume of space) in sea salt aerosol is given by $V_{\mathrm{H}_{2} \mathrm{O}}=V$ $V_{\mathrm{NaCl}}$, with $V$ the total volume concentration of the wet sea salt and $V_{\mathrm{NaCl}}$ the volume concentration of dry sea salt. The water mass concentration $m_{\mathrm{H}_{2} \mathrm{O}}$ is then calculated from the total sea salt concentration $m_{\mathrm{NaCl}}$ as

$$
\begin{aligned}
& m_{\mathrm{H}_{2} \mathrm{O}}=\rho_{\mathrm{H}_{2} \mathrm{O}} V_{\mathrm{H}_{2} \mathrm{O}} \\
& =\rho_{\mathrm{H}_{2} \mathrm{O}}\left(V-V_{\text {dry }}\right) \\
& =\rho_{\mathrm{H}_{2} \mathrm{O}}\left(\xi^{3} V_{\text {dry }}-V_{\text {dry }}\right) \\
& =\rho_{\mathrm{H}_{2} \mathrm{O}} V_{\text {dry }}\left(\xi^{3}-1\right) \\
& =\rho_{\mathrm{H}_{2} \mathrm{O}}\left(m_{\mathrm{NaCl}} / \rho_{\mathrm{NaCl}}\right)\left(\xi^{3}-1\right) \\
& =m_{\mathrm{NaCl}} \times\left(\rho_{\mathrm{H}_{2} \mathrm{O}} / \rho_{\mathrm{NaCl}}\right)\left(\xi^{3}-1\right)
\end{aligned}
$$

with $\xi(\mathrm{RH})=r / r_{\text {dry }}$. This holds for the fractional relative humidity $h$ greater than the crystallization value 0.45 . The expression for $\xi$ is $\xi(h)=c_{\mathrm{SS}}\left[b_{\mathrm{SS}}+1 /(1-h)\right]^{1 / 3}$ with $\rho_{\mathrm{NaCl}}$ the density of $\mathrm{NaCl}\left(2.165 \mathrm{~g} \mathrm{~cm}^{-3}\right)$ and with $c_{\mathrm{SS}}=1.08$ and $b_{\mathrm{SS}}=1.2$.

Hysteresis effects are represented by the treatment of Ghan et al. (2001a). For RH between the crystallization and deliquescence RH, the total metastable aerosol water content (step 1+step 2) is calculated. If the actual current aerosol water content is greater than half this value, the aerosol is taken to be wet and the equilibrium water content is distributed over all modes in proportion to their sulfate and sea salt concentrations. Otherwise, the aerosol is taken to be dry. The deliquescent-RH point is set to a constant value of $80 \%$ (appropriate for ammonium sulfate, following Ghan et al., 2001a). The critical RH is set to a constant value of $35 \%$ (appropriate for ammonium sulfate, following Ghan et al., 2001a) for the hysteresis calculation. As the water associated specifically with sea salt is not a tracked variable, this treatment is for the aerosol phase water as a whole.

2.6 Incorporation of sulfate produced by in-cloud aqueousphase oxidation

The sulfate produced by in-cloud oxidation of $\mathrm{SO}_{2}$ is distributed over a selected set of populations such that each activating particle receives an equal portion of that sulfate:

$$
P_{i, q}^{\text {cloud }}=\frac{\zeta_{i} N_{i}}{\sum \zeta_{i} N_{i}} \frac{\Delta\left[\mathrm{H}_{2} \mathrm{SO}_{4}\right]_{\text {cond }}}{\Delta t}
$$

where $\zeta_{i}$ is the fraction of particles in population $i$ that activate to form cloud droplets, $N_{i}$ the particle number concentration in population $i$, and $\Delta\left[\mathrm{H}_{2} \mathrm{SO}_{4}\right]_{\text {cond }}$ is the concentration of sulfate produced in-cloud during the time step $\Delta t$.

MATRIX provides the host model cloud module with either the number concentration of soluble particles for each population, an estimate of the number of activating particles based on constant activating fractions for each population, or an estimate of the number of activating particles based on the aerosol activation parameterizations of Abdul-Razzak and Ghan $(1998,2000)$. For the number concentration of soluble particles, the populations treated as soluble are selected by setting the soluble (or activating) fraction of particles, $\kappa_{i}$, for each population. Default values for $\kappa_{i}$ are set to unity for populations ACC, DS1, DS2, BC2, BC3, BCS, OCS, SSA, SSC, SSS, and MXX, 0.7 for population OCC, and zero for all other populations.

The droplet activation parameterization of Abdul-Razzak and Ghan (1998, 2000), which treats multimodal and multicomponent aerosols, provide the activated fraction for the number and mass concentrations for each population, based on the composition of each population and the cloud updraft velocity. The population-average hygroscopicity parameters are key in this treatment. The composition of the soluble components of mineral dust is treated as in Ghan 
et al. (2001a). Populations that are thought of as insoluble cores with soluble shells, such as coated BC and dust populations, may have a small soluble mass fraction that is effective at enhancing activation. All populations are included in the activation calculation and each population may have a nonzero activated fraction. The number concentration of activating particles for each population is saved for use in the cloud module, where aqueous chemistry, scavenging of interstitial particles (due to Brownian diffusion of particles to droplets), collision-coalescence, evaporation, aerosol resuspension, and wet removal are calculated.

\subsection{Coagulation}

A derivation of coagulation between populations for production terms $P_{i, q}^{\text {coag }}$ and loss terms $L_{i, q}^{\text {coag }}$ for the mass concentration of species $q$ in population $i$ is given in Appendix B. The production terms are

$$
P_{i, q}^{\mathrm{coag}}=\sum_{k=1}^{n} \sum_{l>k}^{n} g_{i k l, q} K_{k l}^{(3)} N_{k} N_{l}\left[\left(1-\delta_{k i}\right) m_{k, q}+\left(1+\delta_{l i}\right) m_{l, q}\right]
$$

where $g_{i k l, q}$ is unity if coagulation between population $k$ and $l$ adds species $q$ to population $i$ and is zero otherwise, $K_{k l}^{(3)}$ is a population-average coagulation coefficient (defined in the Appendix B), $\delta_{k l}$ is the Kronecker delta, and $m_{j, q}$ is the mean mass concentration of species $q$ per particle in population $j$. Populations $k$ and $l$ are distinct populations, and population $i$ may be a third distinct population or the same population as $k$ or $l$. The loss terms are

$$
L_{i, q}^{\mathrm{coag}}=\sum_{j \neq 1}^{n} d_{i j} K_{i j}^{(3)} N_{j} N_{i} m_{i, q}=\left(\sum_{j \neq i}^{n} d_{i j} K_{i j}^{(3)} N_{j}\right)\left(N_{i} m_{i, q}\right) \equiv f_{i}^{(3)} Q_{i, q}
$$

The coagulation coefficient $K_{i j}$ is the sum of five contributions: Brownian coagulation, the convective Brownian diffusion enhancement, gravitational collection, turbulent inertial motion, and turbulent shear. The kernels are described in Jacobson (2005), and the values shown in Fig. 15.7 of Jacobson (2005) were reproduced by the MATRIX model. The collision efficiency for the gravitational collection was taken from Eq. (12-78) of Pruppacher and Klett (1980). The dependence of $K_{i j}$ on temperature and pressure was examined by calculating $K_{i j}$ for all pairs of particle sizes for a set of diameters ranging from $0.003-30 \mu \mathrm{m}$ at several values $T$ and $p$. At a pressure of $101325 \mathrm{~Pa}$, the ratio $K_{i j}(200 \mathrm{~K}) / K_{i j}(288 \mathrm{~K})$ ranged from 0.6 to 1.4 , and the ratio $K_{i j}(325 \mathrm{~K}) / K_{i j}(288 \mathrm{~K})$ ranged from 0.9 to 1.2 , showing a rather weak temperature dependence for $K_{i j}$. The Brownian $K_{i j}$ is directly proportional to the sum of particle diffusion coefficients and thus depends on the Cunningham slip-flow correction to those coefficients, the particle Knudsen numbers, the mean free path of air, and thus the ambient pressure. At a temperature of $288 \mathrm{~K}$, the ratio $K_{i j}(10132.5 \mathrm{~Pa}) / K_{i j}(101325 \mathrm{~Pa})$ ranged from 0.41 to 8.0 , and the ratio $K_{i j}(1013.25 \mathrm{~Pa}) / K_{i j}(101325 \mathrm{~Pa})$ ranged from 0.29 to 46 , showing a significant dependence for $K_{i j}$ on pressure. The dependence of $T$ and $p$ on $K_{i j}$ is included through lookup tables for the population-average coagulation coefficients $\bar{K}_{i j}$ with table dimensions for $T, p$, and each of the lognormal parameters $D_{g, i}, D_{g, j}, \sigma_{g, i}$, and $\sigma_{g, j}$ for populations $i$ and $j$. Table temperatures were 200, 288, $325 \mathrm{~K}$ and pressures were $101325,10132.5$, and $1013.25 \mathrm{~Pa}$. $D_{g, i}$ and $D_{g, j}$ each spanned the interval $[0.003,30.0] \mu \mathrm{m}$ with 81 evenly-spaced (log scale) values, and for $\sigma_{g, i}$ and $\sigma_{g, j} 1.6$, 1.8, and 2.0. For each pair of coagulating modes, $\sigma_{g, i}$ and $\sigma_{g, j}$ are fixed, and $T, p, D_{g, i}$ and $D_{g, j}$ are each linearly interpolated from the tabulated values. Precise mass conservation is accomplished by rescaling all mass variables for each species at the end of each time step as needed to remove minor inaccuracies in the approximate analytic solutions when large time steps are used. These inaccuracies are decreased as the time step or coagulation rates are reduced.

\subsection{Intermodal transfer of sulfate from the Aitken to the accumulation mode}

As newly-formed particles grow by condensation of gases onto a preexisting particle and self-coagulation of particles, the mean diameter of the Aitken (AKK) mode may approach that of the accumulation (ACC) mode. To prevent the AKK mode from becoming too broad and containing excessively large particles, particles may be transferred to the ACC mode as the diameter of the AKK mode approaches that of the ACC mode. This can be done in MATRIX in one of three ways. The first method is to transfer the fraction $F_{\text {trans }}$

$F_{\text {trans }}=\left[\frac{\left(D_{\mathrm{p}, \mathrm{AKK}}-D_{\mathrm{p}, \mathrm{AKK}, \min }\right)}{\left(D_{\mathrm{p}, \mathrm{ACC}}-D_{\mathrm{p}, \mathrm{AKK}, \min }\right)}\right]^{p}$

from AKK to ACC during the time step, where $D_{\mathrm{p}, \mathrm{AKK}}$ is the mean mass diameter of mode AKK. $D_{\mathrm{p}, \mathrm{AKK} \text {,min }}$ is the minimum value of $D_{\mathrm{p}, \mathrm{AKK}}$ and as well the pre-selected size at which newly-formed particles may appear $(3-20 \mathrm{~nm}$ in this model). $D_{\mathrm{p}, \mathrm{ACC}}$ is the mean mass diameter of mode ACC. The exponent $p$ is an adjustable parameter in the range $2 \leq p \leq 6$; the larger its value, the more intermodal transfer is delayed until the mean mass diameter of the AKK mode closely approaches the diameter of the ACC mode. As long as $D_{\mathrm{p}, \mathrm{AKK}}$ is near the size at which new particles are formed, there is no transfer; if the particles in mode AKK have grown to the size of mode ACC, the two modes are fully merged and the AKK mode is emptied and ready to receive freshlyformed particles. When there are modest differences in mean particle size between the two modes, the transfer is spread over several time steps. This approach meets the criteria given in Whitby et al. (2002) for a stable intermodal transfer scheme. The second method follows Wilson et al. (2001), which is equivalent to Binkowski and Roselle (2003) with the diameter of intersection replaced by the fixed diameter $\left(D_{g n \mathrm{AKK}} D_{g n \mathrm{ACC}}\right)^{1 / 2}$. The third method is that of Binkowski 

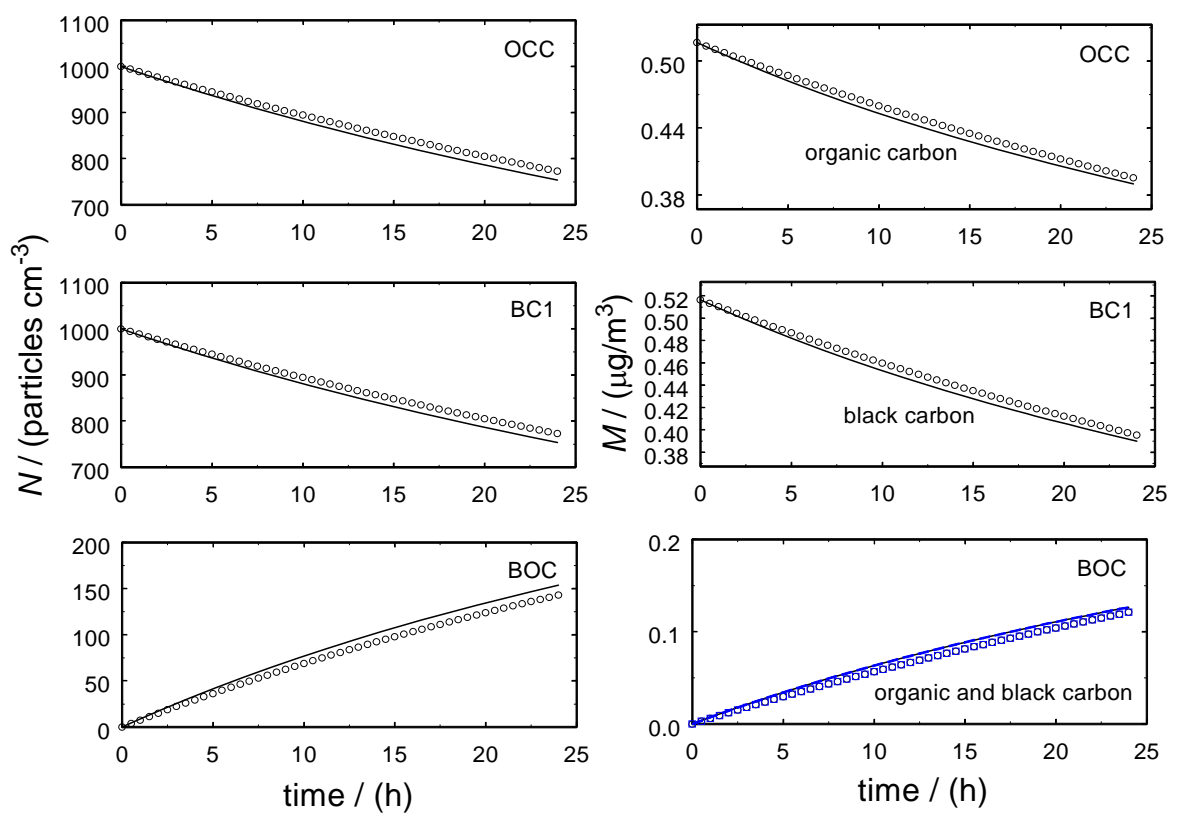

Fig. 1. Number and mass concentrations as a function of time for the coagulation of population OCC and BC1 to form BOC. Solid lines are results from MATRIX applied as a discrete model, open symbols are results from the standard MATRIX model.

and Roselle (2003) without modification, where the intersection of the size distributions of AKK and ACC is calculated and than the fraction of the total number of Aitken mode particles greater than this diameter is moved over into the larger mode.

\section{Box model results}

To evaluate some of the capabilities of MATRIX, first we examine it as as a box model. The coagulation scheme is tested, followed by a sensitivity study on aerosol activation for configuration 1-8. The following parameterizations were used: (1) the thermodynamic equilibrium model EQSAM (see Sect. 2.4), (2) the nucleation mechanism by Napari et al. (2002), including ion to ion recombination by Turco et al. (1998) (see Sect. 2.3) and conversion into NPF by Kerminen and Kulmala (2002) (see Appendix A1), and (3) mode transfer by the fractional transfer method (Eq. 23) with $p=4$.

\subsection{Sensitivity of coagulation to model time stepping}

Several test cases are examined focusing on coagulation of donor populations $\mathrm{A}$ and $\mathrm{B}$ to produce a distinct receptor population $C$. This process is symbolized by the key interaction $\mathrm{A}+\mathrm{B} \rightarrow \mathrm{C}$, although there are six distinct interactions: $\mathrm{A}+\mathrm{C} \rightarrow \mathrm{C}, \mathrm{B}+\mathrm{C} \rightarrow \mathrm{C}, \mathrm{A}+\mathrm{B} \rightarrow \mathrm{C}$, and self-coagulation within all three populations. Here we compare MATRIX box simulations with a $0.5-1 \mathrm{~h}$ time step, to a discrete model simulation, where the time step was subdivided as needed so as not to remove more particles from a grid box than present in that box. In all cases a 24 -h period was simulated with a $0.5-$ $1 \mathrm{~h}$ time step. Initial lognormal distributions are indicated as $\left[N\left(\mathrm{~cm}^{-3}\right), D_{g}(\mu \mathrm{m}), \sigma_{g}(1)\right]$.

Figure 1 shows results for number and mass concentrations $N(t)$ and $M(t)$ for the coagulation $\mathrm{OCC}+\mathrm{BC} 1 \rightarrow$ BOC. Initial distributions for the donor populations were $\left[10^{3}, 0.053,1.8\right]$. Both $N(t)$ and $M(t)$ were accurately predicted for all three populations. Figure 2 shows results for $\mathrm{AKK}+\mathrm{BC} 1 \rightarrow \mathrm{BCS}$ where the initial distributions were $\left[10^{4}\right.$, $0.026,1.6]$ for AKK and $\left[10^{3}, 0.053,1.8\right]$ for BC1. Even though both $N(t)$ and $M(t)$ changed considerably more than in Fig. 1, the results were again quite accurate; the number of sulfate-coated BC particles was very well predicted. Therefore we conclude that the coagulation scheme is suitable to be applied for long time steps of $0.5-1 \mathrm{~h}$ such as used in global climate models.

\subsection{Aerosol activation and configuration of aerosol popula- tions}

Aerosol activation is tested for each of the eight configurations described in Sect. 2. Initial number concentrations $\mathrm{N}\left(\mathrm{cm}^{-3}\right)$ were AKK (2000), ACC (200), DD1 (10), DD2 (1), SSA (20), SSC (0.08), BC1 (1000), OCC (1000), and initial mass concentrations $\mathrm{M}\left(\mu \mathrm{g} \mathrm{m}^{-3}\right)$ were sulfate $(0.913), \mathrm{BC}$ (0.627), OC( 0.369), dust (6.53), sea salt (7.16), ammonium (0.343). The production rates of gas-phase $\mathrm{H}_{2} \mathrm{SO}_{4}$ and aqueous sulfate were both set to $0.18 \mu \mathrm{g} \mathrm{m}^{-3} \mathrm{~h}^{-1}$, and the $\mathrm{NH}_{3}$ source rate was set to two moles ammonia per mole sulfate. 

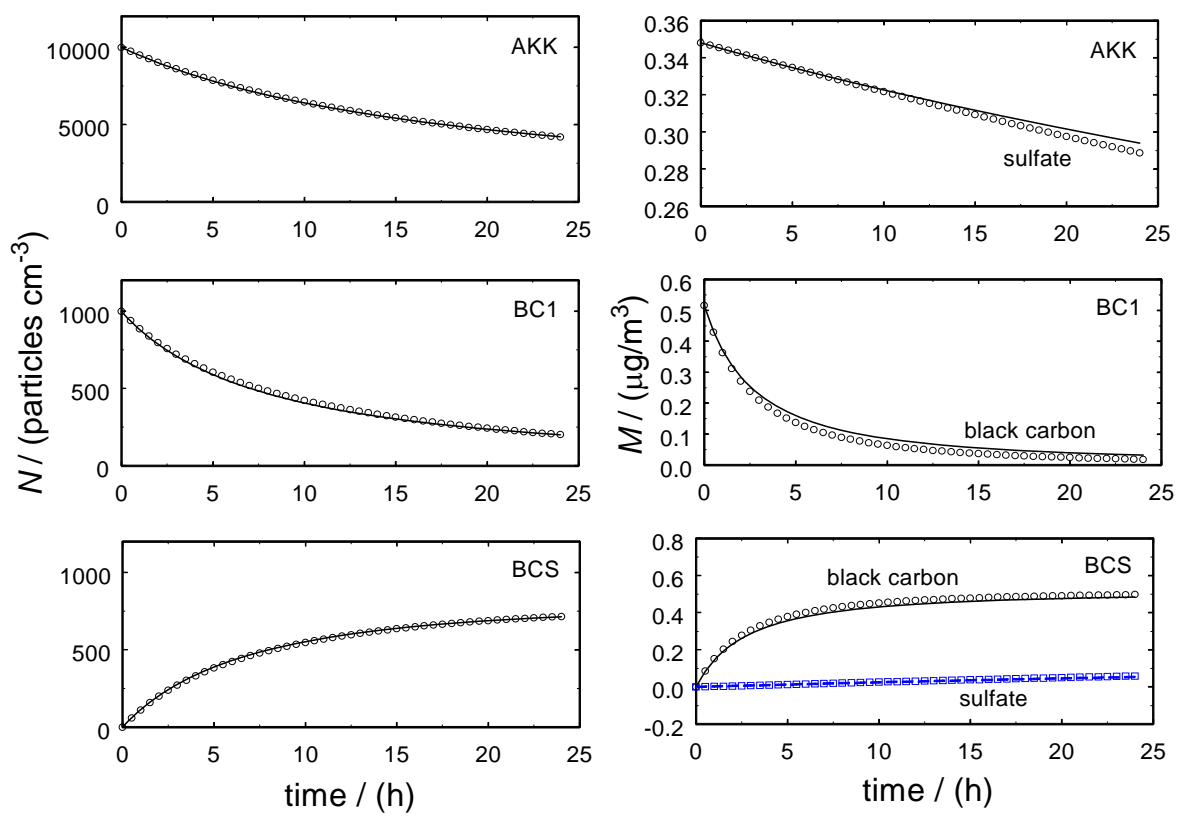

Fig. 2. Number and mass concentrations as a function of time for the coagulation of population AKK and BC1 to form BCS. Line styles the same as in Fig. 1.

A fixed updraft velocity was set to $0.5 \mathrm{~m} \mathrm{~s}^{-1}$. Figure 3 shows that both at the initial time and 6 hours later, all configurations except 4 and 8 give very similar numbers of activated particles though the number of aerosol species tracked varies from 35 to 51; configuration 4 and 8 do not represent the smaller sulfate particles with a distinct Aitken mode.

For all configurations except 4 and 8 , the activated aerosol was comprised of all of SCC and DD2 (DS2 acquired no particles), $\sim 95 \%$ of population SSA, two-thirds of population ACC, $\sim 0.6 \%$ of population AKK, and variable contributions from populations containing BC and OC. For configuration $1-3$, the activating fraction of accumulation mode dust was smaller than that of population ACC, but increased over the 6-h period as dust particles acquired sulfate. Particles remaining in population $\mathrm{BC} 1$ acquired enough sulfate to yield a small activating fraction (0.0006 with configuration 1) after $6 \mathrm{~h}$. When population BCS was present it showed an activated fraction of $\sim 30 \%$; when absent there were more particles present in population $\mathrm{BC} 2$. The total particle number increased slightly due to a small amount of new particle formation. Configurations 5-8 do not represent distinct populations for accumulation and coarse mode dust, yet the total numbers of activating particles for these configurations was very similar to those for configurations 1-4; however, combining population AKK and ACC to form a single sulfate population (configuration 4 and 8 ) led to a significantly higher number of activated particles. The box model results demonstrate the significant impact the choice of aerosol configuration has on the overall aerosol simulation. Considering that mode or population configurations are usually fixed in an aerosol model, it is important to point out the consequences of those basic model settings.

\section{The global climate model}

This section demonstrates the power of MATRIX for applications on a global model scale. We demonstrate that with reasonable model input, model output is suitable for comparison with observations. For this purpose, we introduce MATRIX into the Goddard Institute for Space Studies (GISS) General Circulation Model (GCM) climate modelE (Schmidt et al., 2006; Hansen et al., 2005), which was used as the host model for the microphysical MATRIX scheme. The model was employed on a horizontal resolution of $4^{\circ} \times 5^{\circ}$ latitude by longitude and 23 vertical layers. The model uses a 30 min time step for all physics calculations. A complete model description is given by Schmidt et al. (2006); features of the model relevant to the present calculations are briefly presented here.

\subsection{Sulfate chemistry}

The sulfate aerosol module is based on the earlier work of Koch et al. (1999) and Koch et al. (2006) and includes prognostic simulations of the mass distributions of DMS, MSA, $\mathrm{SO}_{2}$ and sulfate. It also includes a semi-prognostic simulation of $\mathrm{H}_{2} \mathrm{O}_{2}$, full details of which can be found in the work of Koch et al. (1999). Briefly, the $\mathrm{H}_{2} \mathrm{O}_{2}$ production rate is calculated using fields of hydroperoxy radical $\left(\mathrm{HO}_{2}\right)$ 


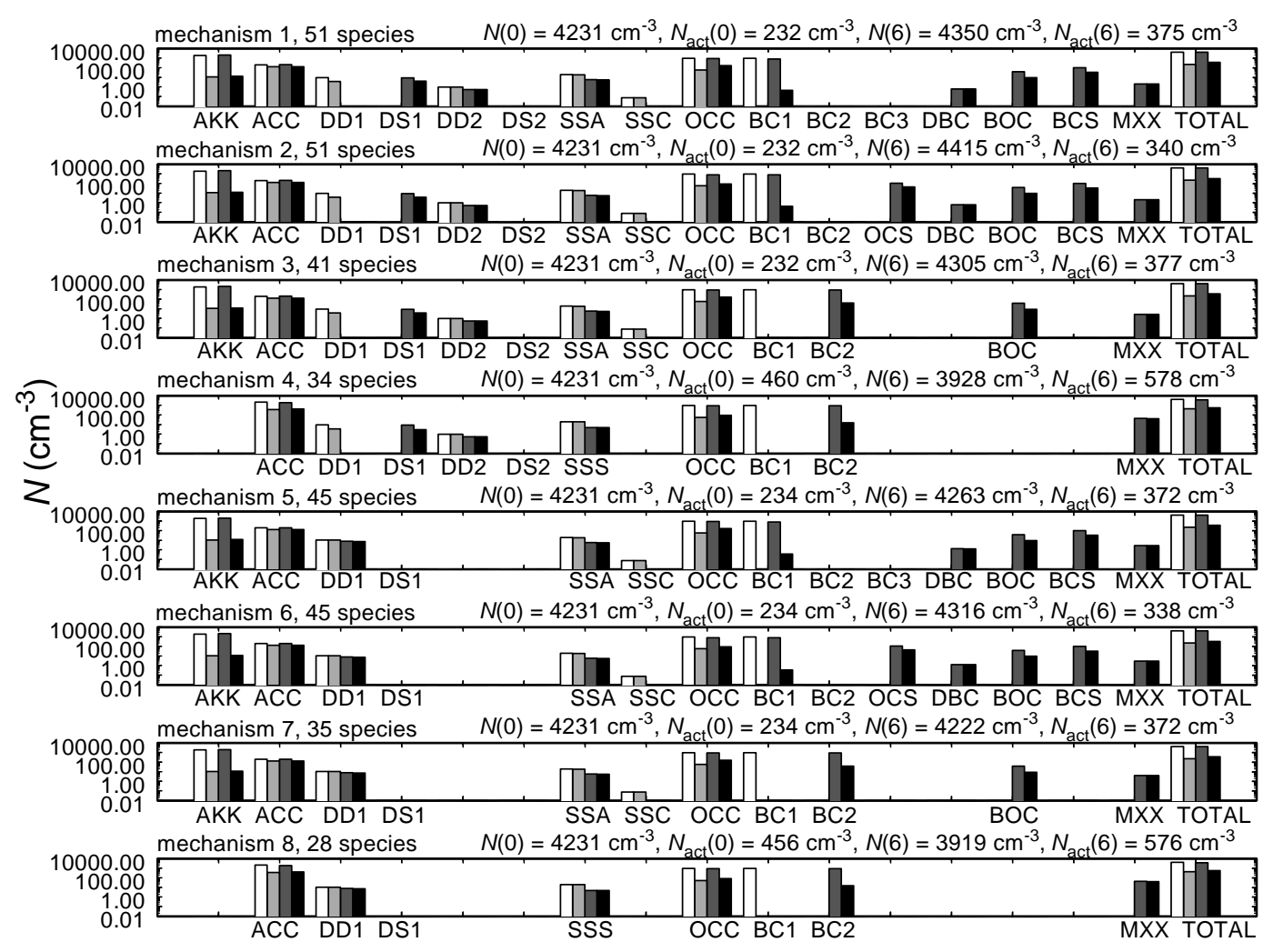

Fig. 3. Illustration of cloud activation for each of the eight aerosol configurations (mechanisms 1-8). White bars are initial total number concentrations, light-gray bars are initial activating number concentrations, dark gray bars are total number concentrations after $6 \mathrm{~h}$ evolution, black bars are activating number concentrations after $6 \mathrm{~h}$ evolution.

concentration and $\mathrm{H}_{2} \mathrm{O}_{2}$ is destroyed photochemically and by reaction with $\mathrm{OH}$ using fields of $\mathrm{H}_{2} \mathrm{O}_{2}$ photolysis rate and $\mathrm{OH}$ concentration. Optional, modelE can be run with sulfate and nitrate chemistry coupled (Bell et al., 2005; Bauer et al., 2007) to the tropospheric gas-phase chemistry scheme (Shindell et al., 2003). The sulfate chemistry scheme provides the aqueous sulfate production rate for liquid clouds and the $\mathrm{H}_{2} \mathrm{SO}_{4}$ concentration for the MATRIX scheme.

\subsection{Emissions}

The term $P_{i, q}^{\text {emis }}$ (see Sect. 2.2) is the mass concentration emission rate of species $q$ into population $i$. Number concentration emission rates $E_{i}^{\text {num }}$ are derived from mass concentration emission rates assuming lognormal size distributions and particle densities. Lognormal parameters $D_{g, E}$ and $\sigma_{g, E}$ (Table 1a) are derived from Table 2 of Easter et al. (2004), except for sea salt and dust particles, which use particle sizes appropriate for the GISS interactive emission models.

The emissions of the natural aerosols sea salt, dimethylsulfide (DMS) (Koch et al., 2006), and mineral dust (Miller et al., 2006) are calculated interactively in the model, depending on surface wind speed and other surface conditions.
Sea salt emissions are calculated for two size classes, appropriate for the SSC and SSA populations. Mineral dust emissions are calculated for 4 size bins, as described in (Miller et al., 2006), and are distributed into the DD1 and DD2 populations.

Most sulfur emissions are in form of gaseous phase sulfur dioxide $\left(\mathrm{SO}_{2}\right)$; we assume that $2.5 \%$ of the sulfur is emitted as sulfate particles. $99 \%$ of the mass of these direct sulfate emissions are assigned to the ACC population, and $1 \%$ of its mass into the $\mathrm{AKK}$ population. Industrial carbonaceous emissions are assigned to the $\mathrm{BC} 1$ and $\mathrm{OCC}$ population, but carbonaceous emissions from biomass burning sources are assigned to the BOC population.

Since here we wish to simulate present-day climate, the trace gas $\mathrm{SO}_{2}$ and ammonia $\left(\mathrm{NH}_{3}\right)$ (Bouwman et al., 1997) emissions are based on the anthropogenic emissions for 1995 from the Emissions Database for Global Atmospheric Research (EDGAR3.2) (Olivier and Berdowski, 2001). Black (BC) and organic carbon (OC) emissions are from Bond et al. (2004). Biomass burning emissions for $\mathrm{BC}$ and $\mathrm{OC}$ are from the Global Fire Emission Database (GFED) model by van der Werf et al. (2003). Natural OM emissions are derived from terpene emissions (Guenther et al., 1995), by assigning 10\% 

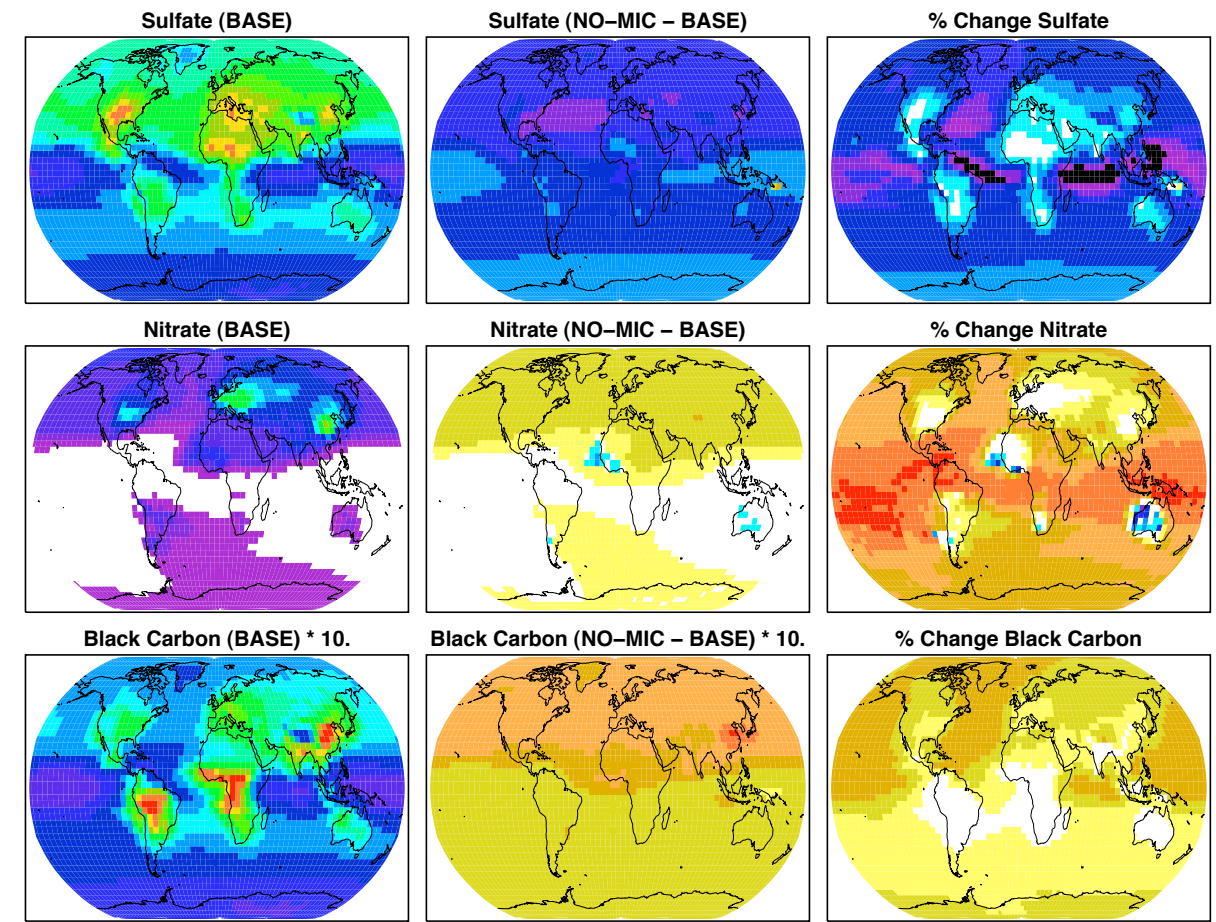

Black Carbon (NO-MIC - BASE) * 10.
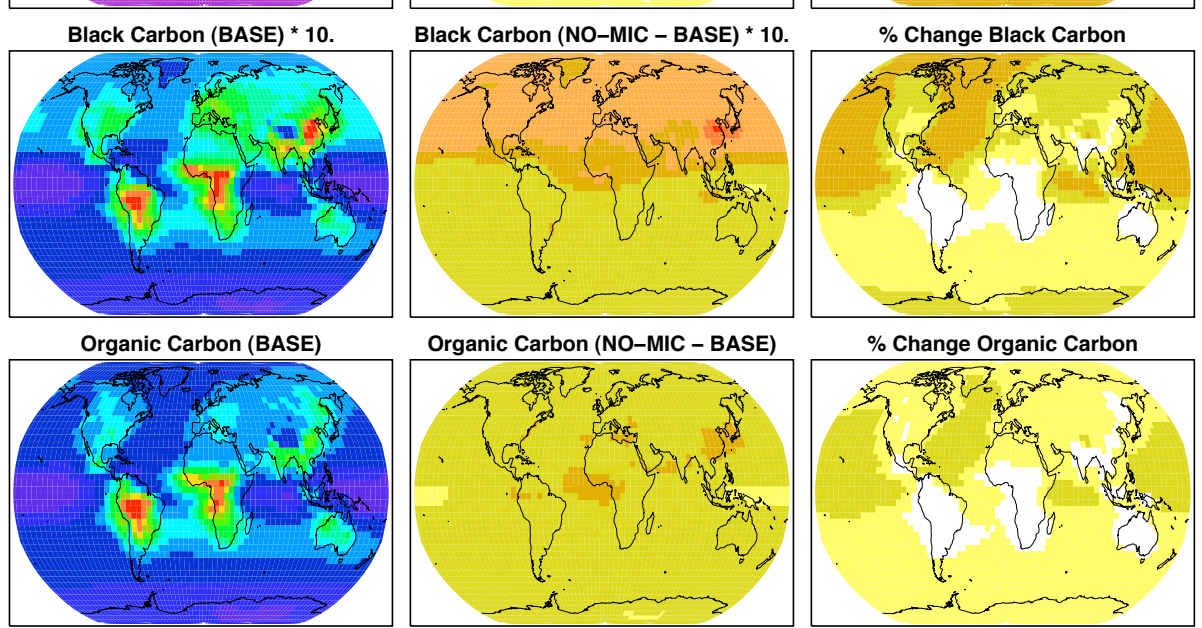

$\%$ Change Organic Carbon
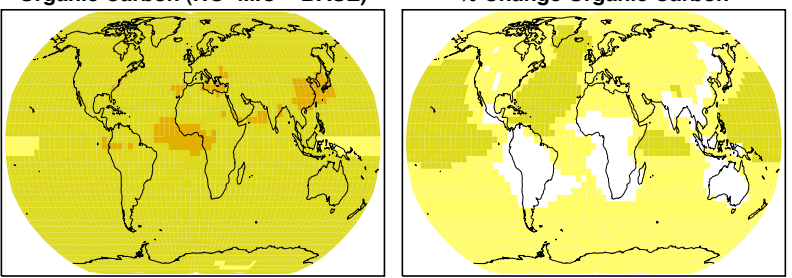

Dust (BASE) * 0.05
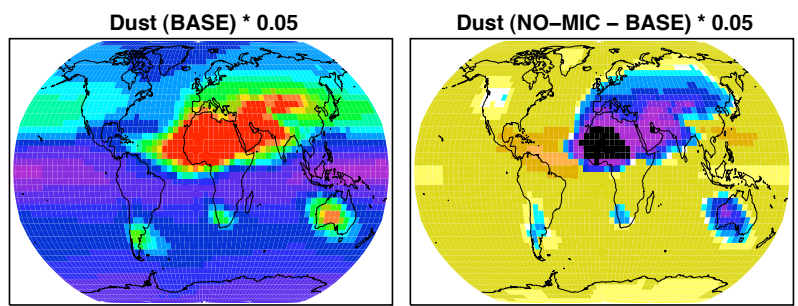

$\%$ Change Dust
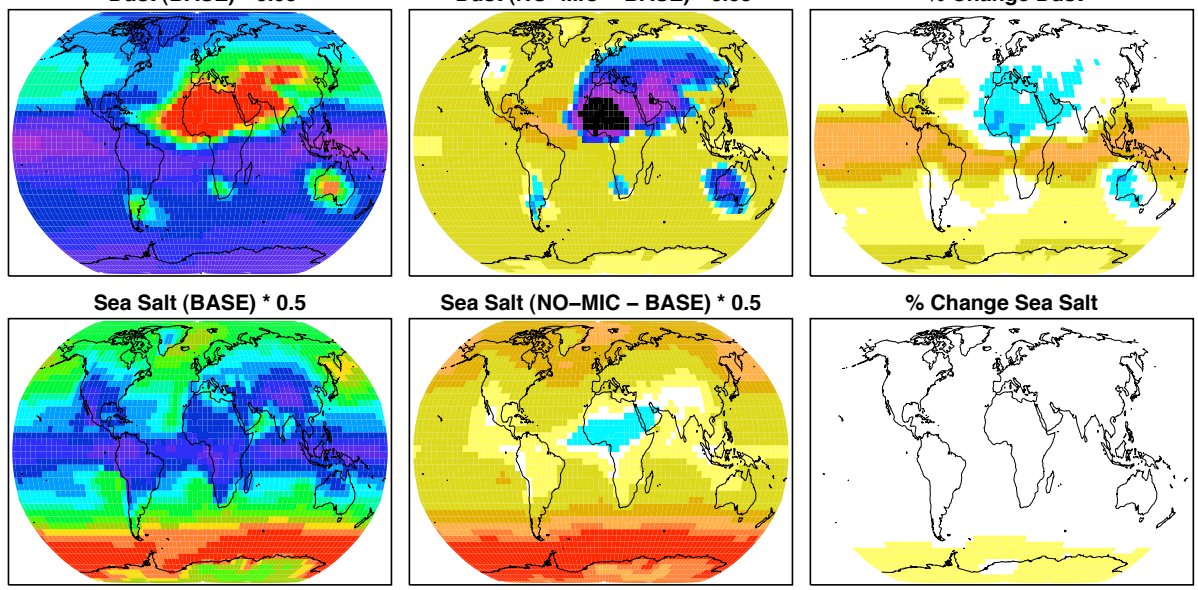

$\%$ Change Sea Salt
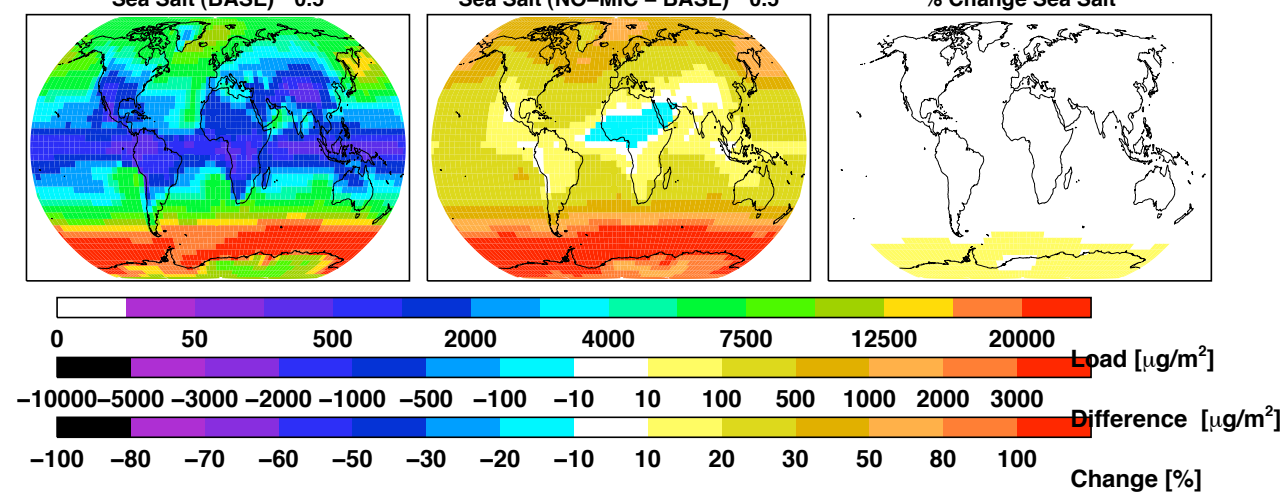

Fig. 4. Column mean load per species (left column) and difference between NO-MIC and BASE (middle column) in units of $\left[\mu \mathrm{g} / \mathrm{m}^{3}\right]$. The right column presents the percentage change of NO-MIC in respect to the BASE simulation [(NO-MIC-BASE)/NO-MIC] in [\%]. Note that the load and difference plots of black carbon, dust and sea salt are multiplied by a factor, given in the maps title, to match the color bar scheme. 
of the terpene emission mass to the organic carbon mass and number concentration emission. The $10 \%$ fraction of the terpene emissions is added to the mass of the OC emissions, before conversion to number concentrations as we assume that a certain amount of this material tributes to new particle formation as supposed to condense on preexisting particles.

\subsection{Transport and removal}

Tracers, heat, and water vapor are advected using the highly nondiffusive Quadratic Upstream Scheme (QUS) of Prather (1986), which uses nine subgrid-scale spatial moments as well as the mean within each grid box. This increases the effective resolution of the tracer field and allows the GISS model to produce reasonable climate fields with relatively coarse resolution.

Turbulent dry deposition is based on the resistence-inseries scheme described in Koch et al. (1999) and Chin et al. (1996). The scheme is coupled to the model boundary layer scheme of the GCM and depends on the mean diameter of the aerosol population. Gravitational settling depends on the aerosol population mean diameter and density and accounts for the effects of RH on density and size. The wet deposition schemes of the GISS modelE are described in Koch et al. $(1999,2006)$. The model treats two types of clouds, convective and stratiform clouds. Tracer treatment in clouds follows the cloud processes, so that tracers are transported, dissolved, evaporated, and scavenged (with cloud-water autoconversion and by raindrop impaction beneath clouds). This parameterization requires information about aerosol size and solubility, which are calculated for each aerosol population by MATRIX. The averaged solubility per aerosol population is calculated by using a volume weighted approach, depending on the chemical composition of the aerosol particles. Number and mass concentrations are both treated in the model's advection and deposition schemes.

\section{GCM simulations}

The performance of MATRIX on the global scale was examined by comparing a simulation of the full MATRIX scheme (configuration 1) with a simulation that excludes the microphysical processes of nucleation, coagulation and condensation. This leads basically to a simulation where all aerosols stay externally mixed as emitted, except particles that are emitted as internal mixtures (i.e. BC and OC from biomass burning). We compare these two extreme cases, detailed mixed populations and externally mixed populations, to observations, in order to examine the combined impact of microphysical processes such as nucleation, coagulation and condensation on the overall aerosol simulation.

As discussed in the previous sections, MATRIX provides a wide choice of configurations and parameterizations. In Sect. 3 all eight configurations for different definitions re- garding aerosol populations were tested with the box model. On the global scale now we examine configuration 1, the most complex setup, using the following parameterizations: (1) The thermodynamic equilibrium model EQSAM (see Sect. 2.4), (2) the nucleation mechanism by Napari et al. (2002), including ion to ion recombination by Turco et al. (1998) (see Sect. 2.3) and conversion into NPF by Kerminen and Kulmala (2002) (see Appendix A1) and (3) mode transfer by the fractional transfer method (Eq. 23) with $p=4$. The GCM is applied for a 6 year simulation under current climate conditions; the mean over the last 5 years of the simulations is analyzed in the following sections.

\subsection{Aerosol mass sensitivity and comparison to observa- tions}

Two experiments were carried out to examine the impact of microphysical processes on the overall aerosol simulation. The experiment that includes the most complex configuration 1 (BASE) is compared with an experiment using exactly the same model setup, but excluding the microphysical processes of nucleation, condensation and coagulation (NOMIC). The NO-MIC experiment basically represents an mass only scheme, representing only externally mixed aerosols, where only those aerosol populations are filled that experience chemical production or emission. For the current configuration following populations will be used: ACC (comprises entirely of sulfate), BC1, BOC, OCC, DD1, DD2, SSA and SSC. Fixed size and solubility is assumed for each population. Note that for NO-MIC there is no means to render the insoluble populations (BC1, DD1, DD2) soluble.

Table 3 presents the budget for each mass tracer, and the summation over each species, for the BASE simulation including atmospheric burden, emission- and removal rates, and production and loss terms for individual microphysical processes. The summation over all species in one population, e.g. BOC, including the contributions from nitrate, ammonium, ammonia, and aerosol water, determines the overall chemical composition in each population. Since nitrate, ammonium, ammonia, and aerosol water are treated as bulk species and are distributed over the populations like sulfate we give here only their annual mean burdens; $\mathrm{NH}_{3}(0.15 \mathrm{Tg})$, $\mathrm{NH}_{4}^{-}(0.37 \mathrm{Tg}), \mathrm{NO}_{3}(0.13 \mathrm{Tg})$, and aerosol water $(27.8 \mathrm{Tg})$.

For each mass tracer, e.g., accumulation mode sulfate ACC SU, the total production rate (e.g. emission, nucleation, coagulation, in-cloud condensation, outside-cloud condensation, plus mode transfer) is balanced by the total loss rate (here coagulation, wet and dry removal). The mean atmospheric lifetime (turnover time) is calculated as the atmospheric load divided by the total loss rate. The total loss rate is balanced by the total production rate. Because of conservation of matter for all species, except sulfate which as well experiences condensation, the total production by coagulation, summed over the populations, is equal to the total loss by coagulation, the only loss of the species being wet or dry 
Table 3. Annual mean budget per microphysical process. Budget information are presented for the microphysical procesees of coagulation (production and loss term are given separately), condensation (dry (outside cloud) and aqueous (in cloud)), and mode transfer (overall loss or production rate due to mass transfer into a different population). The minus signs mark loss processes. For rates no entry means $\mid$ rate $\mid<1 \mathrm{Gg} \mathrm{yr}^{-1}$.

\begin{tabular}{|c|c|c|c|c|c|c|c|c|c|c|c|}
\hline species & emission & nucleation & $\begin{array}{l}\text { coag. } \\
\text { prod. } \\
\text { [Gg/a] }\end{array}$ & $\begin{array}{r}\text { coag. } \\
\text { loss } \\
\text { cloud } \\
{[\mathrm{Gg} / \mathrm{a}]}\end{array}$ & $\begin{array}{l}\text { conden. } \\
\text { outside }\end{array}$ & $\begin{array}{l}\text { conden. } \\
\text { in cloud }\end{array}$ & $\begin{array}{l}\text { mode - } \\
\text { transfer }\end{array}$ & $\begin{array}{r}\text { wet - } \\
\text { removal } \\
{[\mathrm{Gg} / \mathrm{a}]}\end{array}$ & $\begin{array}{r}\text { dry - } \\
\text { removal } \\
{[\mathrm{Gg} / \mathrm{a}]}\end{array}$ & {$[\mathrm{Gg}]$} & lifetime \\
\hline AKK SU & 50 & 2288 & - & -7050 & 6350 & 393 & -1254 & -666 & -109 & 11.7 & 0.5 \\
\hline ACC SU & 4921 & - & 1928 & -1732 & 9643 & 25415 & 1025 & -35663 & -5466 & 478.0 & 4.0 \\
\hline DD1 SU & - & - & 1096 & -721 & 1193 & 361 & -1554 & -179 & -192 & 31.4 & 4.3 \\
\hline DS1 SU & - & - & 314 & -613 & 639 & 737 & 1733 & -2410 & -392 & 55.4 & 5.8 \\
\hline DD2 SU & - & - & 7 & -12 & 7 & 1 & -1 & -1 & -1 & 0.1 & 1.3 \\
\hline SSA SU & - & - & 297 & -48 & 126 & 1153 & - & -881 & -146 & 9.3 & 2.5 \\
\hline OCC SU & - & - & 17002 & -12013 & 6110 & 14761 & - & -21164 & -4577 & 552.1 & 5.3 \\
\hline BC1 SU & - & - & - & - & 1 & - & - & - & - & - & 0.4 \\
\hline BC2 SU & - & - & - & - & - & - & - & - & - & - & 0.5 \\
\hline BC3 SU & - & - & - & - & - & 1 & - & -1 & - & - & 0.5 \\
\hline DBC SU & - & - & 469 & -344 & 56 & 27 & - & -132 & -75 & 10.9 & 7.1 \\
\hline BOC SU & - & - & 5483 & -235 & 2038 & 5188 & - & -10405 & -1999 & 244.9 & 7.0 \\
\hline BCS SU & - & - & 1679 & -1724 & 737 & 984 & - & -1414 & -259 & 17.4 & 1.8 \\
\hline MXX SU & - & - & 5846 & - & 893 & 230 & - & -4786 & -2148 & 131.3 & 6.8 \\
\hline BC1 BC & 4615 & - & - & -3593 & - & - & -89 & -319 & -615 & 1.2 & 0.1 \\
\hline $\mathrm{BC} 2 \mathrm{BC}$ & - & - & - & -39 & - & - & 67 & -26 & -3 & 0.1 & 0.4 \\
\hline BC3 BC & - & - & - & -10 & - & - & 22 & -11 & -1 & - & 0.4 \\
\hline DBC BC & - & - & 11 & -6 & - & - & - & -3 & -1 & 0.3 & 8.6 \\
\hline $\mathrm{BOC} \mathrm{BC}$ & 3690 & - & 388 & -789 & - & - & - & -2509 & -765 & 50.5 & 5.5 \\
\hline BCS BC & - & - & 4533 & -522 & - & - & - & -3152 & -847 & 50.2 & 4.0 \\
\hline MXX BC & - & - & 27 & - & - & - & - & -20 & -6 & 0.6 & 8.2 \\
\hline OCC OC & 32102 & - & - & -2655 & - & - & - & -21159 & -8183 & 489.7 & 5.5 \\
\hline BOC OC & 30214 & - & 2391 & -241 & - & - & - & -24450 & -7747 & 575.7 & 6.4 \\
\hline MXX OC & - & - & 506 & - & - & - & - & -360 & -132 & 12.8 & 9.4 \\
\hline DD1 DU & 643451 & - & 3977 & -213010 & - & - & -279445 & -46381 & -107990 & 8429.8 & 4.7 \\
\hline DS1 DU & - & - & - & -61012 & - & - & 279425 & -189883 & -28085 & 3535.5 & 4.6 \\
\hline $\mathrm{DD} 2 \mathrm{DU}$ & 914699 & - & 223 & -721516 & - & - & -2511 & -11913 & -179165 & 1408.5 & 0.6 \\
\hline DS2 DU & - & - & - & -481 & - & - & 2512 & -1396 & -622 & 6.4 & 0.9 \\
\hline DBC DU & - & - & 90368 & -62134 & - & - & - & -12098 & -16220 & 1451.6 & 5.8 \\
\hline MXX DU & - & - & 963602 & - & - & - & - & -633254 & -321310 & 26739.1 & 10.1 \\
\hline SSA SS & 370628 & - & - & -73280 & - & - & - & -246915 & -49684 & 1564.3 & 1.5 \\
\hline SSC SS & 1366580 & - & 16 & -724004 & - & - & - & -73954 & -568438 & 236.4 & 0.1 \\
\hline MXX SS & - & - & 797268 & - & - & - & - & -354522 & -441422 & 1996.5 & 0.9 \\
\hline species & [Tg/a] & [Tg/a] & {$[\mathrm{Tg} / \mathrm{a}]$} & [Tg/a] & [Tg/a] & [Tg/a] & [Tg/a] & {$[\mathrm{Tg} / \mathrm{a}]$} & [Tg/a] & {$[\mathrm{Tg}]$} & [d] \\
\hline SU & 5.0 & 2.3 & 33.5 & -24.4 & 27.8 & 49.3 & - & -77.7 & -15.4 & 1.5 & 4.6 \\
\hline $\mathrm{BC}$ & 8.3 & - & 4.9 & -4.9 & - & - & - & -6.0 & -2.2 & 0.1 & 2.8 \\
\hline OC & 62.3 & - & 2.9 & -2.9 & - & - & - & -46.0 & -16.1 & 1.1 & 6.0 \\
\hline DU & 1558.1 & - & 1058.2 & -1058.2 & - & - & - & -895.9 & -653.4 & 41.6 & 5.2 \\
\hline SS & 1737.2 & - & 797.3 & -797.3 & - & - & - & -675.4 & -1059.5 & 3.8 & 0.5 \\
\hline
\end{tabular}

deposition. In the case of sulfate, the production and loss term of coagulation are not equal, as a sulfate particle can experience growth through condensation before coagulation with another particle. (Note, the formation and loss rates for the SSA SU tracer are not balanced in this table, as SSC SU is added to the SSA SU tracer when transported in the model.)

The breakdown of the single processes in Table 3 illustrates some important features of the BASE simulation. Condensation of $\mathrm{H}_{2} \mathrm{SO}_{4}$ in clouds is the largest source of sul- fate in the atmosphere, producing predominantly externally mixed ACC SU particles, followed by substantial sulfate condensation on preexisting aerosols, especially OCC and BOC particles. Coagulation is an equally important mixing process for sulfate-containing particles. This leads especially to the formation of OCC SU, BOC SU and MXX SU particles. The total atmospheric loads show that sulfate mass is present largely in internally mixed populations such as OCC, BOC and MXX, and only $32 \%$ of sulfate mass is present in 
externally mixed populations, such as ACC and AKK. As so far only the condensation of $\mathrm{H}_{2} \mathrm{SO}_{4}$ is considered in MATRIX, all non-sulfate species can only mix through coagulation. Industrial $\mathrm{BC}$ is emitted into the atmosphere as externally mixed particle, populating $\mathrm{BC} 1$. Those small-diameter particles coagulate quickly with larger preexisting particles and mainly move into the BCS population. Biomass burning $\mathrm{BC}$ is emitted directly into the BOC population. The total loads show that the BOC and BCS populations, contain almost all $\mathrm{BC}$ in the atmosphere, which basically only leaves $1 \%$ of $\mathrm{BC}$ in the atmosphere as external mixture. The coagulation rates for $\mathrm{OC}$ are a bit smaller than those of $\mathrm{BC}$, however, the much larger emission rates of OC leads to a much larger fraction, $45 \%$ of OC as external mixture. Coagulation among dust species puts most of the dust into the MXX population. The main constituents of the MXX population are sea salt and dust, mainly because no other population accommodates the combination of those species. Mode transfer, the transfer of a particle into a new population due to its chemical composition, is transferring large amounts of externally mixed dust DD1 or DD2 into the sulfate coated dust populations, DS1 and DS2.

Figure 4 shows the annual mean column load concentrations per species averaged over the last 5 years of the simulations. Including microphysical processes leads to a global increase of sulfate mass by $22 \%$ in the BASE simulation compared to the NO-MIC case. NO-MIC is lacking sulfate nucleation, condensation and coagulation processes. When those processes are neglected less sulfate mass is calculated, which would mainly come from nucleation and condensation (see Table 3). Nucleation adds small Aitken-mode particles into the atmosphere, leading to an overall longer lifetime of sulfate mass. This explains why the changes mainly occur in remote regions. Freshly nucleated particles tend to be engaged in the coagulation and condensation processes, which leads to a wide spread of sulfate material over aerosol populations and size ranges.

The changes seen in the nitrate concentrations simply complement the sulfate changes. More sulfate in the BASE case leads to less nitrate, as sulfate and nitrate compete for available ammonia in the system. Nitrate is reduced by $30 \%$ in the BASE simulation compared to the NO-MIC experiment.

Black carbon and organic carbon mass concentrations decrease globally by $20 \%$ and $10 \%$ in BASE, respectively, compared to NO-MIC. In BASE the coagulation and condensation processes lead to an increase in particles size and solubility and therefore shorten the lifetime of carbonaceous material in the atmosphere. These effects are especially important for reducing concentrations in remote regions.

The dust load is increased by $5 \%$ in the BASE simulation. Including microphysical processes, leads to decreasing dust loads in remote areas and increasing dust loads close to its sources. The removal in remote regions is explained by the fact that aged dust has a higher solubility, and therefore has higher wet removal rates which shortens lifetime and travel distance. The increase in the source region occurs because dust in the MXX population has a smaller mean particle size than the pure DD1 or DD2 populations, which leads to less dry removal, especially gravitational settling of the very large particles in the source regions.

The changes in sea salt mass concentrations are rather small. Sea salt mass increases by $6 \%$ without microphysics, again caused by the shift in size distribution. As number and mass are independent, the mean particle size is not constrained to appropriate or even physically reasonable values. Hence, these distributions of number mean diameter reveal model characteristics not to be taken for granted. For the coarse mode populations, MATRIX tends to transfer mass out of the DS2 and SSC populations too quickly, but not number, with a tendency to predict mean particle sizes that are too small. As the SSC (and SSA) mean particle dry masses are fixed (so that number can be prescribed for these populations), the mean diameter distributions are sharply peaked for these populations. However, for population DS2, there is a large spread in mean diameter per grid box extending to rather small sizes. This is not seen in population DD2 as the mean diameter of this population is strongly influenced by emissions at a fixed mean particle size.

The evaluation of the mass concentrations for the BASE simulation is presented in Fig. 5, where the surface mass concentrations of nitrate, sulfate, black and organic carbon are compared to observations from the North American IMPROVE and the European EMEP network. Nitrate aerosol mass concentrations in the scatter plot show a poor correlation (see Table 4 for statistical measures), which is partly caused by the high spatial fluctuation of nitrate mass concentrations within a grid box. The comparison plots on the regional maps, show that model nitrate tends to be too low in California, but reasonable elsewhere in the country. The simulated European nitrate concentrations show a good match to the observations. Sulfate mass shows an excellent comparison to observations on an annual mean basis in Europe and the United States. The scatter plot shows the slight tendency of the model to simulate too high sulfate mass concentrations in the United States and too low concentrations in Europe. Carbonaceous aerosols are generally underestimated in both regions by the model. However black and organic carbon show high correlation to observations of the IMPROVE data sets. Only few measurement stations in Europe report carbonaceous aerosol concentrations, but compared to those the model seems to underestimate European concentrations.

Comparing the NO-MIC simulation to the above discussed data sets in Europe and the United States (see Table 4), we find quite similar results as comparing the BASE simulation to observations, with a few exceptions; nitrate over $\mathrm{Eu}-$ rope and sulfate over the United States significantly better matches the observations in the model simulation including microphysical processes (BASE). However, microphysical mixing processes (as excluded in NO-MIC) have stronger 

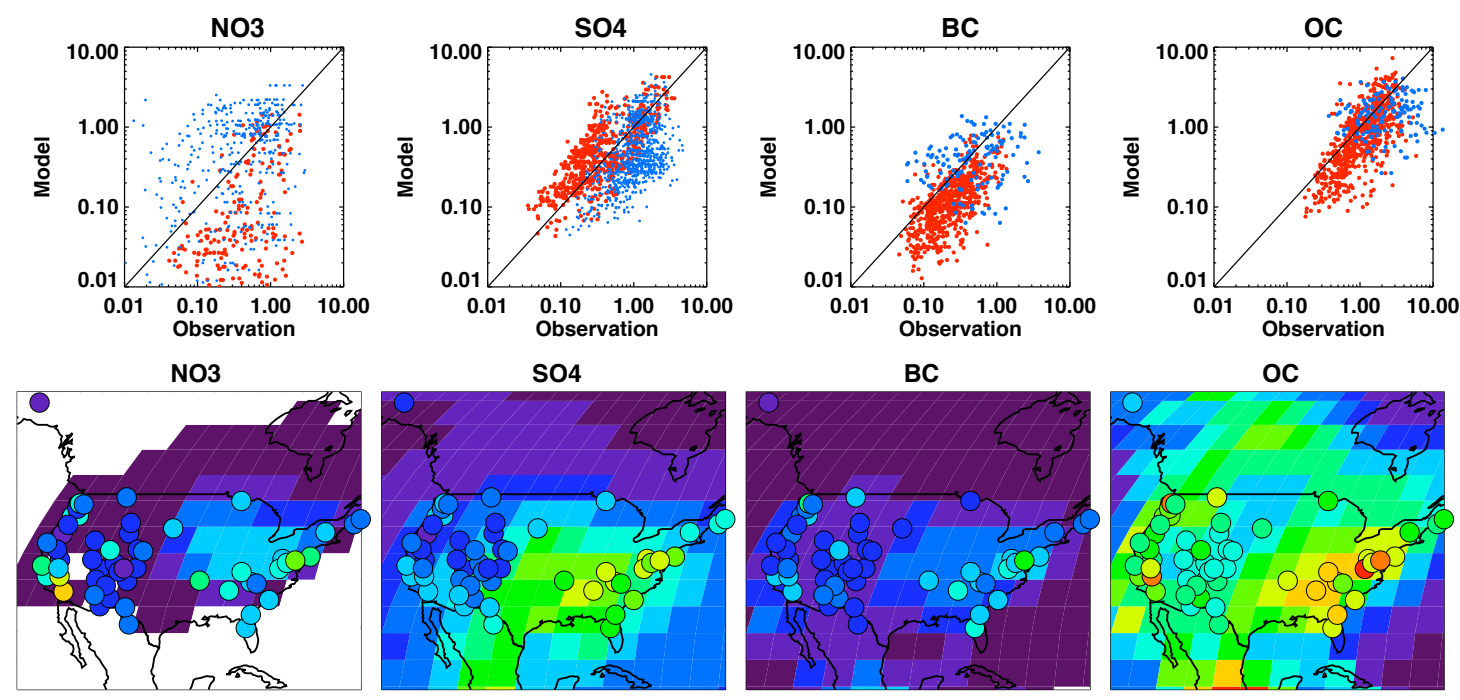

BC

OC
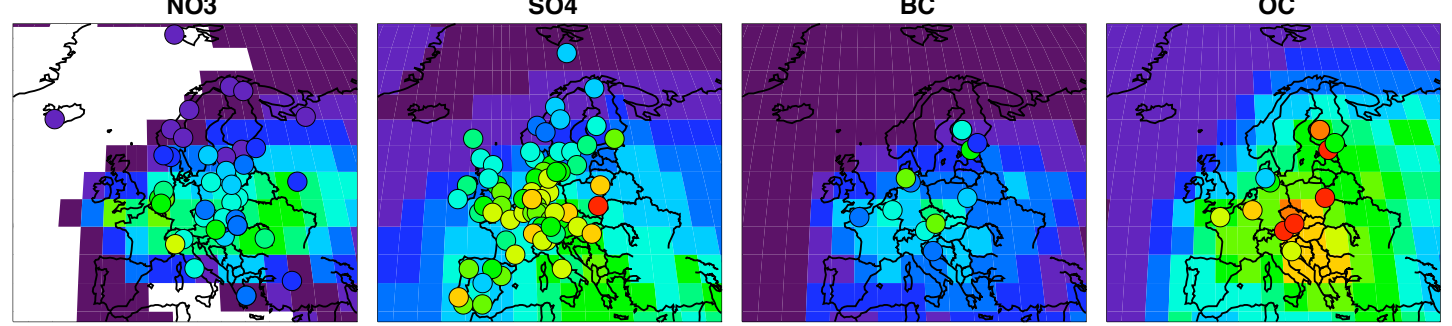

\section{$0.0 \quad 0.1$}

0.3

0.8

1.2

2.0

3.0

5.0

Fig. 5. Scatter plots and maps of surface mass concentrations of nitrate, sulfate, black carbon, and organic carbon as compared to the IMPROVE data set over North America and the EMEP observation data set over Europe. The blue points in the scatter plots (upper panel) show the model to observation comparisons at EMEP stations, and the red points at IMPROVE stations. The measured surface observations are presented as filled circles in the map projections. Units are $\left[\mu \mathrm{g} / \mathrm{m}^{3}\right]$.

Table 4. Statistical analysis of model concentrations and EMEP and IMPROVE observations

\begin{tabular}{lrrrrr}
\hline $\begin{array}{l}\text { data set } \\
\text { species }\end{array}$ & $\begin{array}{r}\text { mean value }\left[\mu \mathrm{g} / \mathrm{m}^{3}\right] \\
\text { observation }\end{array}$ & BASE & NO-MIC & $\begin{array}{r}\text { correlation } \\
\text { BASE }\end{array}$ & NO-MIC \\
\hline EMEP & 0.48 & 0.50 & 1.06 & 0.62 & 0.30 \\
$\mathrm{NO}_{3}$ & 1.22 & 1.21 & 1.21 & 0.41 & 0.41 \\
$\mathrm{SO}_{4}$ & 0.64 & 0.56 & 0.55 & 0.41 & 0.39 \\
$\mathrm{OC}$ & 2.83 & 1.73 & 1.83 & 0.21 & 0.23 \\
$\mathrm{BC}$ & & & & & \\
$\mathrm{IMPROVE}$ & 0.41 & 0.11 & 0.11 & 0.28 & 0.28 \\
$\mathrm{NO}_{3}$ & 0.55 & 0.64 & 0.99 & 0.83 & 0.62 \\
$\mathrm{SO}_{4}$ & 0.29 & 0.18 & 0.17 & 0.70 & 0.69 \\
$\mathrm{OC}^{\mathrm{BC}}$ & 1.28 & 1.17 & 1.21 & 0.70 & 0.70 \\
\hline
\end{tabular}

impacts on aerosol loads in the remote atmosphere (as discussed in Fig. 4).

Black carbon aircraft measurements using the SP2 instrument were performed during three campaigns: win- ter (February 2006) and summer (August 2007) campaigns in Costa Rica (Schwarz et al., 2008) and two flights over Houston Texas in November 2004 (Schwarz et al., 2006). The comparisons between model and observations of black 

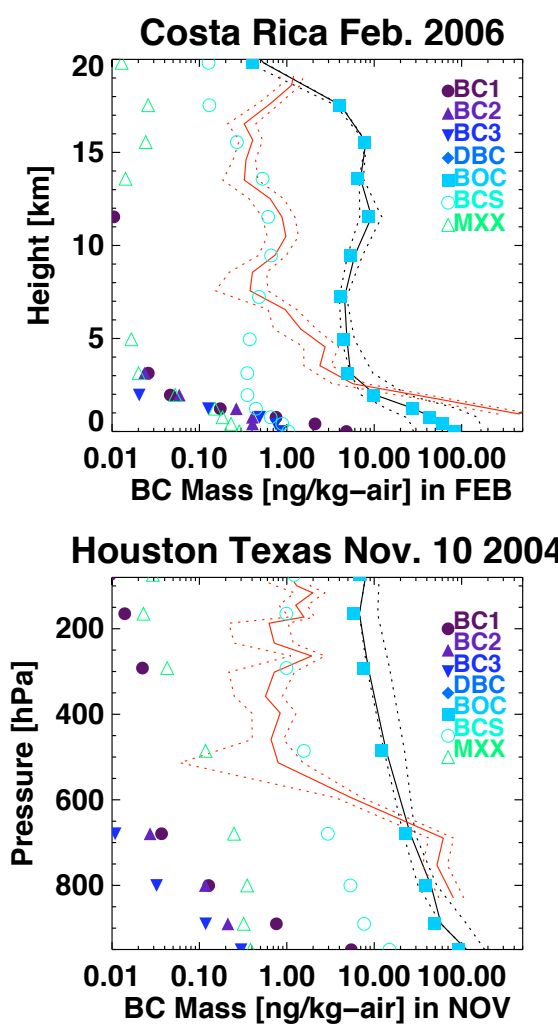
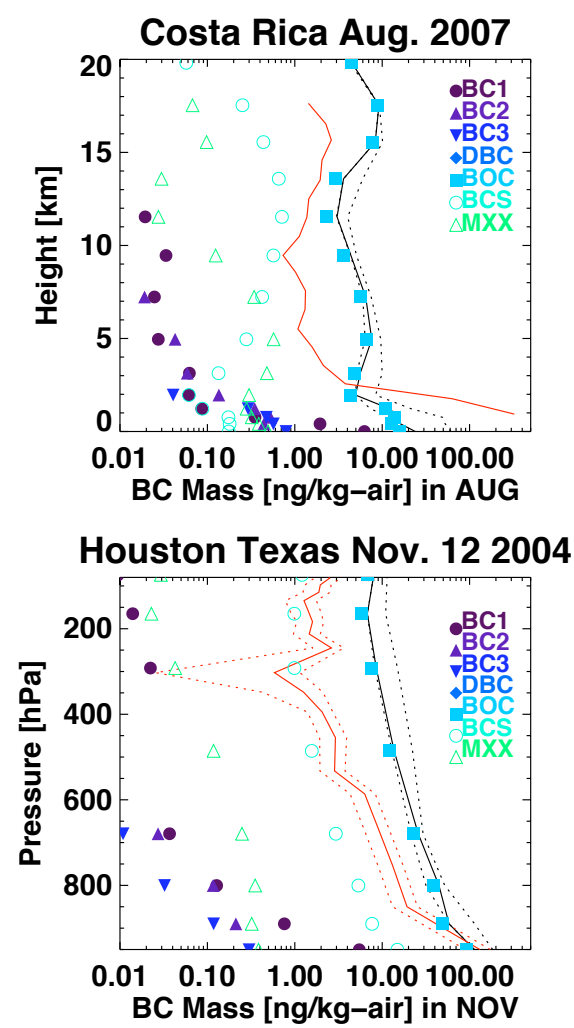

Fig. 6. Vertical profiles of black carbon mass concentrations as observed (red line) over Costa Rica (upper panel) in February 2006 and August 2007 (mean over three flights), and two single flights over Houston, Texas (lower panel) in November 2004 (Schwarz et al., 2008 , 2006). The total simulated BC mass (black line) and it's contribution from the individual populations are shown (colored symbols). Units are [ng/kg-air]. Height in [km] (upper panel) and on pressure levels [hPa] (lower panel).

carbon mass vertical profiles are presented in Fig. 6. The observed concentrations show a sharp gradient in concentrations between boundary layer (PBL) and free tropospheric air over Costa Rica. The model predicts good boundary layer heights, but underestimates BC in the PBL, especially in summer, and overpredicts BC in the free troposphere. Black carbon in Costa Rica mostly comes from biomass burning sources, which has large temporal variability. The model monthly average cannot capture the temporal variability as seen in the aircraft observations. The overestimated BC concentrations in the free troposphere over Costa Rica and Texas may be caused by inefficient cloud scavenging or possibly by underestimated cloudiness in modelE. The predominant aerosol population in both regions is BOC. In both cases OC dominates the population fraction, making those particles hydroscopic. However this still does not lead to sufficient wet removal.

An interesting aspect of the $\mathrm{BC}$ aircraft measurements is that black carbon coatings were also detected. Schwarz et al. (2006) present (see their Fig. 6) the number fractions of internally mixed $\mathrm{BC}$ particles, ranging form 0.2 to 0.8 . As shown in Fig. 6 our simulation predicts BOC as main aerosol pop- ulation class in both regions, Costa Rica and Texas. This would translate into an internally mixing fraction of 1 . In order to match the observed mixing fraction we would need much more pure $\mathrm{BC}$, i.e. $\mathrm{BC}$ in the $\mathrm{BC} 1$ mode. To investigate the simulated $\mathrm{BC}$ mixing states, we performed two sensitivity studies. (1) As discussed in the previous sections, BC and OC from biomass burning sources are directly assigned into the BOC population. A test run was performed where all $\mathrm{BC}$ and $\mathrm{OC}$ is emitted as external mixture to the $\mathrm{BC} 1$ and $\mathrm{OCC}$ populations. However the results of this experiment looked virtually identical to the original experiment as the particles mixed very rapidly and populate BOC. (2) Again BC and OC emissions are treated as an external mixture, but the sizes of the emitted $\mathrm{OC}$ and $\mathrm{BC}$ particles were doubled. The total mass of the emissions remained the same. The results of this test are presented in Fig. 7. Total BC mass concentrations remain very similar to the original experiment, but the predominant aerosol population is now BCS. This demonstrates the importance of the emitted aerosol size distribution. The main mixing process among aerosols is coagulation, which strongly depends on particle size. Shifting OC particles into a larger size class leads to less mixing of $\mathrm{BC}$ and $\mathrm{OC}$. 


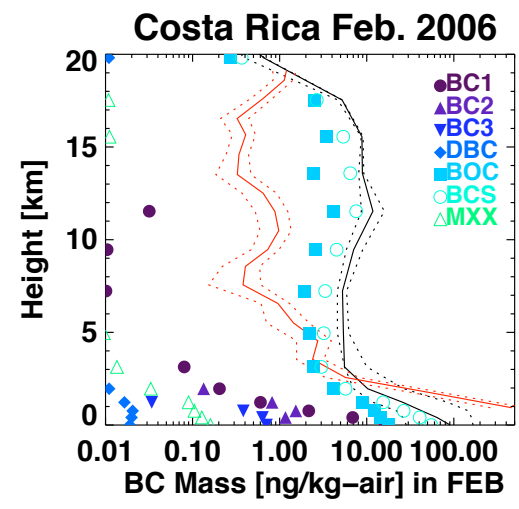

Houston Texas Nov. 102004

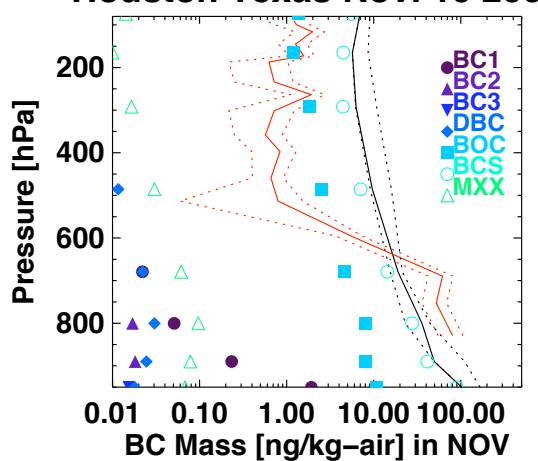

Fig. 7. Like Fig. 6, but presenting model results of Exp. 2.

Figure 8 shows the column load and zonal mean distribution of $\mathrm{BC}$, as sum over all $\mathrm{BC}$ containing populations, for the BASE experiment, and the differences between BASE and Exp. 2. On a global average, BC mass is decreased by $10 \%$ in Exp. 2. A decrease of BC mass is simulated all over the Northern Hemisphere and is most pronounced over Eastern Asia. In the BASE case, most BC is mixed with OC, whereas in Exp. 2 most BC is located in the BCS mode, therefore predominately mixed with sulfate. The shift of $\mathrm{BC}$ form the BOC into the BCS population, leads to a longer lifetime of particles in the BOC population (from 5.2 (BASE) to 6 (Exp. 2) days) and a shortened lifetime of the BCS population (from 5.4 (BASE) to 4.2 (Exp. 2) days), which consequently leads to lower $\mathrm{BC}$ concentrations in sulfate rich areas, like for example East Asia. However, the changes in total BC mass are very small in the regions where the BC aircraft measurements took place, Costa Rica and Houston Texas.

\subsection{Comparison of aerosol number and size to observations}

Aircraft observations from various campaigns (flight tracks are displayed in Fig. 9) and station data from aerosol supersites of the Global Atmosphere Watch program (http: //wdca.jrc.it), are used for the evaluation of modeled aerosol number and size distributions.
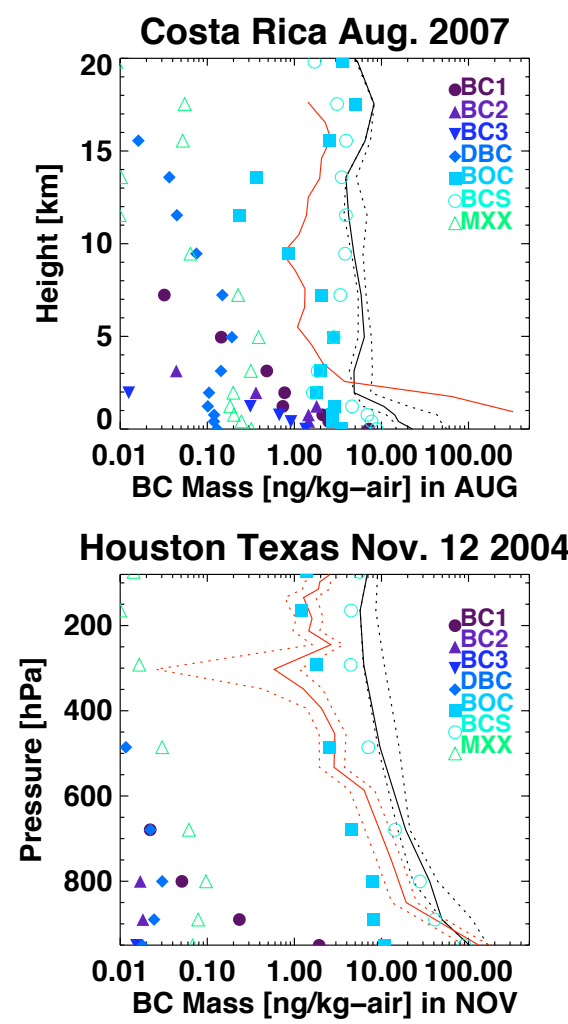

The PEM Tropics-B campaign Raper et al. (2001) took place over the South Pacific ocean in spring 1999. Aerosol size distributions were measured in 30 size bins by two aerosol probes on board the DC- 8 plane. Aerosol number concentrations spanning from 0.1 to $3 \mu \mathrm{m}$ particle diameters as measured by the PCASP, and for particles of diameters between 0.34 and $20 \mu \mathrm{m}$ by the FSSP aerosol probe. In order to compare those observations with the model, model data are interpolated to the flight tracks and monthly mean vertical profiles are calculated. Figure 10 shows the modeled and observed data for fine and coarse mode aerosols and indicates the simulated contributions from the individual populations to the total aerosol number concentration.

The differences between the two aerosol probes are quite large. The model simulation falls between the two measurements for particles sizes smaller than $1 \mu \mathrm{m}$. Here most particles come from the AKK, followed by the ACC, OCC, BOC and $\mathrm{BCS}$ populations. Close to the surface, the coated black carbon populations $\mathrm{BC} 1, \mathrm{BC} 2$ and $\mathrm{BC} 3$ show some small contribution to the total number concentration. Sulfate, nitrate and ammonium are the dominant species in this distribution, as they populate the AKK and ACC class. The two aerosol probes show very different number concentrations for particles larger than $1 \mu \mathrm{m}$. However the model underestimates the number concentrations of those larger particles, 


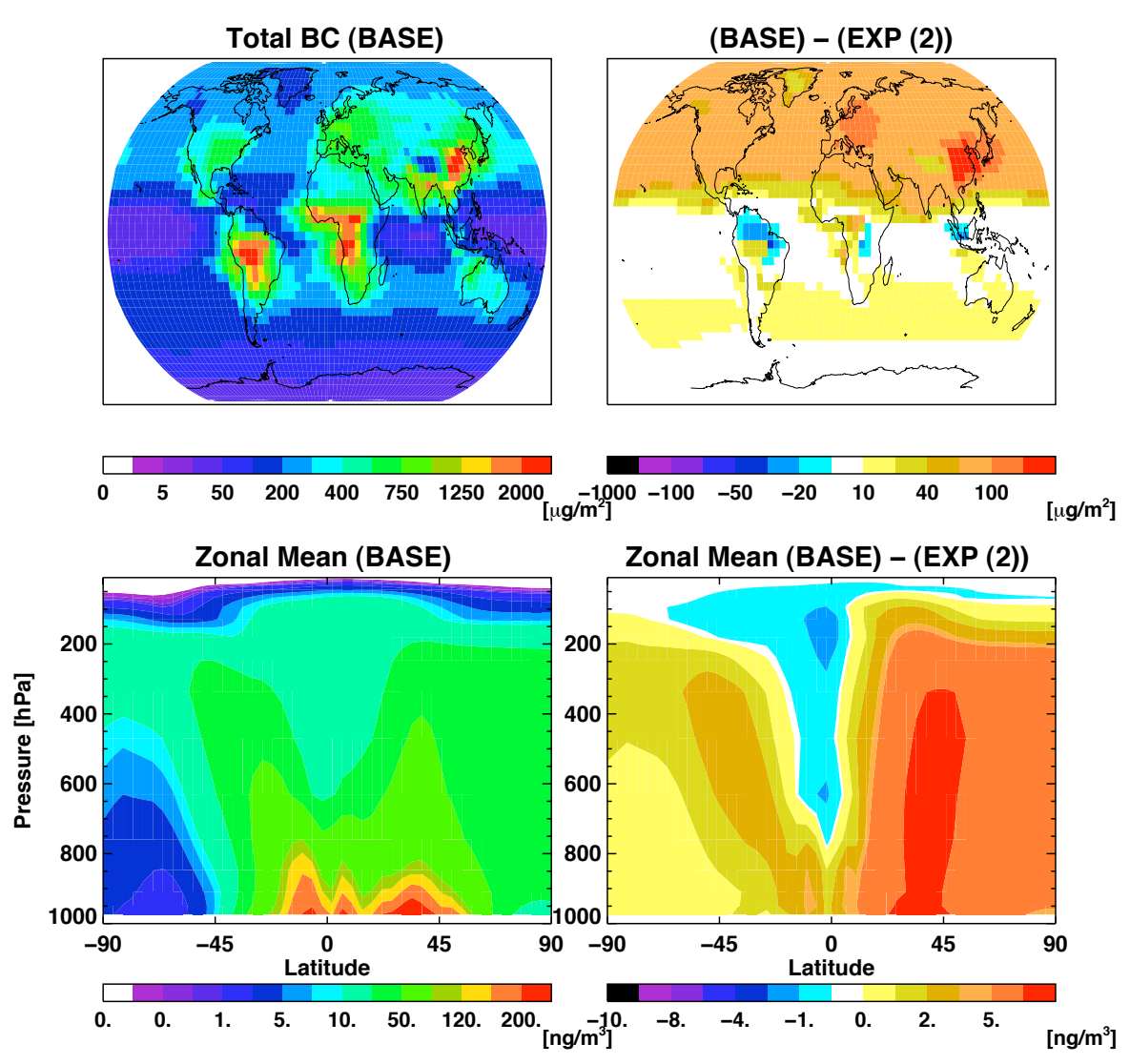

Fig. 8. Total column and zonal mean concentrations of BC mass concentrations for the BASE experiment and differences between BASE and Exp. 2.

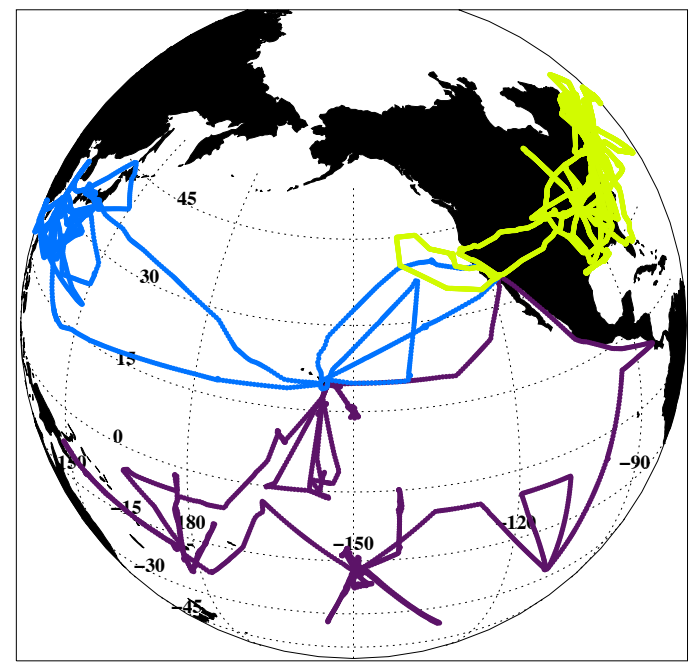

Fig. 9. Flight tracks of the INTEX (green), Trace P (blue) and PEM Tropics (purple) campaign. which mainly come from the MXX and SSA population. The main aerosol components in the MXX population are dust, followed by sea salt and sulfate.

The TRACE-P Jacob et al. (2003) campaign took place from February to April in 2001 over the North Pacific ocean. Vertical profiles of mass and number concentrations are shown in Figs. 11 and 12 as measured on the DC-8. In February the aircraft flew between $150 \mathrm{E}$ and the US West coast sampling much cleaner air than during March and April, when Asian pollution dominated the shown profiles. Figure 11 shows an excellent comparison between modelled and observed $\mathrm{SO}_{2}$ and a good comparison to sulfate mass concentrations. Nitrate and ammonia tend to be underestimated by the model. The measurement data show the same order of magnitude of sulfate and nitrate concentrations in the polluted profiles during March. Number size distributions during TRACE-P were measured in six size bins, spanning from 0.1 to $1550 \mu \mathrm{m}$. Number concentration of particles lower than $1 \mu \mathrm{m}$ are simulated reasonably well by the model (see Fig. 12) and the aerosol number concentrations in the coarse mode are underestimated. The precedence of populations is the same as over the South Pacific as seen from the comparisons to the PEM-Tropics-B campaign. 

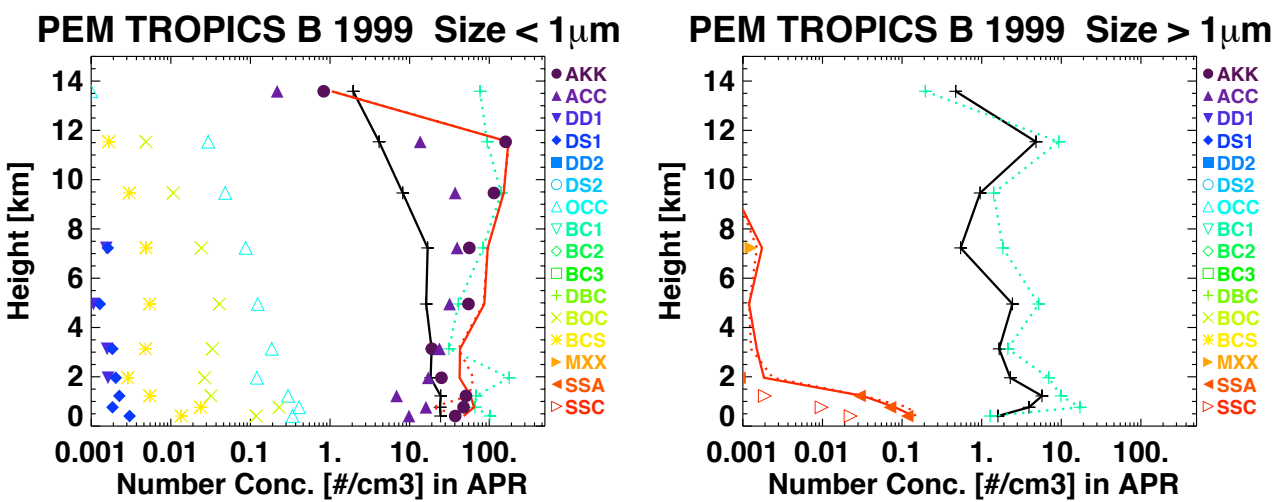

Fig. 10. Vertical profiles of number concentrations as measured by the FSSP (green dotted line) and PCASP (black solid line) aerosol probe on board of the DC-8 air plane are compared to model results (red line). Number concentrations for particles smaller (left) and larger (right graph) than $1 \mu \mathrm{m}$ diameter are shown. The symbols indicate the contribution to the total number concentrations from the individual populations as marked in the graph. Units are [particles $/ \mathrm{cm}^{3}$ ].
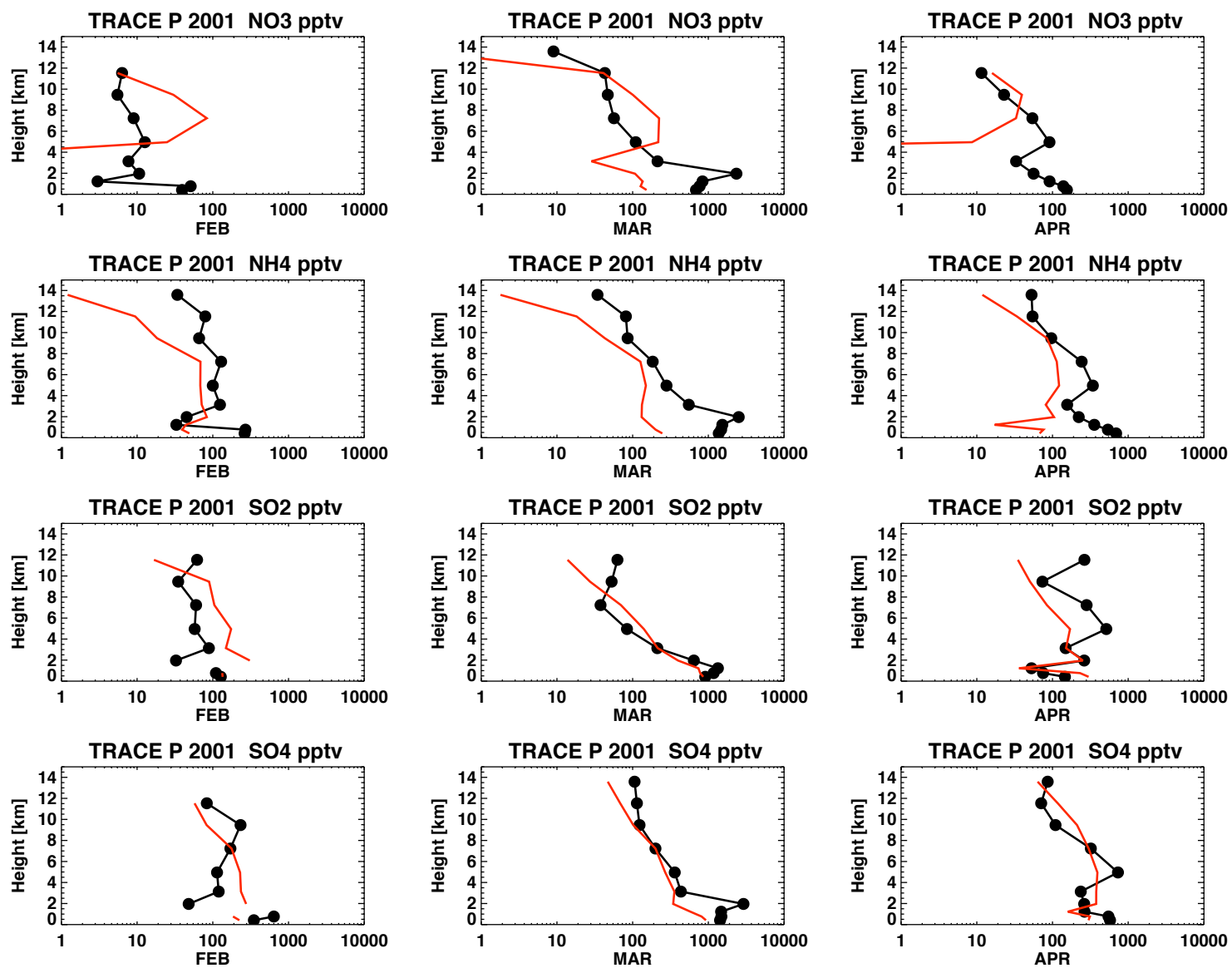

Fig. 11. Vertical profiles of mass concentrations for February (left column), March (middle column) and April (right column) during the TRACE-P campaign in 2001. Measurements by the DC-8 air craft are printed in black, and model results are shown in red. The black dots indicate the model layers onto which the measured data points are interpolated. Following species are presented per panel: nitrate, ammonia, sulfur dioxide and sulfate. Units are $\left[\mathrm{ppt}_{v}\right]$ and height in $[\mathrm{km}]$. 

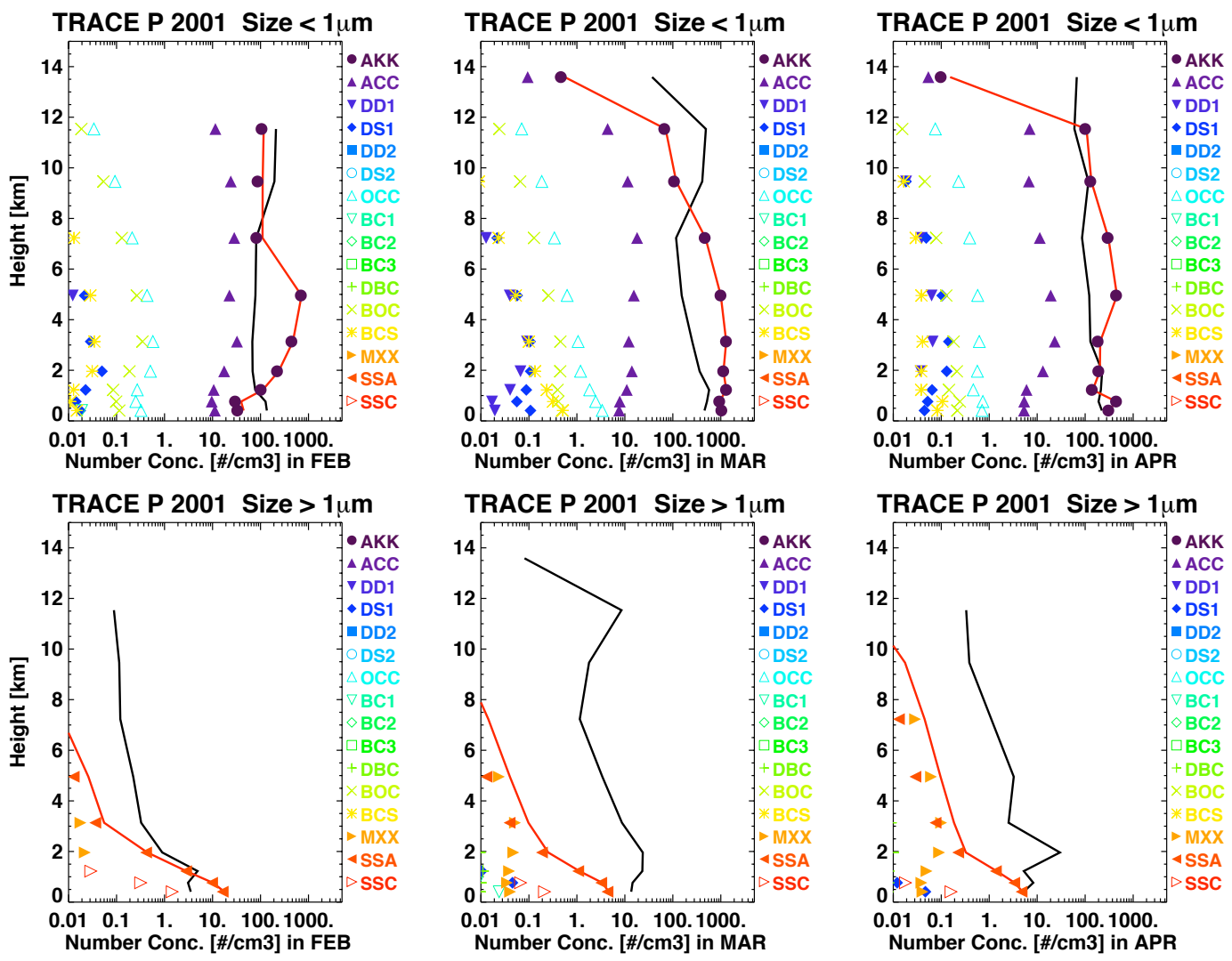

Fig. 12. Vertical profiles of number concentrations for February (left column), March (middle column) and April (right column) during the TRACE-P campaign in 2001. Observations are shown in black, model data are presented as described in Fig. 10. Units are [particles/ $\mathrm{cm}^{3}$ ] and height in $[\mathrm{km}]$.

The campaigns discussed so far mainly sampled marine air masses. In contrast, the INTEX-A (Singh et al., 2006) (Figs. 13 and 14) campaign took place over the North American continent and to a smaller extent over the North Atlantic and Pacific Oceans. The mass observations show a good simulation of nitrate close to the surface, but lack of modelled nitrate at higher altitudes. Model sulfate aerosol mass seems reasonable in the lower atmosphere, but overestimated in higher levels. The comparison to number concentrations shows good agreement for particles lower than $2 \mu \mathrm{m}$ and a lack of particles in the coarse mode, especially in the free troposphere. Observations are given in six size bins spanning from 0.3 to $2 \mu \mathrm{m}$. For these conditions, different populations are important. The BOC population clearly dominates, followed by OCC and ACC in the boundary layer and the MXX population in the free troposphere. The coarse mode shows again mostly contributions from SSC and MXX. Again the MXX population mostly contains dust and sea salt, with minor contributions of sulfate and nitrate.

Station measurements provide the unique possibility to compare model data to long-term observations. Unfortunately only few data sets providing detailed particle size reso- lution information are available. Here we show comparisons to three European stations, provided by the Global Atmosphere Watch program (http://wdca.jrc.it/).

Hohenpeißenberg is a mountain station at $988 \mathrm{~m}$ altitude located in southern Germany. Aerosol size distributions were measured from 0.1 to $6 \mu \mathrm{m}$. The year to year variability is very low, therefore we only compare data to the year 2002, as this was the most complete data set available. Figure 15 shows the annual mean size distribution as observed at Hohenpeißenberg. The model data are interpolated into the observed size bins. The smallest size bin starts at $0.1 \mu \mathrm{m}$. That is the bin in which the highest number concentrations are observed, however even higher concentration might occur at smaller particle sizes. The model captures the size distribution fairly well, but overpredicts the number concentration of particles greater than $1 \mu \mathrm{m}$. The two graphs in the top panel of Fig. 15 show us the population and species contributions to this distribution. Particles smaller than $1 \mu \mathrm{m}$ come from the AKK, and the black carbon populations (BC1, $\mathrm{BC} 2, \mathrm{BC} 3)$. Dominating chemical species are sulfate and nitrate for the Aitken mode and black carbon for particles around $0.05 \mu \mathrm{m}$ size. The part of the size distribution that 

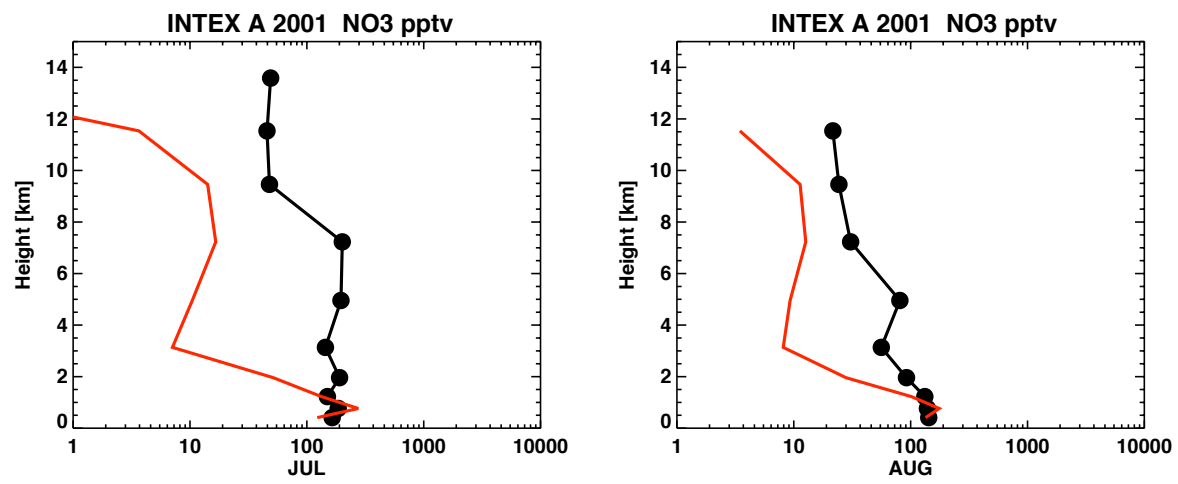

INTEX A 2001 NH4 pptv
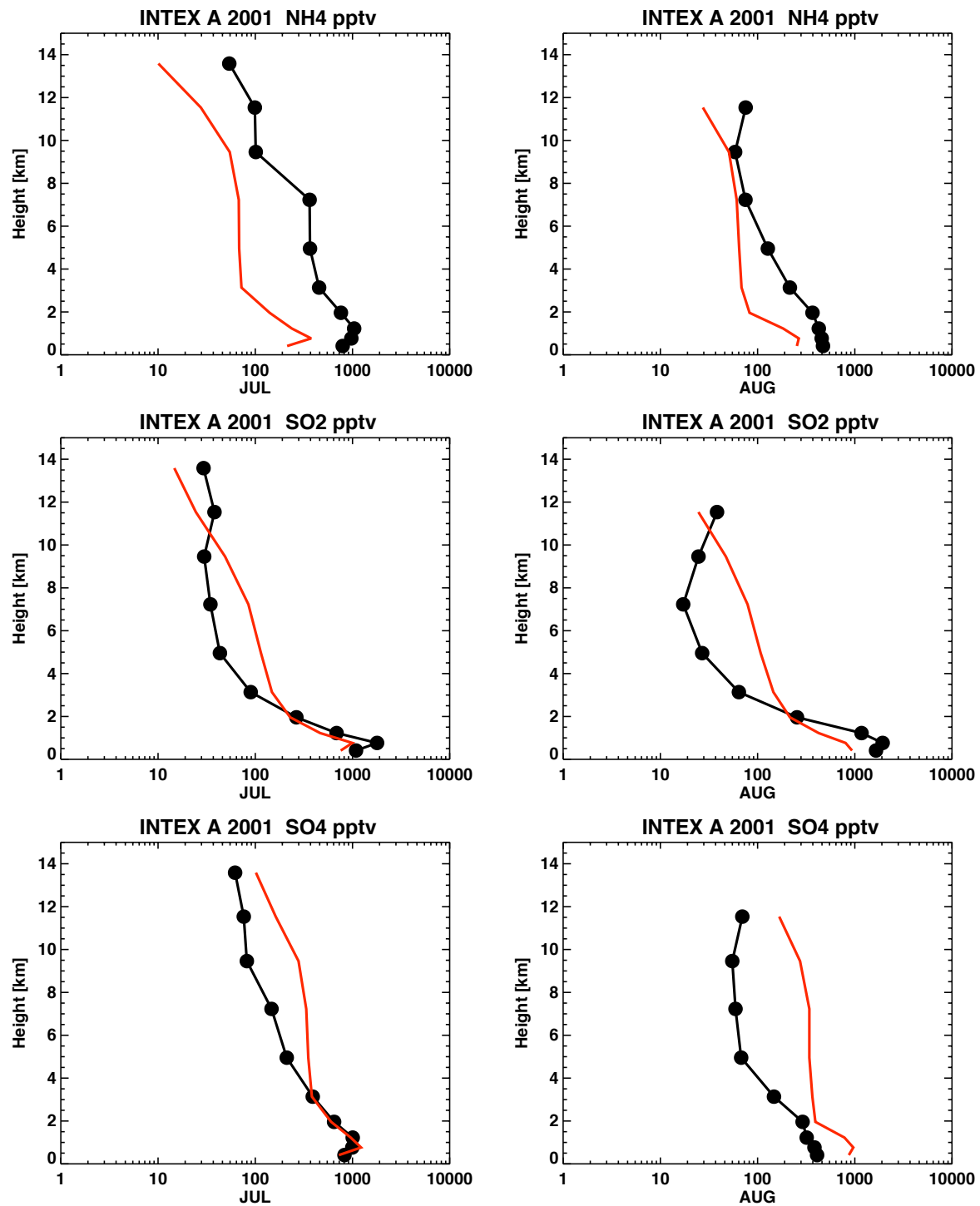

Fig. 13. Vertical profiles of mass concentrations for July (left column), and August (right column) during the INTEX-A campaign in 2001. Measurements by the DC- 8 air craft are printed in black, and model results are shown in red. The black dots indicate the model layers onto which the measured data points are interpolated. Following species are presented per panel: nitrate, ammonia, sulfur dioxide and sulfate. Units are $\left[\mathrm{ppt}_{v}\right]$ and height in $[\mathrm{km}]$. 

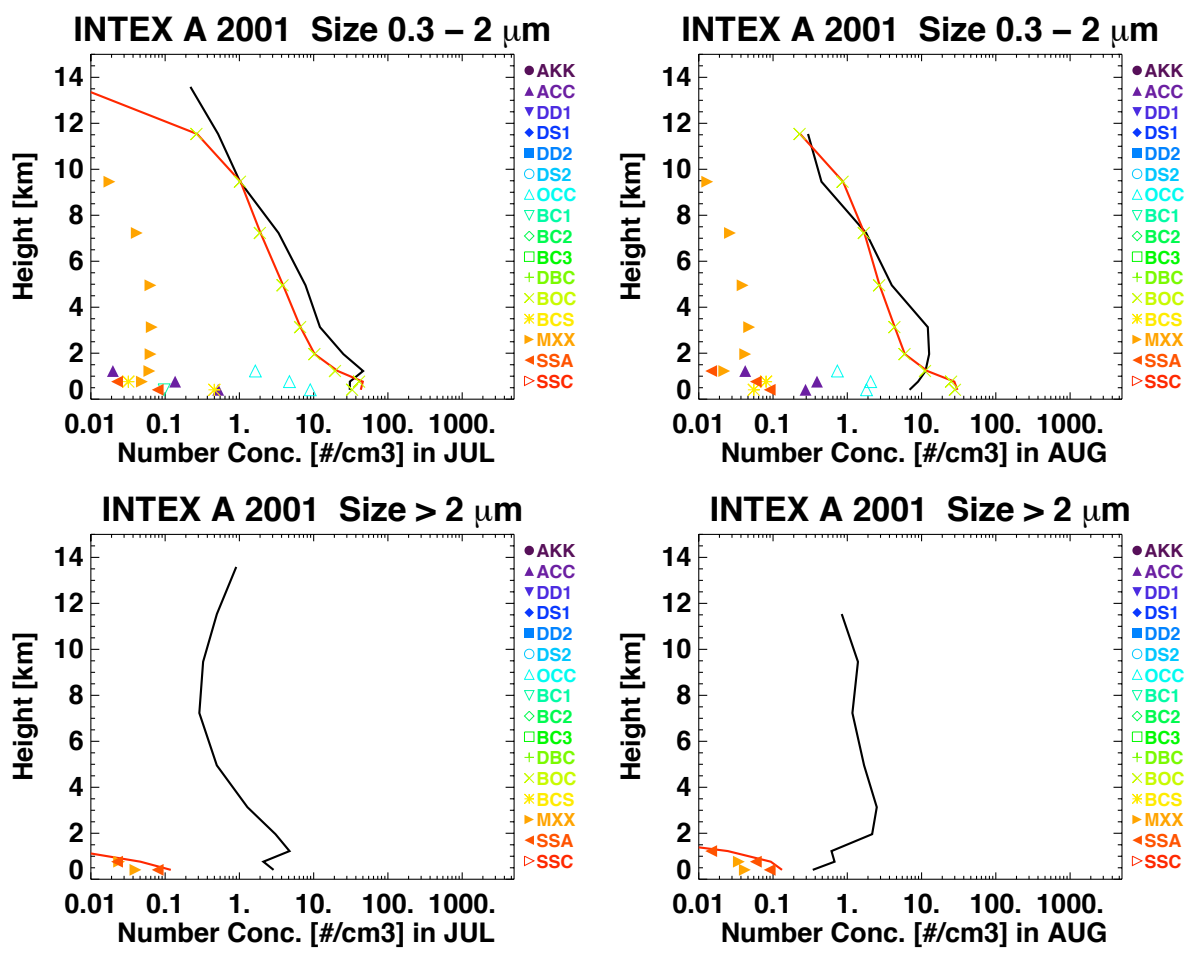

Fig. 14. Vertical profiles of number concentrations as observed during the INTEX-A campaign in 2001, for aerosol particles with diameters between 0.3 to $2 . \mu \mathrm{m}$ (upper panel) and larger than $2 \mu \mathrm{m}$ (lower panel). Color coding as in Fig. 10. Units are [particles $/ \mathrm{cm}^{3}$ ] and height in [km].

is observed and agrees well with the model, particle sizes 0.1 to $1 \mu \mathrm{m}$, have contributions from OCC, BOC, BCS and ACC, and to a limited extent contributions from the dust populations DS1 and DBC. The dominating chemical species in this part of the size distribution are sulfate, nitrate, organic carbon, and black carbon. Particles larger than $1 \mu \mathrm{m}$ belong to the mixed population MXX, and comprise dust, sea salt mixed with sulfate and nitrate.

Pallas is a station located in northern Finland, at $560 \mathrm{~m}$ altitude. Size distribution measurements are available from 0.007 to $0.4 \mu \mathrm{m}$ (see Fig. 15). The model captures the number concentrations at the lower end of the size spectrum. Those particles get formed through nucleation events, belong to the AKK mode and are comprised mostly of sulfate and nitrate. Particle number concentrations of around $0.05 \mu \mathrm{m}$ size are under-predicted by the model, which is primarily black carbon, and model and observations again agree pretty well for particles above $0.07 \mu \mathrm{m}$. Furthermore, the decreasing slope of the size distribution is captured by the model.

Ålesund is located in Spitzbergen, even further north of the Finish station Pallas. The observations show somewhat smaller number concentrations in the nucleation mode, but a maximum in the distribution around $0.2 \mu \mathrm{m}$. The model underestimates the number concentrations at this remote station, where black carbon, sulfate and nitrate dominate the size distribution below $0.1 \mu \mathrm{m}$. Above that size organic carbon is present, and the agreement to observations is much improved.

Figure 16 presents the comparison of the three stations with model results from Exp. 2, where OC and BC emission sizes were doubled. It is very interesting to see how the prior visible gap in Fig. 15 around $1 \mu \mathrm{m}$ particle sizes is now closed, at the expense of underestimating particles around $0.1 \mu \mathrm{m}$.

Overall each population covers a fairly limited size range, causing gaps in the size distribution. This problem is caused by choosing fixed sigma-values for the size distribution of each population in our here presented two-moment model. We expect to see smoother size distributions when resolving higher moments.

\subsection{Summary of GCM results}

MATRIX has been successfully implemented into the GISS climate model and all 8 MATRIX configurations (see Sect. 2.) are functional in the global model. Although not shown here, the performances of configuration 1-4 show comparable results as the box model study. Especially the lack of the Aitken mode AKK in configuration 4 leads to significant changes in the overall model performance. Compressing the dust modes as done in configuration 5-8 further 

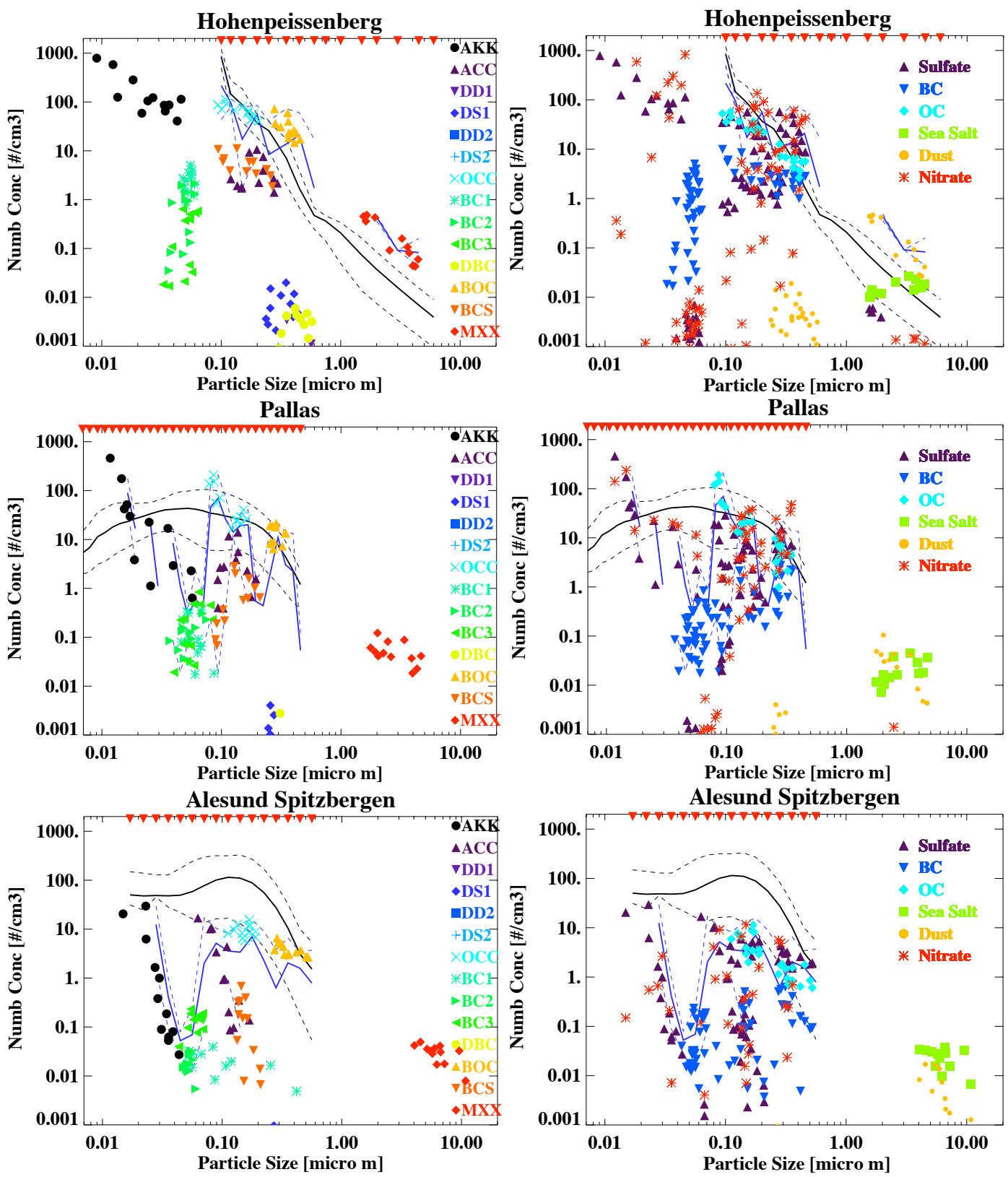

Fig. 15. Aerosol size distributions at three surface stations: Hohenpeißenberg (upper panels), Pallas (middel panels) and Ålesund (lower panels). The observed size distributions are shown in black, and simulated size distributions in blue. The solid lines show the annual mean values and the dotted lines the seasonal maxima and minima. The red triangles at the top of the graph indicated the size bins of the observational data, onto which the modelled data have been interpolated. The colored symbols in the graph indicate the contribution to particles number concentration by population (left column), and by species (right column). Units are $[\mu \mathrm{m}]$ and [particles $\left./ \mathrm{cm}^{3}\right]$.

leads to a decrease in accuracy in the coarse mode model performance. Therefore for global studies configuration 1-3 are the most useful options, although the model populations need further optimization.

The novelty of MATRIX is adding aerosol number, size and mixing to the mass concentrations in the GISS climate model. The strengths and weaknesses of the MATRIX application on the global scale can be summarized as follows:
- The evaluation of aerosol number and size distribution against surface and aircraft measurements demonstrate a good simulation of Aitken and accumulation mode particle sizes. In this study we compared ultra-fine particles, particles below $0.05 \mu \mathrm{m}$, only to two northern European stations, Ålesund and Pallas, and found that the simulated ultra-fine particle number concentrations are a bit too small at Ålesund, Spitzbergen, and too large 

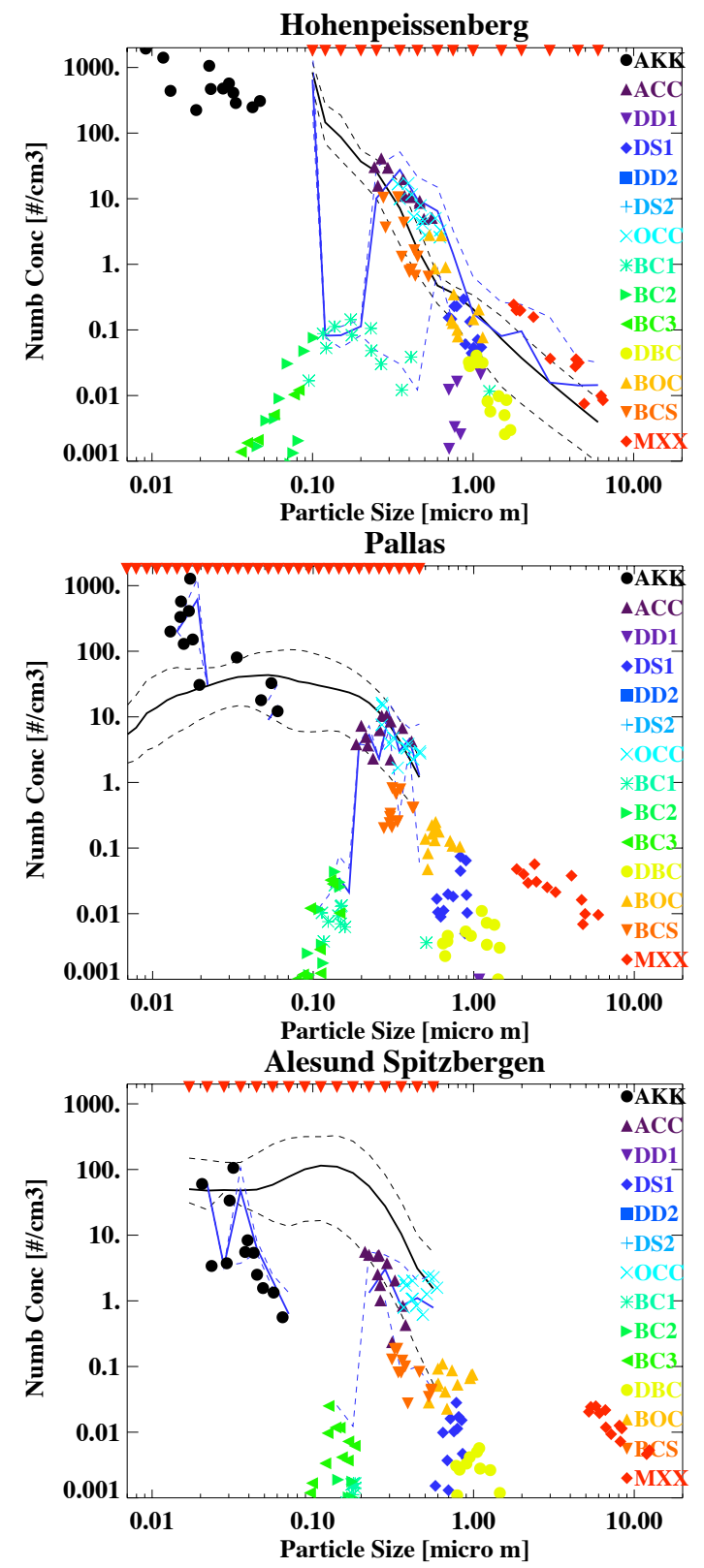

Fig. 16. Aerosol size distributions per population, as shown in the left column in Fig. 15, but for Exp. 2.

in Pallas, Finland. Although MATRIX includes five different nucleation scheme options, in this paper we employed only the Napari scheme, which is known to give very large, most likely excessive, nucleation rates. Further studies are in progress to test all nucleation schemes and their climate impacts. Coarse mode particles are under-represented in the marine environment. Coarse mode aerosol data over land do not show this bias. This points to a lack of coarse sea salt aerosol in our model. Our model calculates sea salt emissions only for two size bins. This was sufficient for the mass based aerosol model version (Koch et al., 2006) of the GISS model, as only the small sea salt particles are important for the calculation of aerosol radiative forcing. However, coarse sea salt particles are important for aerosol mixing processes, since the coarse particles provide large surface areas for chemical and physical interaction. On the other hand the lifetime of coarse particles is very short, therefore their direct climate impacts are probably small. Further studies are needed to determine the detail required for representation of coarse model aerosols to adequately simulate their chemical and climate impacts. Thus, more evaluation has to be carried out in order to better quantify and statistically analyze MATRIX.

- More data sets are available to evaluate aerosol mass concentrations for individual species. Sulfate mass in MATRIX at the surface as well as throughout the troposphere compared very well with observations. This sulfate is formed through gas-phase and aqueouschemistry, nucleation and condensation processes, and spans over the total size range from Aitken mode to coarse mode particles. However due to the lack of detailed observations we could not yet evaluate the mixing state of sulfate.

Nitrate aerosols are calculated only as a mass based scheme, and the distribution over the populations is scaled relative to the sulfate distribution (the same concept applies for ammonium and aerosol water), as discussed in Sect. 2. The evaluation showed rather mediocre results for nitrate mass simulation, with reasonable results close to the earth's surface but underestimation of nitrate mass above the boundary layer. In this simulation the condensation of nitric acid on particle surfaces is not yet explicitly taken into account. This can lead to a lack of nitrate on coarse aerosol particles and explains the poor nitrate correlations in the remote atmosphere and higher altitudes, as demonstrated in Bauer et al. (2007); Bauer and Koch (2005).

The evaluation of the carbonaceous aerosol mass close to the surface shows good results, however the vertical distribution of black carbon in the atmosphere gave very different results between the microphysical model and the sensitivity experiment where microphysical processes are excluded. Although the comparison to aircraft profiles in Texas and Costa Rica showed that MATRIX overestimates tropospheric black carbon concentrations in those regions, we know from further evaluations with AERONET data (not shown in this paper) that we generally underestimate black carbon column concentrations. Furthermore we learned from the comparison to the Costa Rica aircraft measurements that black carbon is too frequently mixed in MATRIX, which leads globally to excessive solubility rates and too short life time for black carbon. 
- A major challenge in this endeavor is the evaluation of the aerosol mixing state. Observations of the chemical composition of single particles are extremely limited. Initial evaluation indicates that MATRIX underestimates the fraction of externally mixed aerosols. Coagulation is the most efficient process for generating internally mixed aerosols. Coagulation depends strongly on the size of the particles, as demonstrated in this paper by the sensitivity experiments. However, there is limited information in emission inventories about the size of the emitted particles. One problem thus could be the quality of model inputs. Aerosol number, surface area, composition, and mixing state is now included in global models, but these properties are not given for emissions, so the aerosol fields cannot be initialized correctly. Some emission models (Hogrefe et al., 2003; Bond et al., 2004) can apply chemical specification or size distribution when the emission inventory contains sufficient description of the underlying sources. Compounding this challenge, however, is the fact that processes affecting important aerosol characteristics occur rapidly after emission (Zhang et al., 2004; Jacobson and Seinfeld, 2004; Shiraiwa et al., 2007). Thus, even if aerosol characteristics suited to provide inputs for microphysical models such as MATRIX were measured near a source, the size distributions and chemical mixing could be unrepresentative of the actual aerosol properties in a corresponding global model grid box.

- Testing the design of the MATRIX aerosol population concept (the design was guided in large part by the definition of mixing states in the sectional model of Jacobson (2002)) on the global scale showed that the definition of the populations can still be optimized. Some populations are sparsely populated, for example the coated dust and black carbon classes, whereas fine aerosols tend to accumulate in the BCS, the black organic carbon-sulfate population and coarse mode aerosols accumulate in MXX, the mixed population. Change in selection of aerosol population definition may allow more even distribution among them.

\section{Conclusions}

This manuscript gives a detailed description of the microphysical model MATRIX and also describes its performance as box and global models, as part of the GISS climate model. The climate model including MATRIX takes $6 \mathrm{~h}$ computing time to simulate 1 model year, using 15 processors on a Linux Networx cluster. Therefore this model system is very suitable to perform many sensitivity studies as well as perform transient climate simulations. MATRIX provides a wide set of possible aerosol populations or aerosol mixing state configurations, and microphysical parameterizations. It is beyond the scope of this first publication to present, analyze, and evaluate all options of the MATRIX model. However, this paper gives a complete model description, which will serve as reference for all future studies. The MATRIX code is written as a box model and should be readily adaptable within other regional or global model frameworks. MATRIX is based on the quadrature method of moments (QMOM) scheme and the version presented in this paper includes two moments, number and mass, and one quadrature point. The two moment scheme was chosen as a starting point to develop the microphysical package, however our intention is to use higher aerosol moments in the future.

When designing a new model, decisions about what parameterizations to include or how to represent the aerosols will have large impacts on the end product, the impact of aerosols on the earth system. MATRIX tries to be as flexible as possible at this point by including various sub-models and allowing a wide variety of different aerosol population configurations. The presented box model results demonstrate the large impact population configuration can have on cloud activation. However the simulations on the global scale showed that some populations are sparsely populated, because of the tendency for aerosols to mix and to include more than two chemical components. For the Aitken and accumulation mode particles, this leads to a dominance of the black carbon, organic carbon, nitrate and sulfate mixture. In the coarse mode this favors the mixed mode, which allows all chemical species to be included in the aerosol. Our future work will focus on improving the simulation of aerosol mixtures, which will be an ongoing and difficult task. Detailed aerosol measurements are necessary to achieve this goal.

The coupling of the MATRIX aerosol scheme to radiation and cloud schemes will be discussed in separate publications.

\section{Appendix A}

\section{New particle formation}

\section{A1 Conversion of the nucleation rate to a NPF rate}

The nucleation rate (or observed NPF rate at 3-nm diameter in the case of Eisele and McMurry (1997)) is converted to a NPF rate at $D_{\text {npf }}$ for all parameterizations. MATRIX is currently set up to use $D_{\text {npf }}$ as either 3,10 , or $20 \mathrm{~nm}$. Conversion is affected by the factor $F$ in the expression $J_{\mathrm{p}, i}=F J$. Two choices to $F$ are available: (1) A simple mass-conversation approach with $F=\left[D_{\mathrm{p}}^{*} / D_{\mathrm{npf}}\right]^{3}$ conserves the total mass of sulfate in the nucleated particles, where $D_{\mathrm{p}}^{*}$ is $1 \mathrm{~nm}$ except for the Eisele and McMurry (1997) expression where it is $3 \mathrm{~nm}$. (2) A more physically-based expression taking into account the small-particle dynamics is the analytic formula 
for $F$ derived from Kerminen and Kulmala (2002) and Kerminen et al. (2004). It is given by

$J_{\mathrm{p}, i}\left(D_{\mathrm{npf}}, t^{\prime}\right)=J\left(D_{\mathrm{p}}^{*}, t\right) \exp \left(\frac{\eta}{D_{\mathrm{npf}}}-\frac{\eta}{D_{\mathrm{p}}^{*}}\right)$

where the time $t^{\prime}$ at which the new particles appear and is later than the time $t$ at which nucleation occurred on account of the time required for growth, and the parameter $\eta$ is calculated as $\gamma k_{c, \alpha=1} / 4 \pi g_{r} D_{\mathrm{H}_{2} \mathrm{SO}_{4}}$ with $\gamma$ a proportionality factor, $k_{c, \alpha=1}$ the condensation sink (see Eq. 18) calculated with the mass accommodation coefficient $\alpha$ set to unity and the mean free path of air $\left(\lambda_{\text {air }}\right), g_{\mathrm{d}}$ the diameter growth rate $d D_{\mathrm{p}} / d t$, and $D_{\mathrm{H}_{2} \mathrm{SO}_{4}}$ the diffusivity of $\mathrm{H}_{2} \mathrm{SO}_{4}$ in air. The formula is applicable when the pre-existing aerosol and condensable vapor concentrations remain relatively constant during the time step and the total concentration of particles smaller than $D_{\text {npf }}$ remains below $10^{5}-10^{6} \mathrm{~cm}^{-3}$ and there is no self-coagulation. The values of and $g_{\mathrm{d}}$ are assumed constant over a time step, and $\gamma$ is a weakly varying function given by

$\gamma=\gamma_{0}\left[\frac{D_{p}^{*}}{1 \mathrm{~nm}}\right]^{0.2}\left[\frac{D_{\mathrm{npf}}}{3 \mathrm{~nm}}\right]^{0.075}\left[\frac{D_{\text {mean }}}{150 \mathrm{~nm}}\right]^{0.048}\left[\frac{\rho^{*}}{1000 \mathrm{~kg} \mathrm{~m}^{-3}}\right]^{-0.33}\left[\frac{T}{293 K}\right]^{-0.75}$

where $\gamma_{0}$ is $0.23 \mathrm{~nm}^{2} \mathrm{~m}^{2} \mathrm{~h}^{-1}, D_{\text {mean }}$ is the number mean diameter of the pre-existing aerosol and $\rho^{*}$ the density of the critical nucleus (set to $1.6 \mathrm{~g} \mathrm{~cm}^{-3}$ ). Thus $\gamma$ is nearly constant over the time step when these conditions are satisfied. If conditions are approximately steady-state, the difference in times $t^{\prime}$ and $t$ is immaterial. Steady-state assumptions are discussed below. If $\eta$ exceeds $56 \mathrm{~nm}, F$ is set to $10^{-17}$. The diameter growth rate $g_{\mathrm{d}}$ of freshly nucleated particles is calculated as that due to condensation of inorganic vapors $\left(\mathrm{H}_{2} \mathrm{SO}_{4}, \mathrm{NH}_{3}, \mathrm{H}_{2} \mathrm{O}\right)$ only (contributions from low-volatility organic vapors are not yet represented) and is that of free molecular growth given by

$g_{\mathrm{d}}=\frac{d D_{\mathrm{p}}}{d t}=\frac{\alpha}{2 \rho} \bar{c} M_{\mathrm{eff}} C$

with $\alpha$ the mass accommodation coefficient of $\mathrm{H}_{2} \mathrm{SO}_{4}$ (taken as unity following Kerminen and Kulmala, 2002), $\rho$ the density of such particles (set to $1.6 \mathrm{~g} \mathrm{~cm}^{-3}$ ), $\bar{c}$ the mean thermal velocity of an $\mathrm{H}_{2} \mathrm{SO}_{4}$ molecule, $C$ the (steadystate) vapor concentration of $\mathrm{H}_{2} \mathrm{SO}_{4}$, and $M_{\text {eff }}$ is an effective molar mass for $\mathrm{H}_{2} \mathrm{SO}_{4}$ along with the $\mathrm{NH}_{3}$ and $\mathrm{H}_{2} \mathrm{O}$ that accompany it under the assumption of rapid equilibration, $M_{\mathrm{eff}}=M_{\mathrm{H}_{2} \mathrm{SO}_{4}}+n_{\mathrm{NH}_{3}} M_{\mathrm{NH}_{3}}+n_{\mathrm{H}_{2} \mathrm{O}} M_{\mathrm{H}_{2} \mathrm{O}}$ where $n_{\mathrm{NH}_{3}}$ and $n_{\mathrm{H}_{2} \mathrm{O}}$ are the number of $\mathrm{NH}_{3}$ and $\mathrm{H}_{2} \mathrm{O}$ molecules condensing per $\mathrm{H}_{2} \mathrm{SO}_{4}$ molecule. For the number of $\mathrm{NH}_{3}$ molecules per $\mathrm{H}_{2} \mathrm{SO}_{4}$ molecule condensing

$n_{\mathrm{NH}_{3}}=\frac{\text { fluxofNH }}{\text { fluxofH } \mathrm{H}_{2} \mathrm{SO}_{4} \text { toparticle }}=\frac{\bar{c}_{\mathrm{NH}_{3}}}{\bar{c}_{\mathrm{H}_{2} \mathrm{SO}_{4}}} \frac{C_{\mathrm{NH}_{3}}}{C_{\mathrm{H}_{2} \mathrm{SO}_{4}}}=\left(\frac{M_{\mathrm{H}_{2} \mathrm{SO}_{4}}}{M_{\mathrm{NH}_{3}}}\right)^{1 / 2} \frac{C_{\mathrm{NH}_{3}}}{C_{\mathrm{H}_{2} \mathrm{SO}_{4}}}$

with $\bar{c}_{i}$ the mean thermal velocity of a molecule of type $i, C_{i}$ the vapor number concentration of molecular species $i$, and with an upper bound of 2 imposed on $n_{\mathrm{NH}_{3}}$. With $n_{\mathrm{NH}_{3}}$ determined, $n_{\mathrm{H}_{2} \mathrm{O}}$ is calculated by first treating the $\mathrm{H}_{2} \mathrm{SO}_{4}$ in the particles as either (a) $\mathrm{H}_{2} \mathrm{SO}_{4}$ for $n_{\mathrm{NH}_{3}}<0.5$, (b) $\mathrm{NH}_{4} \mathrm{HSO}_{4}$ for $0.5 \leq n_{\mathrm{NH}_{3}} \leq 1.5$, or (c) $\left(\mathrm{NH}_{4}\right)_{2} \mathrm{SO}_{4}$ for $n_{\mathrm{NH}_{3}}>1.5$. The mole fraction sulfur in the particle $\chi_{S}$ is then defined as [mole $\mathrm{S} /\left(\right.$ mole $\mathrm{S}+$ mole $\left._{2} \mathrm{O}\right)$ ]. For each neutralization state, polynomial fits for $\chi_{S}$ in terms of the fractional relative humidity $h$ are used. The Kelvin effect reduces water update and its effect on $\chi_{\mathrm{S}}$ is (optionally) included by replacing $h$ with $h \exp \left(-2 A / D_{\text {npf }}\right)$ with $A$ given by

$A_{\mathrm{H}_{2} \mathrm{SO}_{4}}=[1.2-0.0072(T-273.15)]$

$A_{\left(\mathrm{NH}_{4}\right)_{2} \mathrm{SO}_{4}}=[1.2-0.0072(T-273.15)] \times[1-0.17(1-h)] \times[1+0.95(1-h)]$

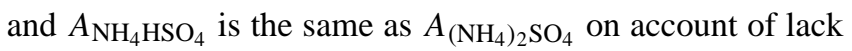
of data for ammonium bisulfate solutions. The first factor is due to the $T$ dependence of surface tension of the solution (taken as that for water), the second factor is due to the dependence of the partial molar volume of water on $h$, and the third term is due to the dependence of the surface tension of the solution on $h$. Once $\chi_{\mathrm{S}}$ is obtained, then $n_{\mathrm{H}_{2} \mathrm{O}}=\left(1-\chi_{\mathrm{S}}\right) / \chi_{\mathrm{S}}$. Reference Lewis (2006).

\section{A2 Calculation of sulfate mass in a newly formed particle}

The sulfate mass in a newly formed particle of ambient diameter $D_{\text {npf }}$ as a function of RH and neutralization regime is now described. For each regime, and for $D_{\text {npf }}$ selected as either 3,10 , or $20 \mathrm{~nm}$, the diameter ratio $D_{\text {npf }} / D_{\text {npf,dry }}$ is calculated from polynomial fits and used to convert the ambient particle volume ( $\pi D_{\text {npf }}^{3} / 6$ ) to dry particle volume, from which a sulfate $\left(\mathrm{SO}_{4}^{2-}\right)$ mass can be calculated (using appropriate densities and molecular weights for each regime). The Kelvin effect is taken into account. The calculated sulfate mass at a given RH is stored in a lookup table at increments of $1 \% \mathrm{RH}$ for each regime.

We now describe the determination of the $\left[\mathrm{H}_{2} \mathrm{SO}_{4}\right]$ using in calculation of the nucleation rate and diameter growth rate $g_{\mathrm{d}}$. The gas-phase chemistry processes are calculated prior to the aerosol processes. Accumulation of $\mathrm{H}_{2} \mathrm{SO}_{4}$ during the time step $\Delta \mathrm{t}$ of $0.5 \mathrm{~h}$ yields spuriously high initial $\mathrm{H}_{2} \mathrm{SO}_{4}$ concentrations for calculation of the nucleation rate directly from the initial $\left[\mathrm{H}_{2} \mathrm{SO}_{4}\right]$ and taking the total number of new particles formed as $J_{\mathrm{p}, i} \Delta \mathrm{t}$. Under suitable conditions, a steady-state $\mathrm{H}_{2} \mathrm{SO}_{4}$ concentration $\left[\mathrm{H}_{2} \mathrm{SO}_{4}\right]_{S S}$ can be derived from an estimate of its average production rate $P_{\mathrm{H}_{2} \mathrm{SO}_{4}}$ over the time step and its loss rate due to condensation on existing particles (the condensation sink) $k_{c}$. A time constant $\tau$ is defined as $1 / k_{c}$, and when $\Delta t \geq n_{\tau} \tau$ with $n_{\tau}$ a small integer (see below), the steady-state assumption is invoked, and an initial estimate of $\left[\mathrm{H}_{2} \mathrm{SO}_{4}\right]_{\mathrm{SS}}$ is obtained as (Binkowski and Shankar, 1995)

$\left[\mathrm{H}_{2} \mathrm{SO}_{4}\right]_{\mathrm{SS}}=P_{\mathrm{H}_{2} \mathrm{SO}_{4}} / k_{c}=\left[\mathrm{H}_{2} \mathrm{SO}_{4}\right](\tau / \Delta t)$

where the average production rate is based on the assumption that the sulfuric acid concentration at the beginning of 
the time step $\left[\mathrm{H}_{2} \mathrm{SO}_{4}\right]$ was produced by gas-phase chemistry during the current time step, which is perhaps a good approximation when significant production has occurred. Since $\tau \leq \Delta t,\left[\mathrm{H}_{2} \mathrm{SO}_{4}\right]_{\mathrm{SS}}$ can not exceed $\left[\mathrm{H}_{2} \mathrm{SO}_{4}\right]$.

\section{A3 Calculation of steady state concentrations}

A further consideration arises under conditions for which very high nucleation rates would occur and consumption of $\mathrm{H}_{2} \mathrm{SO}_{4}$ by new particles formed during the time step cannot be neglected in determining the loss rate of $\mathrm{H}_{2} \mathrm{SO}_{4}$. This is especially important with the ternary nucleation parameterization. A proper balance between consumption of $\mathrm{H}_{2} \mathrm{SO}_{4}$ by $\mathrm{NPF}$ and condensational growth is obtained by solving

$\frac{d\left[\mathrm{H}_{2} \mathrm{SO}_{4}\right]}{d t}=P-k_{c}\left[\mathrm{H}_{2} \mathrm{SO}_{4}\right]-J_{\mathrm{p}, \mathrm{i}}\left(\left[\mathrm{H}_{2} \mathrm{SO}_{4}\right]\right) m_{\mathrm{q}, \mathrm{i}}^{\mathrm{npf}}=0$

at steady- state with the initial $\left[\mathrm{H}_{2} \mathrm{SO}_{4}\right]$ taken as $\left[\mathrm{H}_{2} \mathrm{SO}_{4}\right]_{\mathrm{SS}}$ obtained from Eq. (A4). The r.h.s. is positive with this value of $\left[\mathrm{H}_{2} \mathrm{SO}_{4}\right]$ as $J_{\mathrm{p}, i}=F J$ is always non-zero $\left(J_{\mathrm{p}, i} \geq 10^{-24} \mathrm{~cm}^{-3} \mathrm{~s}^{-1}\right)$. Equation (A5) is then solved approximately by reducing $\left[\mathrm{H}_{2} \mathrm{SO}_{4}\right]$ by a factor of 1.1-1.5 until the r.h.s. becomes negative and $\left[\mathrm{H}_{2} \mathrm{SO}_{4}\right]_{\mathrm{SS}}$ is then set to the final value. This provides a lower limit (within a factor of 1.1-1.5) for the actual $\left[\mathrm{H}_{2} \mathrm{SO}_{4}\right]_{\mathrm{SS}}$ if Eq. (A5) were solved exactly, and the slight underestimation of the $\left[\mathrm{H}_{2} \mathrm{SO}_{4}\right]_{\mathrm{SS}}$ defined by Eq. (A5) in part compensates for the neglect the loss of $\left[\mathrm{H}_{2} \mathrm{SO}_{4}\right]$ due to condensational growth of the new particles beyond $D_{\text {npf }}$ during the time step. When $k_{c}$ is small enough that $\tau>\Delta t$, the calculated initial $\left[\mathrm{H}_{2} \mathrm{SO}_{4}\right]_{\mathrm{SS}}$ from Eq. (A4) exceeds $\left[\mathrm{H}_{2} \mathrm{SO}_{4}\right]_{0}$ and the steady-state assumption cannot be invoked. For a time step of $0.5 \mathrm{~h}, k_{c}$ must be at least $5.6 \times 10^{-4} \mathrm{~s}^{-1}$ to have $\left[\mathrm{H}_{2} \mathrm{SO}_{4}\right]_{\mathrm{SS}} \leq\left[\mathrm{H}_{2} \mathrm{SO}_{4}\right]$. For a lognormal distribution with a number mean diameter of $150 \mathrm{~nm}$ and geometric standard deviation of 1.5 , and taking $D_{\mathrm{H}_{2} \mathrm{SO}_{4}}$ as $1.0 \times 10^{-5} \mathrm{~m}^{2} \mathrm{~s}^{-1}$, a number concentration of $88 \mathrm{~cm}^{-3}$ is required to yield a $k_{c}$ value of $5.6 \times 10^{-4} \mathrm{~s}^{-1}$ (derived from Table 1 of Kerminen and Kulmala (2002). This is a significant amount of aerosol, and hence smaller aerosol loadings and values of $k_{c}$ leading to $\tau>\Delta t$ will likely occur at a significant frequency in atmospheric models. When $\Delta t<n_{\tau} \tau$ the steady-state assumption is not invoked and the equation

$\frac{d\left[\mathrm{H}_{2} \mathrm{SO}_{4}\right]}{d t}=P-k_{c}\left[\mathrm{H}_{2} \mathrm{SO}_{4}\right]$

is solved to yield

$\left[\mathrm{H}_{2} \mathrm{SO}_{4}\right]=\left[\mathrm{H}_{2} \mathrm{SO}_{4}\right]_{0} e^{-k_{c} t}+\frac{P t}{1+k_{c} t}$

where $\left[\mathrm{H}_{2} \mathrm{SO}_{4}\right]_{0}$ is the concentration at the beginning of the time step before gas-phase chemistry, and with the assumption that all $\mathrm{H}_{2} \mathrm{SO}_{4}$ present was generated by gas-phase chemistry during the current time step $\left(\left[\mathrm{H}_{2} \mathrm{SO}_{4}\right]_{0}=0\right)$, the solution is

$\left[\mathrm{H}_{2} \mathrm{SO}_{4}\right]=\frac{P}{k_{c}}\left(\frac{k_{c} t}{1+k_{c} t}\right)=\left[\mathrm{H}_{2} \mathrm{SO}_{4}\right]_{\mathrm{SS}}\left(\frac{1 / \tau}{1+t / \tau}\right)$ and the $\mathrm{H}_{2} \mathrm{SO}_{4}$ concentration at the middle of the time step $\left[\mathrm{H}_{2} \mathrm{SO}_{4}\right]_{\Delta t / 2}$ is given by

$$
\left[\mathrm{H}_{2} \mathrm{SO}_{4}\right]_{\Delta t / 2}=\frac{P}{k_{c}+2 / \Delta t}
$$

and is used to calculate the nucleation rate and $g_{\mathrm{d}}$. This expression neglects the consumption of $\mathrm{H}_{2} \mathrm{SO}_{4}$ through the formation of new particles and gives an upper limit for the actual $\left[\mathrm{H}_{2} \mathrm{SO}_{4}\right]_{\Delta t / 2}$. Equation (A8) shows that for $t=\Delta t=n_{\tau} \tau$, $\left[\mathrm{H}_{2} \mathrm{SO}_{4}\right]$ is within $\left[100 /\left(n_{\tau}+1\right)\right] \%$ of its steady-state value when only production and condensation are considered, and since inclusion of NPF reduces $\tau$ and makes the approach to steady-state more rapid, the choice $n_{\tau}=2$ leads to application of the steady-state approximation under conditions for which the sulfuric acid concentration will rise to within $33 \%$ of its steady-state value within the time step. For all values of $\tau$, the NPF and condensational growth rates are first calculated independently using the initial concentration $\left[\mathrm{H}_{2} \mathrm{SO}_{4}\right]_{0}$ as if each process were permitted to consume all available $\mathrm{H}_{2} \mathrm{SO}_{4}$. If the total $\mathrm{H}_{2} \mathrm{SO}_{4}$ consumed by the two processes exceeds $\left[\mathrm{H}_{2} \mathrm{SO}_{4}\right]_{0}$, the NPF and condensational growth rates are both reduced by the same factor such that the total $\mathrm{H}_{2} \mathrm{SO}_{4}$ consumption is limited to $\left[\mathrm{H}_{2} \mathrm{SO}_{4}\right]_{0}$. This favors a proper balance between consumption of $\mathrm{H}_{2} \mathrm{SO}_{4}$ by NPF and by condensational growth. For parity between these processes, the condensation rate is calculated from the same $\mathrm{H}_{2} \mathrm{SO}_{4}$ concentration described here to calculate the nucleation rate.

\section{Appendix B}

\section{Derivation of production and loss terms for coagulation}

For the coagulation of population $k$ with population $l$ to produce particle number or mass (or neither) in population $i$, there are three cases. The first case occurs when $k=l=i$, which is self-coagulation within a single population. The second case occurs when $k \neq l \neq i$, in which the distinct populations $k$ and $l$ coagulate to form a third distinct population $i$. The third case occurs when either $k=i$ or $l=i$ (but not both) in which mass and number are lost from population $k$ or $l$ and mass but not number is gained in population $i$. Before discussing these cases, we define the population-average coagulation coefficient or order $n$ as

$\bar{K}_{k l}^{(n)}=\frac{\int_{0}^{\infty} \int_{0}^{\infty} D_{1}^{(n)} K\left(D_{1}, D_{2}\right) n_{k}\left(D_{1}\right) n_{l}\left(D_{2}\right) d D_{1} d D_{2}}{\int_{0}^{\infty} \int_{0}^{\infty} D_{1}^{(n)} n_{k}\left(D_{1}\right) n_{l}\left(D_{2}\right) d D_{1} d D_{2}}$

for number size distributions $n_{k}$ and $n_{l}$ for populations $k$ and $l$, respectively, and particle diameters $D_{1}$ and $D_{2}$. Note that for $n \neq 0, \bar{K}_{k l}^{(n)}$ is not symmetric in $k$ and $l$, and for $n \neq 0$ the first index labels the donor population ( $k$ or $l$ ) providing concentration of diameter moment $n$ to the receiving population (i). 
The present model tracks number and mass concentrations only. The rate of change of number concentration $N_{i}$ in population $i$ is expressed as

$\frac{d N_{i}}{d t}=P_{N, i}^{\text {coag }}-L_{N, i}^{\text {coag }}$

and the rate of change of mass concentration $Q_{i, q}$ of species $q$ in population $i$ is similarly expressed as

$\frac{d Q_{i, q}}{d t}=P_{Q, i}^{\mathrm{coag}}-L_{Q, i}^{\mathrm{coag}}$

Case 1: For the first case (self-coagulation), mass concentrations do not change and number concentration is reduced according to

$L_{N, i}^{\mathrm{coag}}(i+i \rightarrow i)=\frac{1}{2} \int_{0}^{\infty} \int_{0}^{\infty} K\left(D_{1}, D_{2}\right) n_{i}\left(D_{1}\right) n_{i}\left(D_{2}\right) d D_{1} d D_{2}=\frac{1}{2} \bar{K}_{i i}^{(0)} N_{i}^{2}$

Case 2: For the second case, particles in population $k$ coagulates with particles in population $l$ to add new particles and mass of species $q$ to a population $i$ that is neither population $k$ nor population $l$. Each coagulation event removes a particle from each of populations $k$ and $l$ and adds a particle to population $i$. For the number concentration production rate in population $i$

$P_{N, i}^{\mathrm{cog} g}(k+l \rightarrow i)=\int_{0}^{\infty} \int_{0}^{\infty} K\left(D_{1}, D_{2}\right) n_{k}\left(D_{1}\right) n_{l}\left(D_{2}\right) d D_{1} d D_{2}=N_{k} N_{l} \bar{K}_{k l}^{(0)}$

and the number concentration loss rate for population $k$ and population $l$ is also $L_{N, i}^{\text {coag }}=N_{k} N_{l} \bar{K}_{k l}^{(0)}$. For the mass concentration of $q$, begin from the loss of third diameter moment in population $k$.

$\frac{d M_{3, k}}{d t}=-\int_{0}^{\infty} \int_{0}^{\infty} D_{1}^{(3)} K\left(D_{1}, D_{2}\right) n_{k}\left(D_{1}\right) n_{l}\left(D_{2}\right) d D_{1} d D_{2}$

The normalized third moment for population $k$ can be expressed as

$\bar{M}_{3, k}=\frac{\int_{0}^{\infty} \int_{0}^{\infty} D_{1}^{(3)} n_{k}\left(D_{1}\right) n_{l}\left(D_{2}\right) d D_{1} d D_{2}}{\int_{0}^{\infty} \int_{0}^{\infty} n_{k}\left(D_{1}\right) n_{l}\left(D_{2}\right) d D_{1} d D_{2}}=\frac{M_{3, k} N_{l}}{N_{k} N_{l}}$

and combining Eqs. (A6) and (A7)

$\frac{d M_{3, k}}{d t}=-N_{k} N_{l} \bar{M}_{3, k} \frac{\int_{0}^{\infty} \int_{0}^{\infty} D_{1}^{(3)} K\left(D_{1}, D_{2}\right) n_{k}\left(D_{1}\right) n_{l}\left(D_{2}\right) d D_{1} d D_{2}}{\int_{0}^{\infty} \int_{0}^{\infty} D_{1}^{(3)} n_{k}\left(D_{1}\right) n_{l}\left(D_{2}\right) d D_{1} d D_{2}}=-N_{k} N_{l} \bar{M}_{3, k} \bar{K}_{k l}^{(3)}$

The mass concentration $Q_{k, q}$ of species $q$ in population $k$ is related to the third moment as

$Q_{k, q}=\rho_{k, q} V_{k}=\frac{\pi}{6} \rho_{k, q} M_{3, k}=\frac{\pi}{6}\left(\frac{m_{k, q}}{\frac{\pi}{6} \bar{M}_{3, k}}\right) M_{3, k}=\left(\frac{m_{k, q}}{\bar{M}_{3, k}}\right) M_{3, k}$

with $V_{k}$ the total aerosol volume concentration of population $k, \rho_{k, q}$ the mass of $q$ per volume of particle, $m_{k, q}$ the average mass of $q$ per particle in population $k$. Combining Eqs. (B8) and (B9), for the mass concentration loss of $q$ in population $k$

$L_{Q, k, q}^{\mathrm{coag}}(k+l \rightarrow i)=\frac{d Q_{k, q}}{d t}=-\frac{d M_{3, k}}{d t}\left(\frac{m_{k, q}}{\bar{M}_{3, k}}\right)=N_{k} N_{l} \bar{K}_{k l}^{(3)} m_{k, q}$

and for likewise for population $l$

$L_{Q, l, q}^{\mathrm{cogg}}(k+l \rightarrow i)=\frac{d Q_{l, q}}{d t}=-\frac{d M_{3, l}}{d t}\left(\frac{m_{l, q}}{\bar{M}_{3, l}}\right)=N_{k} N_{l} \bar{K}_{k l}^{(3)} m_{l, q}$

The production term for population $i$ then balances these losses

$P_{Q, i, q}^{\text {coag }}(k+l \rightarrow i)=N_{k} N_{l}\left(\bar{K}_{k l}^{(3)} m_{k, q}+\bar{K}_{l k}^{(3)} m_{l, q}\right)$

Case 3: For the third case, population $k$ (or $l$ ) coagulates with population $i$, reducing number and mass concentrations in population $k$ and increasing the mass concentration of $q$ (but not number concentration) in population $i$. Each coagulation event removes a particle from population $k$, and using previous results we have for the loss of number concentration in population $k$

$L_{N, k}^{\text {coag }}(k+i \rightarrow i)=N_{k} N_{i} \bar{K}_{k i}^{(0)}$

and for the loss of mass concentration of $q$ in population $k$.

$L_{Q, k, q}^{\text {coag }}(k+i \rightarrow i)=N_{k} N_{i} \bar{K}_{k i}^{(3)} m_{k, q}$

For the mass production of $q$ in population $i$

$P_{Q, i, q}^{\mathrm{coag}}(k+i \rightarrow i)=N_{k} N_{i} \bar{K}_{k i}^{(3)} m_{k, q}$

The expressions for production and loss rates obtained in these three cases are now combined and summed over populations as appropriate. For the production terms for number concentration in population $i$, only the second case is nonzero, and summing over all pairs of populations $k$ and $l$

$P_{N, i, q}^{\mathrm{coag}}=\sum_{k \neq i}^{n} \sum_{l>k, l \neq i}^{n} d_{i k l} K_{k l}^{(0)} N_{k} N_{l}$

where $d_{i k l}$ is unity if coagulation of populations $k$ and $l$ is defined to produce particles in population $i$ and zero otherwise, and there are $n$ populations. Recall that in the second case population $i$ must be distinct from both $k$ and $l$. The summand is symmetric in $k$ and $l$, and the summation should include either $k>l$ or $l>k$, but not both. For the loss terms for number concentration, there is the self-coagulation term and all pairs of populations whose intermodal coagulation results in the loss of particles from population $i$

$L_{N, i}^{\mathrm{coag}}=\frac{1}{2} K_{i i}^{(0)} N_{i}^{2}+\left(\sum_{j \neq i}^{n} d_{i j} K_{i j}^{(0)} N_{j}\right) N_{i}$

where $d_{i j}$ (not symmetric in $i, j$ ) is unity if coagulation of population $j$ with population $i$ results in the removal of particles from population $i$ and zero otherwise. 
For the production terms for mass concentration of $q$ in population $i$, only in the second and third cases are nonzero and are combined as

$$
P_{Q, i, q}^{\mathrm{coag}}(k+l \rightarrow i, k+i \rightarrow i)=N_{k} N_{l}\left[\left(1-\delta_{k i}\right) \bar{K}_{k l}^{(3)} m_{k, q}+\left(1-\delta_{l i}\right) \bar{K}_{l k}^{(3)} m_{l, q}\right]
$$

where the Kronecker delta $\delta_{k i}\left(\delta_{k i}=1\right.$ for $k=i, \delta_{k i}=0$ for $k \neq i$ ) omits the $k$ term since if $k=i$, population $k$ does not add mass to population $i$, and similarly for $\delta_{l i}$. For the first case above, $\delta_{k i}=\delta_{l i}=0$; for the second case, $\delta_{k i}=0$ and $\delta_{l i}=1$. Summing over all pairs of populations $k$ and $l$, the production term for population $i$ is

$$
P_{Q, i, q}^{\mathrm{coag}}=\sum_{k=1}^{n} \sum_{l>k}^{n} g_{i k l, q} N_{k} N_{l}\left[\left(1-\delta_{k i}\right) K_{k l}^{(3)} m_{k, q}+\left(1-\delta_{l i}\right) K_{l k}^{(3)} m_{l, q}\right]
$$

where $g_{i k l, q}$ is unity if coagulation of populations $k$ and $l$ is defined as producing particles in population $i$ and either population $k$ or $l$ is defined to contain species $q$; it is zero if either of these conditions is not met. For the loss terms for mass concentration of $q$ in population $i$

$$
L_{Q, i, q}^{\mathrm{coag}}=\sum_{j \neq i}^{n} d_{i j} N_{j} N_{i} K_{i j}^{(3)} m_{i, q}=\left(\sum_{j \neq i}^{n} d_{i j} K_{i j}^{(3)} N_{j}\right)\left(N_{i} m_{i, q}\right) \equiv f_{i}^{(3)} Q_{i, q}
$$

where $d_{i j}$ (not symmetric in $i, j$ ) is unity if coagulation of population $j$ with population $i$ results in the removal of particles from population $i$ and zero otherwise (as defined above).

Acknowledgements. This work has been supported by the NASA MAP program Modeling, Analysis and Prediction Climate Variability and Change (NN-H-04-Z-YS-008-N). Work at Brookhaven National Laboratory was supported in part by the U.S. Department of Energy's Atmospheric Science Program (Office of Science, OBER) under Contract No. DE-AC02-98CH10886. Observational data were obtained from the NASA Langley Research Center Atmospheric Science Data Center, the EMEP, IMPROVE and GAW network. We thank Joshua Schwarz for providing the aircraft measured black carbon data sets and his helpful discussions.

Edited by: V. F. McNeill

\section{References}

Abdul-Razzak, H. and Ghan, S. J.: A parameterization of aerosol activation - 1. Single aerosol type, J. Geophys. Res., 103(D6), 6123-6131, 1998.

Abdul-Razzak, H. and Ghan, S.: A Parameterization of Aerosol Activation. Part 2: Multiple Aerosol Types, J. Geophys. Res., 105, 6837-6844, 2000.

Ackermann, I. J., Hass, H., Memmesheimer, M., Ebel, A., Binkowski, F. S., and Shankar, U.: Modal aerosol dynamics model for Europe: Development and first applications, Atmos. Environ., 32, 2981-2999, 1998.
Adams, P. J. and Seinfeld, J. H.: Predicting global aerosol size distributions in general circulation models, J. Geophys. Res., 107(D19), 4370, doi:10.1029/2001JD001010, 2002.

Bauer, S. E. and Koch, D.: Impact of Heterogeneous Sulfate Formation at Mineral Dust Surfaces on Aerosol Loads and Radiative Forcing in the GISS GCM, J. Geophys. Rev., 110, D17202, doi:10.1029/2005JD005870, 2005.

Bauer, S. E., Mishchenko, M., Lacis, A., Zhang, S., Perlwitz, J., and Metzger, S.: Do Sulfate and Nitrate Coatings on Mineral Dust have Important Effects on Radiative Properties and Climate Modeling?, J. Geophys. Rev., 112, D06307, doi:10.1029/2005JD006977, 2007.

Bell, N., Koch, D., and Shindell, D. T.: Impacts of ChemistryAerosol coupling on tropospheric ozone and sulfate simulations in a general circulation model, J. Geophys. Rev., 111, D14305, doi:10.1029/2004JD005538, 2005.

Binkowski, F. S. and Roselle, S.: Models-3 Community Multiscale Air Quality (CMAQ) model aerosol component 1. Model description., J. Geophys. Res., 108(D6), 4183, doi:10.1029/2001JD001409, 2003.

Binkowski, F. S. and Shankar, U.: Models-3 Community Multiscale Air Quality (CMAQ) model aerosol component 1. Model description, J. Geophys. Res., 100, 26 191-26 209, 1995.

Bond, T. C., Streets, D., Yarber, K., Nelson, S., Woo, J., and Klimont, Z.: A technology-based global inventory of black and organic carbon emissions form combustion, J. Geophys. Res, 109, D14203, doi:10.1029/2003JD003697, 2004.

Bouwman, A. F., Lee, D. S., Asman, W. A. H., Dentener, F. J., Hoek, K. W. V. D., and Olivier, J.: A Global High-Resolution Emission Inventory for Ammonia, Global Biogeochem. Cy., 11, 561-587, 1997.

Chang, Li.-S., Schwartz, S. E., McGraw, R., and Lewis, E. R.: Sensitivity of aerosol properties to new particle formation mechanism and primary emissions in a continental scale chemical transport model, J. Geophys. Res., submitted, 2008.

Chin, M., M., D. J. J., Gardner, G. M., Foreman-Fowler, M. S., Spiro, P. A., and Savoie, D. L.: A global three-dimensional model of tropospheric sufate, J. Geophys. Res., 101, $18667-$ 18 690, 1996.

Easter, R. C., Ghan, S. J., Zhang, Y., Saylor, R., Chapman, E., Laulainen, N., Abdul-Razzak, H., Leung, L., Bian, X., and Zaveri, R.: MIRAGE: Model description and evaluation of aerosols and trace gases, J. Geophys. Res., 109, D20210, doi:10.1029/2004JD004571, 2004.

Eisele, F. L. and McMurry, P. H.: Recent progress in understanding particle nucleation and growth, Phil. Trans. R. Soc. Lond. B, 352, 191-201, 1997.

Ghan, S. J. and Schwartz, S. E.: Aerosol properties and processes A path from field and laboratory measurements to global climate models, B. Am. Meteorol. Soc., 8, 1059-1083, 2007.

Ghan, S. J., Laulainen, N., Easter, R., Wagener, R., Nemesure, S., Chapman, E., Zhang, Y., and Leung, R.: Evaluation of aerosol direct radiative forcing in MIRAGE, J. Geophys. Res., 106, 52955316, 2001.

Ghan, S., Easter, R., Hudson, J., and Bréon, F.-M.: Evaluation of aerosol indirect radiative forcing in MIRAGE, J. Geophys. Res., 106, 5317-5334, 2001.

Gong, S. L., Barrie, L. A., Blanchet, J. P., von Salzen, K., Lohmann, U., Lesins, G., Spacek, L., Zhang, L. M., Girard, 
E., Lin, H., Leaitch, R., Leighton, H., Chylek, P., and Huang, P.: Canadian Aerosol Module: A size-segregated simulation of atmospheric aerosol processes for climate and air quality models, 1, Module development, J. Geophys. Res, 108, 4007, doi:10.1029/2001JD002002, 2003.

Guenther, A. B., Hewitt, N., Erickson, D., Fall, R., Geron, C., Graedel, T., Harley, P., Klinger, L., Lerdau, M., McKay, W. A., Pierce, T., Scholes, B., Steinbrecher, R., Tallamraju, R., Taylor, J., and Zimmerman., P.: A global model of natural volatile organic compound emissions, J. Geophys. Res., 100, 8873-8892, 1995.

Hansen, J., Sato, M., Ruedy, R., Nazarenko, L., Lacis, A., Schmidt, G., Russell, G., Aleinov, I., Bauer, M., Bauer, S., Bell, N., Cairns, B., Canuto, V., Cheng, Y., Genio, A. D., Faluvegi, G., Fleming, E., Friend, A., Hall, T., Jackman, C., Kelley, M., Kiang, N., Koch, D., Lean, J., Lerner, J., Lo, K., Menon, S., Miller, R., Minnis, P., Novakov, T., Oinas, V., Perlwitz, J., Perlwitz, J., Rind, D., Romanou, D., Shindell, D., Stone, P., Sun, S., Tausnev, N., Thresher, D., Wielicki, B., Wong, T., Yao, M., and Zhang, S.: Efficacy of Climate Forcing, J. Geophys. Res, 110, D18104, doi:10.1029/2005JD005776, 2005.

Hanson, D. R.: Mass accommodation of $\mathrm{H} 2 \mathrm{SO} 4$ and $\mathrm{CH} 3 \mathrm{SO} 3 \mathrm{H}$ on water-sulfuric acid solutions from $6 \%$ to $97 \%$ RH, J. Phys. Chem., A 109, 6919-6927, 2005.

Herzog, M., Weisenstein, D., and Penner, J.: A dynamic aerosol module for global chemical transport models: Model description, J. Geophys. Res., 109, D18202, doi:10.1029/2003JD004405, 2004.

Hogrefe, C., Sistla, G., Zalewsky, E., Hao, W., and Ku, J.Y: An assessment of the emissions inventory processing systems EMS2001 and SMOKE in grid-based air quality models, J. Air Waste Manage. Assoc., 53(9), 1121-1129, 2003.

Iversen, T.: A scheme for process-tagged $\mathrm{SO} 4$ and $\mathrm{BC}$ aerosols in NCAR CCM3: Validation and sensitivity to cloud processes, J. Geophys. Res., 107, 4751, doi:10.1029/2001JD000885, 2002.

Jacob, D. J., Crawford, J., Kleb, M., Connors, V. S., Bendura, R. J., Raper, J. L., Sachse, G. W., Gille, J. C., Emmons, L., and Held, C. L.: Transport and chemical evolution over the Pacific (TRACE-P) aircraft mission: Design execution and first results, J. Geophys. Res, 108(D20), 9000, doi:10.1029/2002JD003276, 2003.

Jacobson, M.: Analysis of aerosol interactions with numerical techniques for solving coagulation, nucleation, condensation, dissolution, and reversible chemistry among multiple size distributions, J. Geophys. Res., 107(D19), 4366, doi:10.1029/2001JD002044, 2002.

Jacobson, M. and Seinfeld, J. H.: Evolution of nanoparticle size and mixing state near the point of emission, Atmos. Environ., 38(13), 1839-1850, 2004.

Jacobson, M.: Fundamentals of Atmospheric Modeling, Cambridge University Press, 2005.

Jacobson, M. Z.: Global direct radiative forcing due to multicomponent anthropogenic and natural aerosols, J. Geophys Res., 106, 1551-1568, 2001.

Jaecker-Voirol, A. and Mirabel, P.: Heteromolecular nucleation in the sulfuric acid-water system, J. Geophys. Res., 23, 2053-2057, 1989.

Kerminen, V. M. and Kulmala, M.: Analytical formulae connecting the real and the apparent nucleation rate and the nuclei number concentration for atmospheric nucleation events, J. Aerosol Sci., 33, 609-622, 2002.

Kerminen, V. M., Anttila, T., Lehtinen, K., and Kulmala, M.: Parameterization for atmospheric new-particle formation: Application to a system involving sulfuric acid and condensable watersoluble organic vapors, Aerosol Sci. Tech., 38, 1001-1008, 2004.

Koch, D., Jacob, D., Tegen, I., Rind, D., and Chin, M.: Tropospheric sulfur simulation and sulfate direct radiative forcing in the Goddard Institute for Space Studies general circulation model, J. Geophys. Res., 104, 23 799-23 822, 1999.

Koch, D., Schmidt, G., and Field, C.: Sulfur, sea salt and radionuclide aerosols in the GISS modelE, J. Geophys. Res., 111, D06206, doi:10.1029/2004JD005550, 2006.

Kulmala, M., Maso, M. D., Makela, J. M., Pirjola, L., Vakeva, M., Aalto, P., Miikkulainen, P., Hameri, K., and O’Dowd, C. D.: On the formation, growth and composition of nucleation mode particles, Tellus, 53B, 479-490, 2001.

Lauer, A., Hendricks, J., Ackermann, I., Schell, B., Hass, H., and Metzger, S.: Simulating aerosol microphysics with the ECHAM/MADE GCM Part I: Model description and comparison with observations, Atmos. Chem. Phys., 5, 3251-3276, 2005, http://www.atmos-chem-phys.net/5/3251/2005/.

Lewis, E. R.: The effect of surface tension (Kelvin effect) on the equilibrium radius of a hygroscopic aqueous aerosol particle, J. Aerosol Sci., 37, 1605-1617, 2006.

McGraw, R.: Description of aerosol dynamics by the quadrature method of moments, Aerosol Sci. Tech., 27, 255-265, 1997.

Metzger, S., Mihalopoulos, N., and Lelieveld, J.: Importance of mineral cations and organics in gas-aerosol partitioning of reactive nitrogen compounds: case study based on MINOS results, Atmos. Chem. Phys., 6, 2549-2567, 2006, http://www.atmos-chem-phys.net/6/2549/2006/.

Metzger, S. M., Dentener, F. J., Jeuken, A., Krol, M., and Lelieveld, J.: Gas/aerosol partitioning 2: Global model results, J. Geophys. Res., 107(D16), doi:10.1029/2001JD001102, 2002a.

Metzger, S. M., Dentener, F. J., Lelieveld, J., and Pandis, S. N.: Gas/aerosol partitioning 1: A computationally efficient model, J. Geophys. Res., 107(D16), doi:10.1029/2001JD001103, 2002b.

Miller, R. L., Cakmur, R., Perlwitz, J., Geogdzhayev, I., Ginoux, P., Kohfeld, K., Koch, D., Prigent, C., Ruedy, R., Schmidt, G., and Tegen, I.: Mineral dust aerosols in the NASA Goddard Institute for Space Sciences ModelE atmospheric general circulation model, J. Geophys. Res., 111, D06208, doi:10.1029/2005JD005 796, 2006.

Napari, I., Noppel, M., Vehkamaki, H., and Kulmala, M.: Parametrization of ternary nucleation rate for H2SO4NH3-H2O vapors, J. Geophys. Res., 107(D19), 4381, doi:10.1029/2002JD002132, 2002.

Nenes, A., Pilinis, C., and Pandis, S. N.: Isorropia: A new thermodynamic model for multiphase multicomponent inorganic aerosols, Aquat. Geochem., 123-152, 1998.

Okuyama, K., Kousaka, Y., Kreidenweis, S., Flagan, R., and Seinfeld, J.: Studies in binary nucleation: the dibutylphthalate/dioctylphthalate system, J. Chem. Phys., 89, 6442-6453, 1988.

Olivier, J. and Berdowski, J.: Global emissions sources and sinks, chap. The climate System, ISBN 905809255 0, Swets and Zeitlinger Publishers, Lisse, The Netherlands, 33-78, 2001.

Prather, M. J.: Numerical advection by conservation of second order 
moments., J. Geophys. Res., 91, 6671-6680, 1986.

Pruppacher, H. and Klett, J.: Microphysics of Clouds and Precipitation, D. Reidel Publishing Company, Dordrecht/Boston/London, 1980.

Raper, J. L., Kleb, M., Jacob, D., et al.: Pacific Exploratory Mission in the tropical Pacific: PEM-Tropics B, March-April 1999, J. Geophys. Res., 106(D23), 32 401-32 425, 2001.

Riemer, N., Vogel, H., Vogel, B., and Fiedler, F.: Modeling aerosol on the mesoscale- $\gamma$ : Treatment of soot aerosol and its radiative effects, J. Geophys. Res., 108(D4), 4601, doi:10.1029/2003JD003448, 108.

Schmidt, G. A., Ruedy, R., Hansen, J., Aleinov, I., Bell, N., Bauer, M., Bauer, S., Cairns, B., Cheng, Y., DelGenio, A., Faluvegi, G., Friend, A., Hall, T. M., Hu, Y., Kelley, M., Kiang, N., Koch, D., Lacis, A. A., Lerner, J., Lo, K. K., Miller, R. L., Nazarenko, L., Oinas, V., Perlwitz, J., Perlwitz, J., Rind, D., Romanou, A., Russell, G. L., Shindell, D. T., Stone, P. H., Sun, S., Tausnev, N., and Yao, M.-S.: Present day atmospheric simulations using GISS ModelE: Comparison to in-situ, satellite and reanalysis data, J. Climate, 19, 153-192, 2006.

Schwarz, J. P., Gao, R. S., Fahey, D. W., Thomson, D. S, et al.: Single-particle measurements of midlatitude black carbon and light- scattering aerosols from the boundary layer to the lower stratosphere, J. Geophys. Res., 111, D16207, doi:10.1029/2006JD007076, 2006.

Schwarz, J. P., Spackman, J. R., Fahey, D. W., Gao, R. S., Lohmann, U., Stier, P., Watts, L. A., Thomson, D. S., Lack, D. A., Pfister, L., Mahoney, M. J., Baumgardner, D., Wilson, J. C., and Reeves, J. M.: Coatings and their enhancement of black-carbon light absorption in the tropical atmosphere, J. Geophys. Res., 113, D03203, doi:10.1029/2007JD009042, 2008.

Seinfeld, J. H. and Pandis, S. N.: Atmospheric Chemistry and Physics. From Air Pollution to Climate Change, John Wiley and Sons Inc., New York, 1998.

Shindell, D. T., Faluvegi, G., and Bell, N.: Preindustrial-to-presentday radiative forcing by tropospheric ozone from improved simulations with the GISS chemistry-climate GCM, Atmos. Chem. Phys., 3, 1675-1702, 2003, http://www.atmos-chem-phys.net/3/1675/2003/.

Shiraiwa, M., Kondo, Y., Moteki, N.,Takegawa, N., Miyazaki, Y., and Blake, D.R.: Evolution of mixing state of black carbon in polluted air from Tokyo, Geophys. Res. Lett., 34, L16803, doi:10.1029/2007GL029819, 2007.

Singh, H., Brune, W., Crawford, J., et al.: Overview of the summer 2004 intercontinental chemical transport experiment North America (INTEX-A), J. Geophys. Res., 111, D24S01, doi:10.1029/2006JD007905, 2006.
Stier, P., Feichter, J., Kinne, S., Kloster, S., Vignati, E., Wilson, J., Ganzeveld, L., Tegen, I., Werner, M., Balkanski, Y., Schulz, M., Boucher, O., Minikin, A., and Petzold, A.: The aerosolclimate model ECHAM5-HAM, Atmos. Chem. Phys., 5, 11251156, 2005, http://www.atmos-chem-phys.net/5/1125/2005/.

Turco, R., Zhao, J., and Yu, F.: A new source of tropospheric aerosols: Ion-ion recombination, Geophys. Res. Lett., 25, 635638, 1998.

Usoskin, I. and Kovaltsov, G.: Cosmic ray induced ionization in the atmosphere: Full modeling and practical applications, J. Geophys. Res., 111(D21), doi:10.1029/2006JD007150, 2006.

van der Werf, G. R., Randerson, J., Collatz, G., and Giglio, L.: Carbon emission from fires in tropical and subtropical ecosystems, Glob. Change Biol., 9, 547-562, 2003.

Vehkamäki, H., Kulmala, M., Napari, I., Lehtinen, K., Timmreck, C., Noppel, M., and Laaksonen, A.: An improved parameterization for sulfuric acid-water nucleation rates for tropospheric and stratospheric conditions, J. Geophys. Res., 107(D22), 4622, doi:10.1029/2002JD002184, 2002.

Whitby, E. R., Stratmann, F., and Wilck, M.: Merging and remapping modes in modal aerosol dynamics models: a Dynamic Mode Manager, J. Aerosol Sci., 33(4), 623-645, 2002.

Wilson, J., Cuvelier, C., and Raes, F.: A modeling study of global mixed aerosol fields, J. Geophys. Res., 106, 34 081-34 108, 2001.

Wright, D. L., McGraw, R., Benkovitz, C. M., and Schwartz, S. E.: Six-moment representation of multiple aerosol populations in a sub-hemispheric chemical transformation model, Geophys. Res. Lett., 27, 967-970, 2000.

Wright, D. L., Kasibhatla, P. S., McGraw, R., and Schwartz, S. E.: Description and evaluation of a six-moment aerosol microphysical module for use in atmospheric chemical transport models, J. Geophys. Res, 1068, 20 275-20 291., 2001.

Wright, D. L.: Numerical advection of moments of the particle size distribution in Eulerian models, J. Aerosol Sci., 38(3), 352-369, 2007.

Yu, S., Kasibhatla, P. S., Wright, D. L., Schwartz, S. E., McGraw, R., and Deng, A.: Moment-based simulation of microphysical properties in the eastern United States: Model description, evaluation, and regional analysis, J. Geophys. Res., 108, 4353, doi:10.1029/2002JD002890, 2003.

Zhang, K. M., Wexler, A. S., Zhu, Y. F., Hinds, W. C., and Sioutas, C.: Evolution of particle number distribution near roadways. Part II: the 'road-to-ambient' process, Atmos. Environ., 38, 6655$6665,2004$. 